Florida International University FIU Digital Commons

$8-25-2017$

\title{
Respondent Perceived Threat During the Information Systems Requirements Determination Process: Understanding and Mitigation
}

Alfred Castillo

Florida International University, acast084@fiu.edu

DOI: 10.25148 /etd.FIDC004017

Follow this and additional works at: https://digitalcommons.fiu.edu/etd

\section{Recommended Citation}

Castillo, Alfred, "Respondent Perceived Threat During the Information Systems Requirements Determination Process: Understanding and Mitigation" (2017). FIU Electronic Theses and Dissertations. 3549.

https://digitalcommons.fiu.edu/etd/3549 


\title{
FLORIDA INTERNATIONAL UNIVERSITY
}

Miami, Florida

\section{RESPONDENT PERCEIVED THREAT DURING THE INFORMATION SYSTEMS \\ REQUIREMENTS DETERMINATION PROCESS: UNDERSTANDING AND MITIGATION}

\begin{abstract}
A dissertation submitted in partial fulfillment of the
\end{abstract}
requirements for the degree of

DOCTOR OF PHILOSOPHY

in

BUSINESS ADMINISTRATION

by

Alfred Castillo 
To: Dean Joanne Li

College of Business

This dissertation, written by Alfred Castillo, and entitled Respondent Perceived Threat During the Information Systems Requirements Determination Process: Understanding and Mitigation, having been approved in respect to style and intellectual content, is referred to you for judgment.

We have read this dissertation and recommend that it be approved.

Debra VanderMeer

Dinesh Batra

Xia Weidong

Peter J. Clarke

George M. Marakas, Major Professor

Date of Defense: August 25, 2017

The dissertation of Alfred Castillo is approved.

$\begin{array}{r}\text { Dean Joanne Li } \\ \text { College of Business }\end{array}$
Dean of the University Graduate School Gil

Florida International University, 2017 
(C) Copyright 2017 by Alfred Castillo

All rights reserved. 


\section{DEDICATION}

I dedicate this dissertation to my family. Had I known the amount of understanding, sacrifice, and support required of them during the Ph.D. process I may have wavered in my

determination, but then again, they selflessly wouldn't have let me. They are the solid foundation that I have been able to build my life upon. 


\section{ACKNOWLEDGMENTS}

I thank FIU University for the Presidential Fellowship that allowed me to make it through to candidacy, and for the incredible faculty that I got to know over the years. I also want to thank my committee members for being a part of helping me realize this dream. I want to thank my advisor and mentor, Dr. George Marakas, for taking me as his understudy. I realize that I was quite the challenge, and I don't think he knew what he signed up for when he agreed to be my chair, but he saw me through to the end. He invested himself in me and helped me see light where all I saw was darkness during this arduous endeavor, of which I am eternally grateful. The advice I have received from him will carry me far in my personal life and career. I thank Dr. Weidong Xia for relentlessly believing in me and providing guidance from the Masters to the Ph.D. Besides my family, he has been one of the most selfless and developmental individuals I was fortunate enough to have in my life, and I would not have believed any of this was at all possible without him. I thank Dr. Debra VanderMeer for her extreme patience and open-door policy with me. She has an amazing intuition for saying exactly what you need, when you need it. Conversations with her gave me the confidence to break the ice on publishing my work, and her keen eye and unwavering demand for quality in my work produced some of the most positive responses I may ever see. I also want to give a shout-out to my twin during the Ph.D. program, Arturo Castellanos, for allowing me to keep my sanity. It was like I was in boot camp all over again, and we were each other's rock. I will treasure our friendship for the rest of my life. There are too many others to thank for making their mark in some constructive way so that I could get this far, but there is only so much space to do so. 


\begin{abstract}
OF THE DISSERTATION
RESPONDENT PERCEIVED THREAT DURING THE INFORMATION SYSTEMS REQUIREMENTS DETERMINATION PROCESS: UNDERSTANDING AND

MITIGATION
\end{abstract}

by

Alfred Castillo

Florida International University, 2017

Miami, Florida

Professor George M. Marakas, Major Professor

Requirements determination is a critical driver in a successful software development process. Despite decades of research prescribing various software development methodologies, intended to aid in achieving an eventual convergence between the user's mental models and an informationally equivalent representation that is codified within an information system, we can still attribute many of the deficiencies in software development projects to the improper or ineffective execution of the requirements determination process. This study draws on the user resistance, software development, and psychology literature to discuss how perceived threats by potential users and key respondents can result in suboptimization of a proposed information system via reduction in the quality of their responses during the requirements gathering phase. A laboratory experiment was carried out to explore the sources and effects of various threat perceptions and the effectiveness of 
techniques intended to detect and mitigate such perceptions of threat. The results confirm that perception of threat does lead to a degradation in response quality, with perceived adaptability fully mediating the relationship. The findings on whether interviewer reassurance has a moderating effect on the relationship between threat and perceived adaptability had interesting results, which are discussed. 


\section{TABLE OF CONTENTS}

CHAPTER $\quad$ PAGE

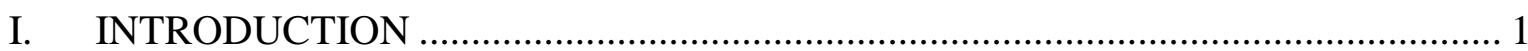

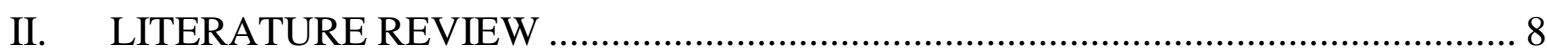

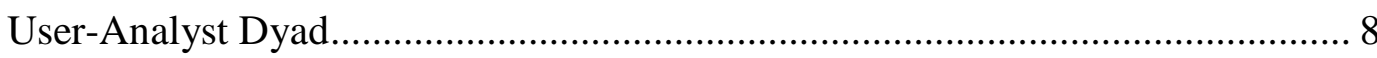

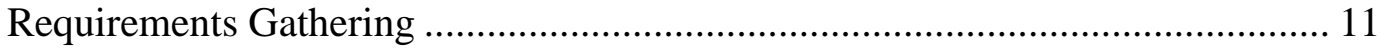

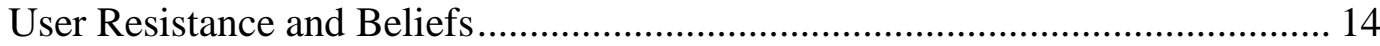

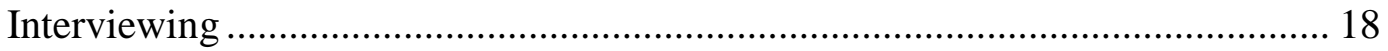

Psychology of Change ...................................................................................... 21

Vocational Effects of Change ………………………....................................... 23

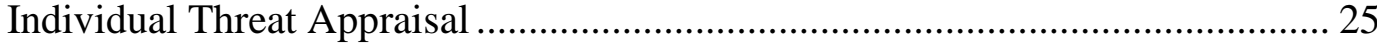

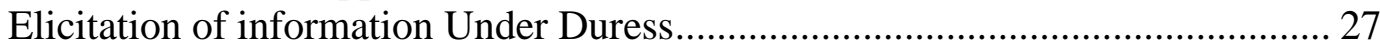

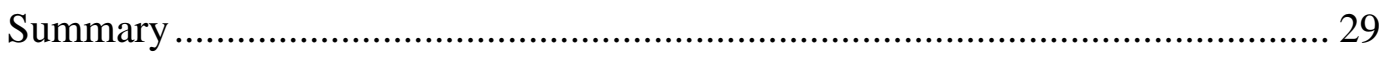

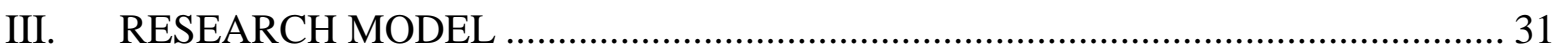

Relationship between Perception of Threat and Response Quality ...................... 31

Relationship between Personal and Contextual Factors on Perception of Threat 32

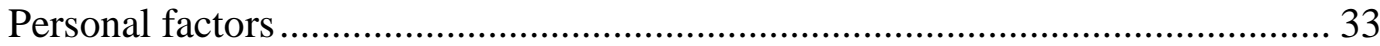

Contextual Factors ............................................................................................ 35

Relationship of Adaptability and Reassurance between Perception of Threat and Response Quality …………………………………………......................... 39

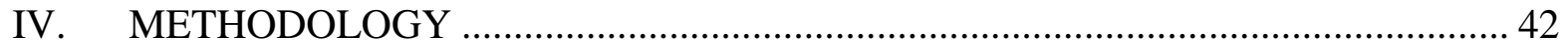

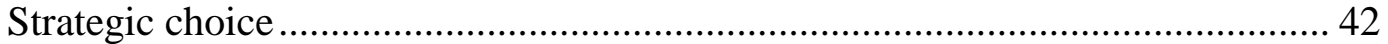

Informed Pilot ........................................................................................ 46

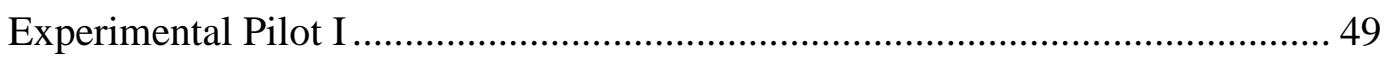

Recruiting and Group Assignment............................................................... 50

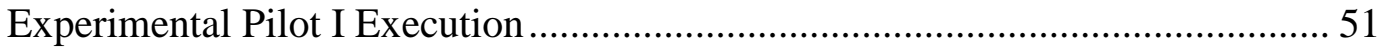

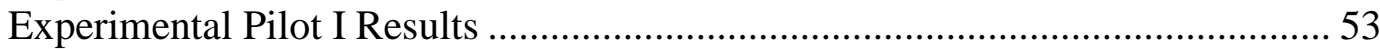

Pilot II and Migration to Qualtrics................................................................... 56

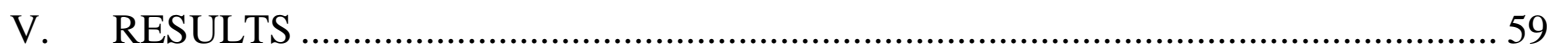

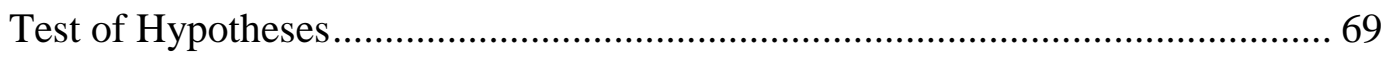

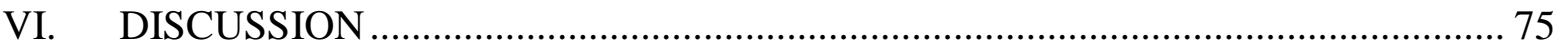

Limitations to the Study .................................................................................. 75

Discussion and Conclusions ................................................................................... 77

Implications for Future Research .................................................................... 84

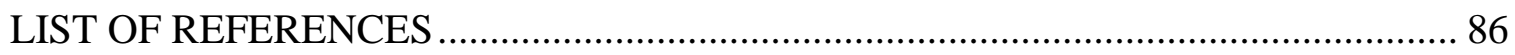

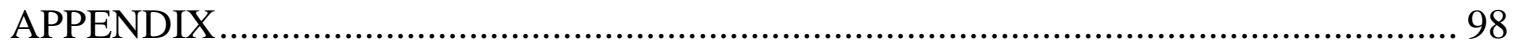




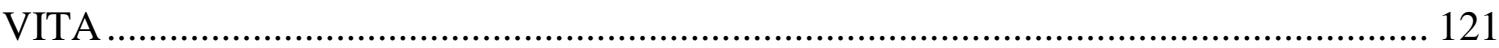




\section{LIST OF TABLES}

TABLE

PAGE

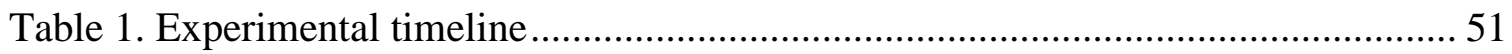

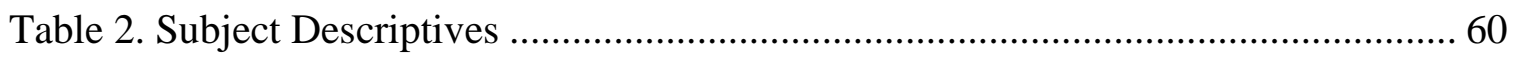

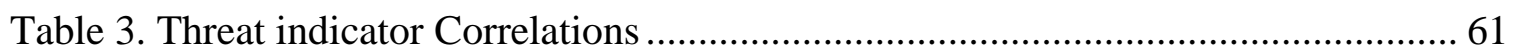

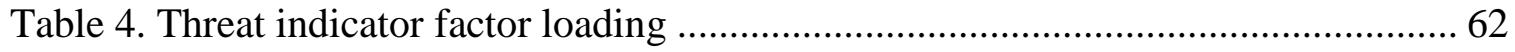

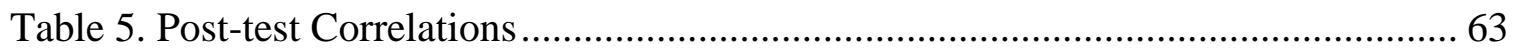

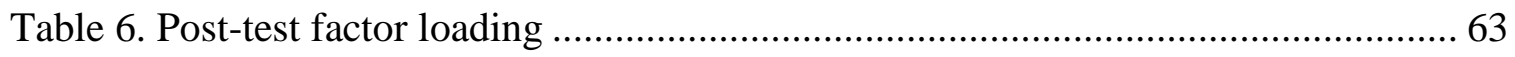

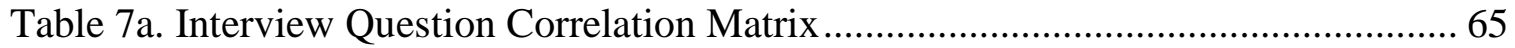

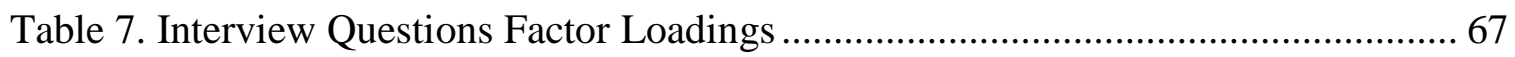

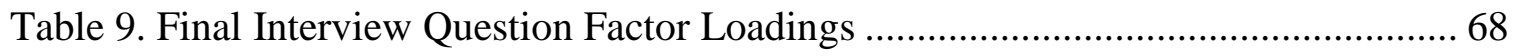

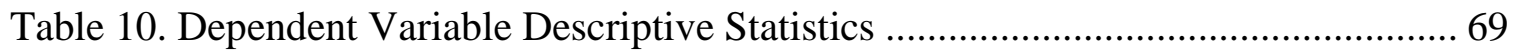

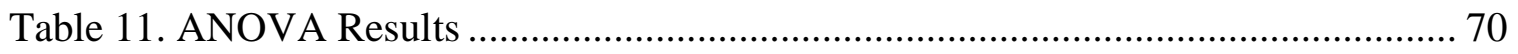

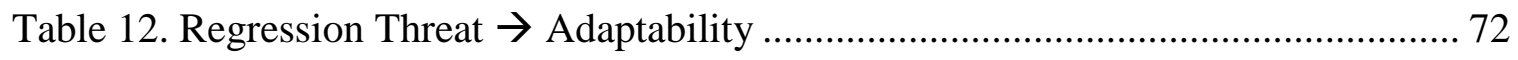

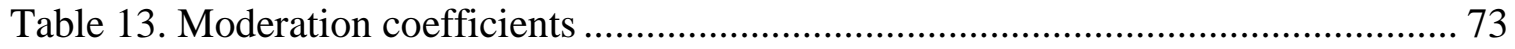

Table 14. Conditional effects of Reassurance on Threat $\rightarrow$ Adaptability ....................... 74 


\section{LIST OF FIGURES}

FIGURE

PAGE

Figure 1. IT-Culture Conflict (Leidner and Kayworth 2006) 15

Figure 2. IS Impact on Job Inputs and Outputs (Joshi 1991)....................................... 17

Figure 3. Job Insecurity Model (Greenhalgh and Rosenblatt 1984)

Figure 4. Protection Motivation Theoretical Model (Rogers and Prentice-Dunn 1997) .. 26

Figure 5. Proposed Research Model . 31

Figure 6. Experimental Flow 49

Figure 7. Qualtrics Experimental Study II Flow 58 


\section{ABBREVIATIONS AND ACRONYMS}

\begin{tabular}{|c|c|}
\hline E-I & Equity-Implementation Model \\
\hline EKS & Episodic Knowledge Structures \\
\hline EPPM & Extended Parallel Process Model \\
\hline ERD & Entity-Relationship Diagram \\
\hline FRD & Functional Requirements Document \\
\hline GAD & Generalized Anxiety Disorder \\
\hline GIM & Grammar-Targeted Interview Method \\
\hline GKS & Generic Knowledge Structures \\
\hline IS & Information Systems \\
\hline ISD & Information Systems Development \\
\hline JAD & Joint Application Development \\
\hline MISC & Motivational Interviewing Skill Code \\
\hline NGT & Nominal Group Techniques \\
\hline PMT & Protection Motivation Theory \\
\hline PRM & Passive Resistance Misuse \\
\hline SCT & Social Cognitive Theory \\
\hline SDLC & Software Development Life-cycle \\
\hline SLT & Social Learning Theory \\
\hline SME & Subject Matter Expert \\
\hline
\end{tabular}




\section{CHAPTER I. INTRODUCTION}

One pervasive characteristic of information technology is the way it has enabled the transformation of organizations if not entire industries. From modest beginnings, where IT was primarily viewed as a support function for the "business side" (Leavitt and Whisler 1958, Zuboff 1988), to more of a strategic partnership (Bradford and Florin 2003), information systems development has been a core driver for the process of creating effective tools to aid in such transformations (Brynjolfsson and Hitt 2000).

Although information systems development was originally a luxury afforded only to large organizations due to the high cost of entry (Porter 2008), as with any action taken by a competitor, the competitive landscape changes and competitors are forced to react to maintain their competitiveness (Tanriverdi, Rai et al. 2010). This has made information systems development capabilities a competitive necessity across modern organizations. A recent analysis of job postings (Smith 2016) suggests that software developers and systems analysts are collectively the highest earners, taking four spots within the top 20 hottest jobs. With commodity software widely available for purchase by new entrants, organizations intending to reap competitive benefits from their IT, are increasingly investing in their ability to develop and customize software to achieve the ever-elusive competitive advantage. In both parallel and contrast to the popularity of software developers and systems analysts increasing over the years, there has also been a long-standing concern about the skyrocketing cost of information system development (ISD) projects (Boehm 1981, Stecklein, Dabney et al. 2004, Eden, Ackermann et al. 2005). The unexpected increases in costs of ISD do not always have to be direct (i.e. project cost overruns, project 
time overruns, etc.). From a resource perspective, an organization that spends too much time on exploration without a comparable focus on exploitation of their existing competencies will do so at the trade-off of ensuring their present viability (March 1991). The more complex development efforts are more explorative, and project time overruns are manifested as occupying valuable subject matter expert (SME) resources from the business to provide the necessary feedback towards developmental efforts. These resources are critical to the day-to-day function of the organization in their roles as SMEs in their respective area. Whether the costs are direct or indirect, research in how ISD can be improved is easily argued to be both a fruitful scholarly pursuit as well as a practical necessity.

Throughout the evolution of ISD, one of the most crucial key contributors to system success is an accurate and effective requirements determination process (Montazemi 1988). Within this essential and complex process, the interaction between the users or key respondents and systems analysts (Newman and Robey 1992), or the user-analyst dyad, has received much attention (Graesser and Franklin 1990, Lauer, Peacock et al. 1992, Nonaka and Takeuchi 1995, Marakas and Elam 1998, Wenger 1998, Orlikowski and Scott 2008, Zappavigna and Patrick 2010, Gavrilova and Andreeva 2012). Inherent to all studies focused on the user-analyst dyad is the presupposition that there exists a competent and knowledgeable user and a competent and knowledgeable analyst who can extract relevant facts and information and transform the user's knowledge into useful system requirements. If the dyad is to function effectively, it is important that there exists an alignment in the knowledge structures of both the user and the analyst so that there can be shared meaning 
(Lauer, Peacock et al. 1992). To better understand this important element, research into the user-analyst dyad can be sub-divided into various granularity of focus ranging from macrolevel process issues such as knowledge acquisition and brokering (Byrd, Cossick et al. 1992, Pawlowski and Robey 2004), bottom-up vs top-down approaches to requirements understanding (Munro and Davis 1977), methodologies and models employed for requirements gathering and when to apply each (Davis 1982, Yadav 1983, Alavi 1984) (Hickey and Davis 2003), capturing the user's mental models (Montazemi and Conrath 1986, Zmud, Anthony et al. 1993), and resolution of ambiguity (Kaulio and Karlsson 1998). There is also a large body of literature that carries the underlying assumption that the requirements gathering process was done well, and focuses on modeling the outcomes of the requirements elicitation activities conceptually to achieve high informational equivalence in the proposed system. Despite a long-standing call for research taking a more micro focus on how requirements determination activities are performed (Teichroew 1972), to more recent calls for studying the socio-materiality of IS (Orlikowski and Scott 2008, Cecez-Kecmanovic, Galliers et al. 2014), there is a dearth of IS literature answering this mandate with regard to the identification and understanding of the specific activities and methods to be employed within the requirements determination process (Marakas and Hornik 1996, Marakas and Elam 1998, Browne and Rogich 2001, Sawyer, Guinan et al. 2010). This research intends to respond to this call by focusing attention and effort toward understanding an important and, as yet unaddressed aspect of the user-analyst dyad during the questioning and response process - that of the potential for perceived threat in the respondent and the subsequent potential for degradation in the quality or quantity of the information derived from said respondent. 
It is well known that there is an exponential rise in the potential cost of correcting an error across the various phases of a development project (Boehm 1981). If we assume that quality or quantity is compromised in this situation, then we must also assume that one of several inefficient activities may likely occur. First, the analyst must expend more effort through increased levels of triangulation, thus creating measurable inefficiencies and costs. In addition, the analyst becomes forced to make assumptions that may not be in keeping with those of the user constituency due to a reduction in information supplied by the user respondents. Finally, the analyst may in effect, unknowingly, possess insufficient information to create a system intended to solve the problem at hand and will therefore design a substandard solution. Should an error (or errors) occur from any or all of these conditions such design flaws when discovered can bear a cost of fixing them that increases exponentially with each phase of development in which the error remains undetected. From this, it is reasonable to take the position that effort or approach intended to improve the quality of the information at its source will provide measurable benefits to the requirements determination process, and ultimately to the resulting system.

The systems development process has evolved from the early days of the SDLC to the more modern iterative development methodologies, primarily to streamline the software development process, improve its accuracy and hence the quality of the resulting system. However, a single characteristic of the user requirements process that has not yielded entirely positive results is the information extraction process itself. A review of the various software development methods (seminal, integrated, and agile) found that requirements determination, regardless of methodology, was the weak link where "requirements 
traceability is rarely supported; requirements are either not adequately captured or partially lost or corrupted during the development process" (pg 3:82) (Ramsin and Paige 2008). One specific area of this process that has yet to be effectively explored within the IS research domain are the emotional and behavioral issues associated with elicitation itself.

The purpose of this study is to explore the general apprehension within the user associated with the requirements elicitation questioning process itself. It seems illogical (if not illadvised), given what we know about potential user resistance to a system (and its potentially detrimental effects on system quality), that we accept the premise that all the key respondents in the various user-analyst dyads are willing participants in the requirements determination process. Several reasons for taking this position can be identified. First, the very process of being interrogated in itself generates apprehension (Guyll, Madon et al. 2013). This apprehension, when combined with certain personal and contextual factors, can elevate itself into a measurable perception of threat that could manifest itself in a compromise of both the quantity and quality of the respondent's input. In addition, in most cases it is safe to make the assumption that the respondent has likely not volunteered for participation in the requirements determination process but has, rather been assigned or mandated to participate (Oreg and Sverdlik 2011). This raises the specter that the respondents' motivation to effectively participate is somewhat less than positive or intrinsic. Further, it is possible that the aforementioned conditions, along with the ultimate existence of the information system product under development being designed could contribute to the creation of one or more perceived threat conditions on the part of the user. Given what we know about the willingness of a respondent to provide relevant information 
under duress, threat, or anxiety, it is likely that the quality and quantity of the information derived from a respondent who perceives a high-level of threat from one or more sources may be negatively affected. Logically, any solicitation for information can be perceived within some continuum of threat ranging from mild (asking someone for the time) to high (asking someone what their banking card pin number is). It follows that an IS artifact can be perceived along some continuum of threat ranging from mild (a system that searches for answers on questions posed to it) to high (a system that thoroughly searches your digital footprint to make life-altering decisions on how you are categorized by law enforcement). Starting with the assumption that if users can be hostile towards the adoption of a technology that is perceived as threatening in some manner, then those that participate in its development may be participating in a hostile manner towards its development, this study seeks to determine the following:

- Given the presence of a high degree of a perceived threat by the respondent in a user-analyst dyad, how is the quality and quantity of the information provided by the respondent impacted by such perceptions of threat?

- Can a process be incorporated by the analyst during the requirements elicitation activities to detect the presence and degree of a perceived threat with the respondent and potentially mitigate the effects of that perceived threat on the quality and quantity of the generated responses?

The remainder of this manuscript proceeds as follows: Chapter II contains coverage of the extant literature related to information requirements determination, user resistance, interview methodologies and psychology considerations for eliciting information. Chapter 
III presents the intended research model employed in this study along with the hypotheses to be tested. Chapter IV contains the methodological design and operationalization of the constructs of interest for the study. Chapter V presents the data analysis and results derived from this study. Chapter VI concludes the manuscript and focuses on the limitations of the study along with a discussion of both the theoretical and applied implications of the results obtained as well as opportunities for future research. 


\section{CHAPTER II. LITERATURE REVIEW}

For over half a century the need for information systems to provide the right information, at the right time, to the right person, and in a comprehensible manner that is useful for driving decisions has been front and center (Ackoff 1967). With all the IS research work that has been done over this time it makes one question whether the focus has been properly targeted. We still experience information systems implementation failures due to technological issues, the scope of features not matching the needs of the organization, the users resisting it, and so on. Today, researchers have generally accepted that although technological issues can be remedied, for the most part, it is still the psychological and organization issues that drive IS failures and should serve to refocus research efforts ( $\mathrm{Au}$, Ngai et al. 2008). Although some work has been done on the social aspects of ISD, including user involvement, we still need to better understand the human interactions that occur in support of the development process. A logical starting point for this is the system requirements determination process. What follows is a presentation of some of the relevant research in the related areas.

\section{User-Analyst Dyad}

The critical first step for successful information systems development (ISD) outcomes is the requirements solicitation in the user-analyst dyad. A classic paper that illustrates this point is that of Newman and Robey (Newman and Robey 1992), which was a the result of Newman's longitudinal research interests at the time (Newman and Sabherwal 1989, 
Newman and Noble 1990). Taking a process model approach to understanding this dyad within two case studies, they studied how the locus of control during an ISD fluctuated during episodes of engagement between analyst-led, user-led, or more of a concerted effort. Interestingly, for ISD to have any chance at success the users' considerations had to drive the development efforts or they would eventually provide resistance. The resistance could lead to either a total failure, or a severe delay in the project until their concerns were addressed. It is no surprise either as a survey carried out on systems analysts revealed that they collectively perceive their role as socio-technical in nature, ranking interpersonal and system development skills significantly higher than all others (Lerouge, Newton et al. 2005). Since user involvement has been long researched and considered almost axiomatic in systems development (Ives and Olson 1984), the case study results in itself was not a novel finding, what was novel was its contribution in looking at the user-analyst dyad in a processual way. By taking a process view of the dyad they clearly illustrated how user resistance can manifest itself throughout the ISD effort, even when the project seems to be headed for success, and how the locus of control shifts between the user and the analyst could serve to reinforce or sabotage said efforts. The shifts between episodes of engagement is interesting, and although this level of analysis is granular in one sense it is still very macro in another sense. An episode of engagement itself, where the analyst and user are interacting to achieve understanding and agreement, could also be viewed in a more micro and processual way. With long-standing calls for more process-level work in the user-analyst dyad (Teichroew 1972, Marakas and Elam 1998), there is a dearth of literature to take up the challenge. Instead, an indirect approach to understanding this dyad 
is by looking at the work that has been done in requirements gathering, user resistance, and elicitation of information from IS and psychology.

The fact is we have frameworks and methodologies we can employ for requirements analysis, but little guidance on exactly how to effectively execute the requirements determination process in the user-analyst dyad beyond ensuring the competence of both parties. However, even ensuring the competence of both parties is problematic. Expertise has been defined in IS as "operative knowledge that manifests itself in the active solution of problems" (Johnson 1984). The problem at hand is developing a system that codifies some specific aspect of the business. The systems analyst's responsibility is in solving the business problem via analysis and design, however they are arguably never really an expert unless they happen to have worked specifically in the area for which the development effort is targeting. Otherwise any systems analyst with general knowledge about analysis and design would be equally qualified. Also, the user's role in the systems development effort is in providing system specifications to the analyst and future approval of the proposed system's features, of which they arguably may also have not achieved expertise in. The contextually specific knowledge has been studied as Episodic Knowledge Structures (EKS) and the generalized and more abstract knowledge has been studied as Generic Knowledge Structures (GKS) (Graesser and Franklin 1990, Lauer, Peacock et al. 1992). Using this lens we can explain the type of expertise in this manuscript to be GKS, otherwise a newly hired, but otherwise experienced, systems analyst and/or domain expert (user) would have to be excluded from development efforts as they are new to the organization and have yet to 
develop EKS specific to the organization even if they have developed EKS towards collaborative developmental efforts.

\section{Requirements Gathering}

Requirements gathering is a sub-process of requirements analysis based on the question/response process in the user-analyst dyad. The analyst asks pertinent questions for a proposed ISD to the domain expert(s) and the domain expert(s) provide answers which eventually become codified into the system via the other sub-processes of requirements analysis, structuring and generation. The process can be divided into three stages of information gathering, representation, and verification (Browne and Ramesh 2002). The requirements determination literature can be divided into two areas: (1) the requirements elicitation process, and (2) the conversion of the output of this process into a generalizable functional requirements document (FRD) and other derivatives (entityrelationship diagrams (ERD), entity lifecycle diagrams, entity state change matrices, data flow diagrams, etc.). There is disproportionately more research work done on the latter, which assumes that the former is well understood. Unfortunately, without adequate work done on the former, the research on the latter could be in vain due to an erroneous understanding of the process used in eliciting the requirements; garbage-in garbage-out.

With the popularity of user involvement in the development process, the distinction between user and respondent has become blurred over the years. Incremental development approaches, such as prototypes, are created and users are expected to sign-off on the validated specifications (Ramsin and Paige 2008). They are in essence gradually accepting 
the system that they are helping to create. As a result, we must not only look at the requirements determination literature, but also the user adoption literature to understand the user-analyst dyad.

Requirement gathering is qualitative in nature and one possible reason for downplaying the elicitation process itself in favor of researching subsequent logical representations is because of the ability to reduce qualitative ambiguity via triangulation. Triangulation can be done via method, sources, analyst, and theory/perspective (Denzin 1978, Patton 1999). Ambiguity in requirements gathering can be resolved by combining methodologies for elicitation, asking various respondents, using different analysts, or using a different lens to analyze the data to find the pertinent themes. This has led to a myriad of methodologies in IS literature for addressing the eventual convergence between the intended system and the user's needs (Hansson, Dittrich et al. 2006, Siau and Tan 2006, Madeyski 2009, Runeson and Höst 2009, Sarker and Sarker 2009, Siau and Rossi 2011), and has served to manage the scope creep of a project by finding commonalities across the broad spectrum of methodologies employed for requirements gathering such that the more salient requirements are focused on (Wilson 2006, McAvoy and Butler 2009).

Although triangulation may seem on the surface as a "silver bullet" to minimizing requirements determination issues, this approach has three detrimental flaws. One was discovered by a software engineer that was tasked with achieving efficiency via increased man power in development efforts, intended to create an equal division of labor but paradoxically exponentially increased the inefficiencies (Brooks 1975). The more people that become involved in a project the more complex coordination then becomes as you 
have created $n(n-1) / 2$ paths between them. In this light, it may seem counterintuitive to have too many system analysts, for example. Another flaw is that triangulation requires having multiple domain experts to solicit information from. Furthermore, there is also the assumption that there is no "clan mentality", where they unilaterally reject the premise of the system and will therefore not be willing participants (Kohli and Kettinger 2004), but more on this next. Another limitation is that triangulation takes time and costs money, yet not doing it does also, providing a "catch 22 " situation. Either triangulation is done at the beginning, or it will be done eventually as not catching design flaws early in the ISD effort has an exponentially negative impact as the project matures (Boehm 1981) and will require eventual rectifying. Although some may interpret this as triangulation being a necessity, the above issues indicate that ensuring the accuracy of the requirements information at the source is most important, and minimizes the need for triangulation.

The methodology employed may also bear no impact on the fact that tacit information is, at best, very difficult to extract from experts (Boisot 1995, Nonaka and Takeuchi 1995, Wenger 1998). As IS becomes more embedded within organizations, spanning complex business processes, the less readily observable the system requirements are and the more reliant we become on extracting the tacit knowledge from the experts (Gavrilova and Andreeva 2012). Using more of a conversational approach with the Grammar-targeted interview Method (GIM) researchers have found a way of improving solicitation of tacit information which would normally be hidden in speech patterns (Zappavigna and Patrick 2010). At the group level some techniques such as joint application development (JAD) provide mechanisms to achieve synergies by leveraging the combined knowledge of 
participants in a freely interactive manner with minimal controls (Dennis, Hayes et al. 1999). Unfortunately, the lack of controls also provides breeding grounds for social and emotional dynamics to undermine the effort (Duggan 2003). Nominal group techniques (NGT) minimize the issues with interaction (including groupthink, overbearing/powerful participant domination, ineffective conflict resolution) (Bartunek and Murninghan 1984), but at the expense of losing the richness that JAD provides via encouraging interaction. A combination of these approaches has shown promising results (Duggan 2003). Although still not a "silver bullet" it does provide research that we can use to improve the process of requirements elicitation, assuming the respondent is a willing participant not intending to subvert the effort.

\section{User Resistance and Beliefs}

Triangulation and other methods also cannot solve dissonance between the users and the proposed system, which is a concern in the IS domain (Lim, Pan et al. 2005). User resistance has long been thought to be the leading cause of information systems failure (Hirschheim and Newman 1988). Some organizational behaviorists and IS researchers have noted that individuals generally resist changes in general (Joshi 1991). One powerful illustration of this is in the healthcare context where physicians enjoy power and autonomy, more so than an average employee enjoys. One study tried to understand why systems implementations in a healthcare context was showing disproportionately larger failure rates, and used a clan lens for qualitatively interpreting the resistance of physicians as one of refusal to give up control and autonomy (Kohli and Kettinger 2004). A misalignment between the user's desire for power, and the system's lack of support in that regard will 
generally lead to resistance (Markus 1983). Users will ultimately evaluate the perceived resulting changes of an IS implementation in terms of changes in equity for themselves, their group, and their employer (Joshi 1991); and even if they didn't arrive at the determination themselves social influence from their group is a powerful contributing factor (Eckhardt, Laumer et al. 2009). This, along with other related work, led to a literature review that consolidated findings on IT-Culture conflict at varying levels of analysis. The three salient identified areas of culture were IT Values, Group Member Values, and Values Embedded in a specific IT (Leidner and Kayworth 2006). The concept of "fit" is the misalignment between the group member's values and the values embedded in a specific IT, called System Conflict. A perceived irrelevance arises from contradictions between their member's values and the group's IT values, called Contribution Conflict. The last provides mixed signals concerning the group's IT values and that which are perceived to be embedded within the system itself, called Vision Conflict (see Figure 1).

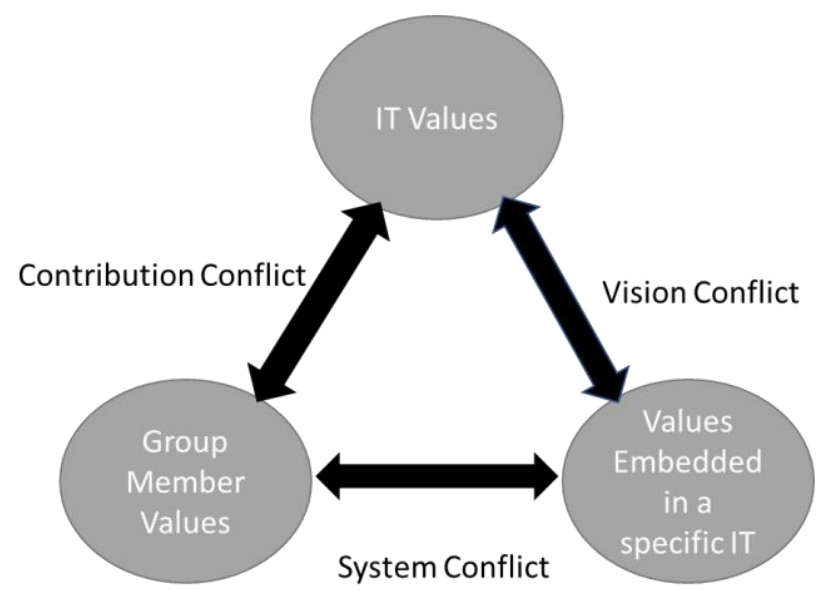

Figure 1. IT-Culture Conflict (Leidner and Kayworth 2006)

There has also been research in the equity-implementation (E-I) model, which provides a theoretical lens for understanding the user's resistance to change (Joshi 1991). This model 
provides three levels of analysis. The first focuses on the perceived net gains of the user. If they are positive, then the user is expected to support the effort. The second is about perceived shared benefit. If the organization benefits without an equitable benefit/profit to the users, then the users can perceive the implementation as unfairly distancing themselves from the organization. The last level is relative perceived benefit of a user, compared to those in their constituency. If the user perceives that the system would favor some members more than others, even if they themselves were the benefactors, the result may lead to resisting the system. The possible outcomes from an organizational and professional perspective by comparing and contrasting increases/decreases and outcomes/inputs required are provided for reference in Figure 2. Many of the causes to resistance have long been under investigation. Hirschheim and Newman viewed resistance as a complex phenomenon tied to innate conservatism, lack of felt need, uncertainty, lack of involvement in the change, redistribution of resources, organizational invalidity, lack of management support, poor technical quality, personal characteristics of the designer, and levels of education from the user's perspective (Hirschheim and Newman 1988). 


\begin{tabular}{|c|c|c|}
\hline & Inputs & Outputs \\
\hline hcrease & $\begin{array}{l}\text { - } \text { More pleasant work environment } \\
\text { - } \text { Less tension, more job satisfaction } \\
\text { - } \text { Better service to customers } \\
\text { - } \text { Recognition, better visibility } \\
\text { - Salary increase, grade increase, or higher- } \\
\text { - level title } \\
\text { - Increase in power and influence } \\
\text { - } \text { Learning a marketable skill } \\
\text { - } \text { Usefulness of the system } \\
\end{array}$ & $\begin{array}{l}\text { - } \text { More work in entering data } \\
\text { - } \text { Bringing higher level skills to the } \\
\text { job } \\
\text { - } \text { Effort in learning a new system } \\
\text { - } \text { Assignment of additional tasks } \\
\text { - More effort in performing tasks in } \\
\text { - } \quad \text { Need to spend more time } \\
\text { - Fear of unknown (e.g. failure) and } \\
\text { the resulting anxiety }\end{array}$ \\
\hline Decre & $\begin{array}{l}\text { - Reduced job satisfaction } \\
\text { - Reduced power } \\
\text { - } \text { employed bargaining power relative to the } \\
\text { - Threat of loss of employment } \\
\text { - Loss of value of marketable skills } \\
\text { - } \text { Reduced importance, control } \\
\text { - } \text { Reduced scope for advancement } \\
\text { - } \text { More role conflict and ambiguity } \\
\text { - Potential failure in learning and adopting } \\
\text { the new system }\end{array}$ & $\begin{array}{l}\text { - } \text { Ease of usage } \\
\text { - } \text { Less effort } \\
\text { information } \\
\text { - Reduced manual effort } \\
\text { - } \text { Reduced cognitive effort } \\
\text { - Less rework due to fewer errors }\end{array}$ \\
\hline
\end{tabular}

Figure 2. IS Impact on Job Inputs and Outputs (Joshi 1991)

With the understanding that there can be conflict between users and a proposed system, the assumption that outcomes of conflict, such as resistance, manifests itself solely overtly was challenged. Overtly the user can perform work-arounds (Ferneley and Sobreperez 2006), which are readily observable. Kim and Kankanhalli developed the construct of "user resistance" as a resistance behavioral measure and use the theory of status quo bias to explain user resistance prior to implementation (Kim and Kankanhalli 2009), and although some work has provided a remedy for some aspects of pre-introduction woes, via careful selection of participants and self-determination (Martinko, Henry et al. 1996), the reality is that all passive resistance misuse (PRM) of an IS system is not necessarily observable or measureable, and can instead manifest itself covertly in a passive aggressive manner (Marakas and Hornik 1996). Why then is there an assumption that these users, which are incorporated into the requirements determination process, are willing participants and will 
be forthcoming with relevant information that would lead to the ultimate success of a system that they do not want? Although some work has touched on it, if we are to attempt to understand possible resistance sources from the user it must be at the interaction between the user and the analyst.

\section{Interviewing}

The interviewing process is powerful and often under estimated. Although questionnaires have long been used as a method of eliciting information from respondents it has several drawbacks when it comes to capturing resistance to change. The first is that questionnaire data provides the opportunity for a temporary measurement of resistance to change, whereas a conversation can capture an individuals' utterances across time providing a richer source of a user's reservations (Bakeman and Quera 2011). The second is that interpreting natural language during a conversation is less obtrusive than questionnaires. The ability to revisit the conversation via recordings, versus reading an answer sheet, allows a more authentic picture to be discerned (Klonek, Lehmann-Willenbrock et al. 2014). Lastly, a natural conversation is less restrictive and allows a user not only to discuss concerns about intended organizational changes (Nord and Jermier 1994), but also to discuss factors that can serve as a driving force of intended organizational change (Lewin 1952). Beyond the methodological benefits to interviewing there are also merits to achieving understanding. A study showed that people immediately attempt to regain cohesion if a question/answer dependency, purposely manipulated to not match, is violated during a conversation as opposed to other methods (Hoeks, Stowe et al. 2013). During 
ambiguity in conversations people find an urge to clarify whereas someone reading a response is forced into sense-making.

Interviewees for the requirements determination process can have cognitive limitations. Users can have a recall bias, suffer from insensitivity to sample sizes or base rates when making generalizations, or provide an inaccurate anchor to serve as a starting point that is too far from ideal (Browne and Ramesh 2002). Furthermore, the analyst themselves can be overconfident and rush the process causing issues down the line. There is a basic understanding that communication with the user and the analyst is key, and there has been some work to improve the communication process between them, but none to our knowledge that mitigates the fact that the user may be an unwilling participant.

Instead, some research has focused on the cognitive convergence between the user and the analyst during interviewing to achieve understanding (Graesser and Franklin 1990, Lauer, Peacock et al. 1992). Others have focused on analysts asking the right type of questions depending on the information needed, and that they implement an appropriate methodology (Marakas and Elam 1998, Duggan 2003, Zappavigna and Patrick 2010). There has even been research on how to better interview as to detect lies, regardless of whether the lie is familiar or unfamiliar to the observer (Warmelink, Vrij et al. 2013). Warmelink et al found that asking background related questions allowed observers to distinguish truths from either form of lies (familiar/unfamiliar), but more detailed questions only allowed observers to detect unfamiliar lies. The reality is that although methodologically you can improve the interview process it still cannot remedy the problem that humans make poor lie detectors for respondents that are providing resistance (Bond and DePaulo 2006). It is 
important to note that no participants in these studies were manipulated such as to attack their beliefs and cause resistance due to dissonance. Doing so would likely yield varying results as the meta-questioning or methodology employed wouldn't matter if the user was not willing to participate and instead chose to intentionally provide inaccurate information.

Although some researchers have called for the incorporation of resistance to change literature into theoretical models of technology acceptance to better understand the resistance of users towards using technology (Bhattacherjee and Hikmet 2007), not many have answered this call. A recent study of the interview process' ability to promote elicitation of factors for or against a proposed organizational change, Klonek et al. dichotomized autonomy change-related discussions as change talk or sustain talk (Klonek, Lehmann-Willenbrock et al. 2014) using MISC (Miller, Moyers et al. 2003). Change talks are utterances that support a proposed change, while sustain talk support sustaining the resistance to the change. Klonek et al. found that communication patterns could lead to a vicious cycle where change agents are triggered by the change talk, and battle against it by verbal means, which serves to promote further resistance. This study indicates that if the interview process is to incorporate elicitation of causes of resistance they are to be careful in not contributing to it. Without some conditioning this may be a challenge as the analyst is not a neutral party to the ISD effort.

Autonomy is not the only situation where users may perceive a threat and engage in communicative resistance. Kehr et al. found in an experimental study that situation-specific assessment of risk and benefits fully mediates the dispositional factors on information disclosure (Kehr, Kowatsch et al. 2015). With a simple mobile application that has the 
automatic collection of information perceived as threatening (location and timing of travel, and violation of traffic laws) and not threatening (distance travelled, attributes of the vehicle), they found that situational factors (perceived privacy) can overcome dispositional factors (general privacy concerns, general institutional trust) on informational disclosure. The balancing act that determined situational factors was by weighting the perceived benefits vs perceived risks of information disclosure. This is another example of how any imposed technology is evaluated by the contributors as a tension between their perceptions, both positive and negative, about the proposed technology, and these perceptions can trump external factors.

\section{Psychology of Change}

The introduction or proposal of any new information system will impose some change on the status quo of the organization's users. This can manifest itself as resistance to change as discussed previously, which has been well studied in the applied psychology literature (Watson 1971). Although originally focused on situational antecedents, resistance to change has expanded more recently to include an individual difference perspective (Oreg 2003). Ambivalence of the individual, as the positive and negative reactions to an object (Kaplan 1972, Van Harreveld, Van der Pligt et al. 2009), can cause dissonance . On one side the user can see the benefit of the imposed change, but they must consolidate that with any perceived negative consequences, which may lead to unpleasantness (Van Harreveld, Van der Pligt et al. 2009). Any conflict between the user and some artifact must be interpreted from the person as an individual, as well as that of a constituent of their group and organization. 
Although an assumption is that users involved in the ISD are willing participants, this assumption is not unique to the IS domain. "An important factor that distinguishes between the various types of change, however, and that has yet to be incorporated into studies of change, is the amount of discretion that individuals have in adopting the change" (pg.338) (Oreg and Sverdlik 2011). Although there is a dearth of literature in regard to the individual effects of organizational change imposition in the IS literature, it is not alone in this regard.

In general, it has been shown that the context of an imposed change can produce ambivalent responses from individuals dependent on their orientation toward the change agent (Oreg and Sverdlik 2011). A psychological perspective of empowerment in the workplace finds that individuals want to find meaning, competence, self-determination, and impact in the workplace (Thomas and Velthouse 1990, Spreitzer 1995). Meaning is the value of a work goal or purpose judged by the alignment to the individual's own beliefs (Thomas and Velthouse 1990). Competence is the perceived self-efficacy, or capability to perform activities with skill (Gist 1987). Self-determination is an individual's sense of having options for engaging in activities (Deci, Connell et al. 1989). Finally, impact is the degree that an individual can influence various outcomes at work (Ashforth 1989). All of these can be affected by a proposed information system via locus of control, self-esteem, access to information, and rewards in either a positive way or a negative way (Spreitzer 1995). Regardless of who (i.e. the manager) actually imposes a change on these dimensions for the user, it can produce ambivalent responses from individuals towards the organization itself. An employee's tendency is to personify organizations and view the management and the organization as the same (Eisenberger, Huntington et al. 1986). 


\section{Vocational Effects of Change}

Organizational behaviorists have studied the nature of job insecurity, which is the leading threat for employees (Greenhalgh and Rosenblatt 1984). The model for job insecurity created in 1984 is still very much applicable today (see Figure 3). There is an interaction between the individual differences of an individual in their level of comfort towards proposed changes and their dependence (self-efficacy and economic) on how a threat signal is interpreted. These interpretations can lead to job insecurity for themselves, or the entire group, which reduces the organizational effectiveness and in turn makes the threat more real.

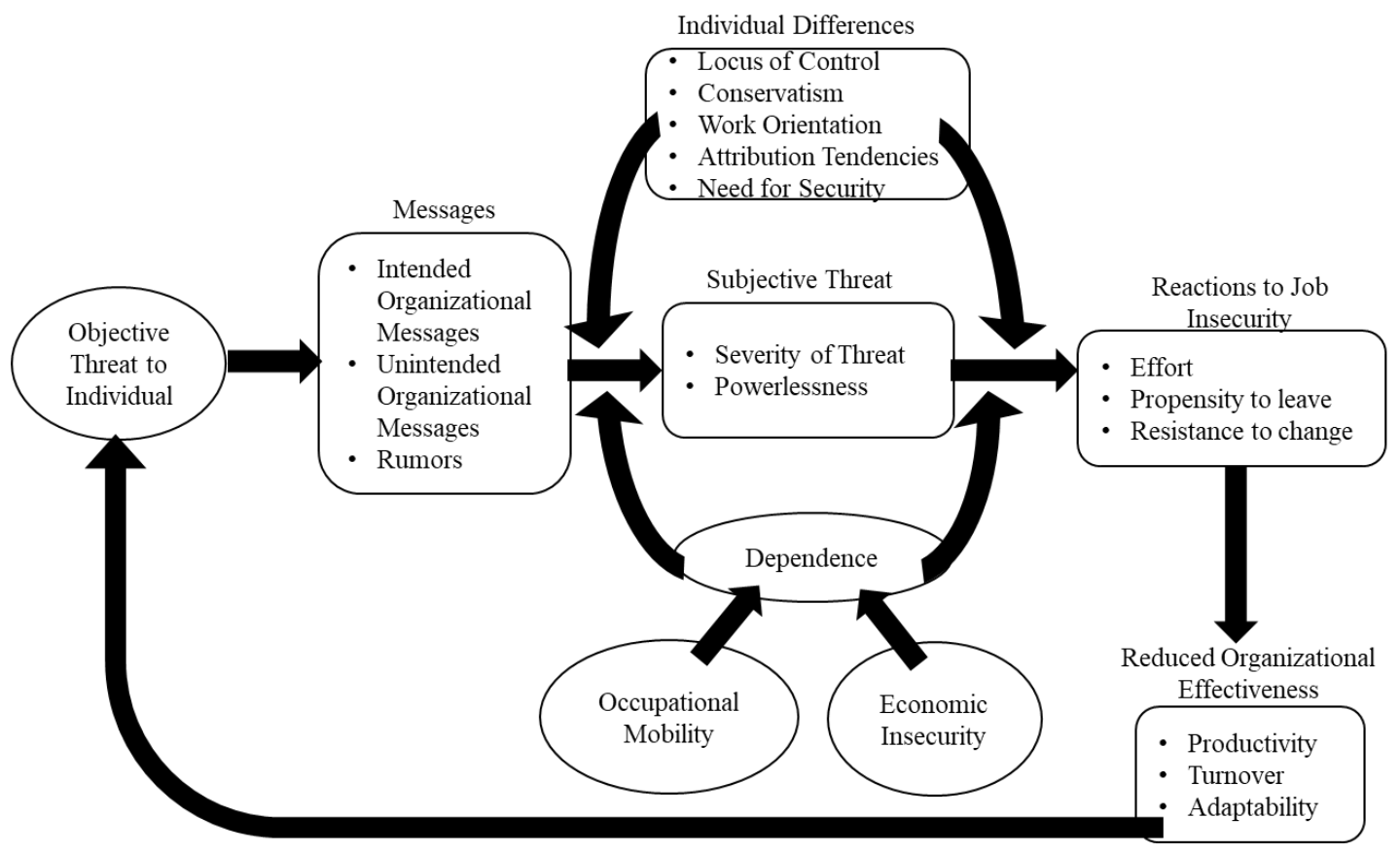

Figure 3. Job Insecurity Model (Greenhalgh and Rosenblatt 1984)

Ambivalence takes into account that employees might have conflicting attitudes toward change, but we still need to understand what triggers the conflicting attitudes (Arkowitz 
2002). Employees emphasize loss of control as the primary cause of resistance (Conner 2006). This is not a new concept to the IS domain. Similar to the IS domain, organizational literature also discusses employee involvement and participation as a means to overcome this obstacle (Coch and French Jr 1948, Sagie and Koslowsky 2000). However, this will only remedy the situation when the perception of the user changes from one of imposed change, to self-initiated change.

Furthermore, dogmatic individuals may not care where the change comes from. These individuals are characterized by rigidity and closed-mindedness in their views and could be inherently more resistant to change (Rokeach 1960). Although dogma is one characteristic, the slew of traits more broadly termed "cognitive rigidity" can contribute to resistance to change (Oreg 2003).

Another reluctance to change can be from "familiarity breeds comfort", where users are expected to give up old habits and hence make themselves uncomfortable (Harrison 1968, Harrison and Zajonc 1970, Watson 1971). The reason for this is that new stimuli can require unfamiliar responses, which produces stress. This is closely related to adaptability of the individual from a novelty perspective. Some individual are better at finding novel solutions outside of a given framework (thinking "outside of the box"), and have been found to crave this novel stimuli (Goldsmith 1984). This is not to say that extreme novelty is welcome in these individuals. New tasks will always require some level of learning and adjustment period and it has been shown that the requisite level of learning and adjustment can produce resistance (Kanter and Wales 1987). 


\section{Individual Threat Appraisal}

How people react to these perceived threats can be understood from the Protection Motivation Theory (PMT) (Rogers and Prentice-Dunn 1997), and the closely related Social Learning Theory (Bandura and McClelland 1977), which later became more pronounced as Social Cognitive Theory (Bandura 2011) in the psychology literature. In PMT there is a two-step appraisal process where the user is evaluating the threat and their ability to cope with it (diminish the threat). Depending on the severity of the threat, if their belief is that they have high self-efficacy in dealing with the threat then the user can provide an adaptive response (adjusting/responding to the threat). Some threats are so high, and their perceived self-efficacy at dealing with it so low, that they may instead resort to a maladaptive response. How likely an individual is to protect themselves will rely on the perceived severity, the perceived probability of occurrence (or vulnerability), the efficacy of any recommended preventive behavior (perceived response efficacy), and the perceived ability of the individual to undertake the recommended preventive behavior (self-efficacy). The sources of information that feeds the perceptions of self-efficacy in dealing with the threat

can be by verbal persuasion, observational learning, prior experience, and personality variables. Once a threat is evaluated it manifests itself along some gradient of fear-arousal (see Figure 4). 


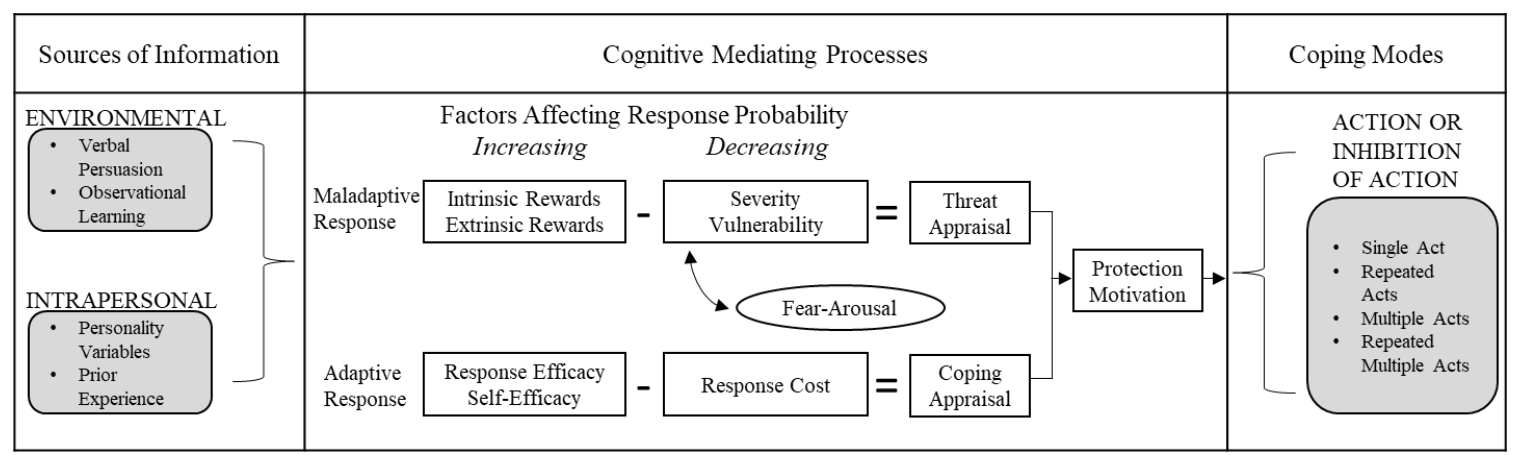

Figure 4. Protection Motivation Theoretical Model (Rogers and Prentice-Dunn 1997)

Manifestations of various levels of arousal has long been studied and shown to affect the performance of the individual experiencing arousal (Yerkes and Dodson 1908, O'Brien and Crandall 2003, Schmader, Johns et al. 2008). The effect can be either linear or inverted-u shaped, depending on the "difficulty" of the task. The PMT theory, along with other research presented in this chapter that discusses the people that enjoy the novel, suggests that if there is a high perceived response efficacy and self-efficacy for a certain threat appraisal, then the result of a new "challenge" will be more of an adaptive instead of a maladaptive response, which explains the linear relationship. People with a low perceived response efficacy and self-efficacy will be overwhelmed and have a dramatic decrease in performance (maladaptive response) as arousal increases, which explains the inverted-u relationship. Because response efficacy and self-efficacy are perceptions, it is possible to mitigate the resulting coping appraisal and increase it by demystification of the process which is influencing the arousal (Schmader, Johns et al. 2008), or constructive discussions about it (Klonek, Lehmann-Willenbrock et al. 2014) which serves to reinforce perceptions of their efficacy. 


\section{Elicitation of information Under Duress}

Being solicited for information can bring out stress in people. It has been shown that being in front of a group of people can cause fear and worry, which has a detrimental effect on verbalization and imagery (Bergman and Craske 2000). Although verbalization is the most readily apparent to an observer, assuming it is not verbal "thought activity", it is the individual's emotional imagery that activates more fear structures (Bergman and Craske 2000). These kinds of images can be the loss of a job, autonomy, self-reliance, etc. Some explanation for this is in the fact that stress has been linked to affective memory, executive functioning, and decision-making. Starcke et al. found that faced with a pending speech activity increased stress causing several physiological responses in the subjects (Starcke, Wolf et al. 2008). These stressed subjects tasked with decision-making tasks then showed reduced decision making capabilities. Although the source of the stress of these was related to speech, in general it has been shown that the decision-making process of a person under general stress suffers dramatically (Keinan 1987). Although subjects were presented with alternatives to problem solving, people under any form of stress rushed to provide suboptimal solutions, via premature closure, nonsystematic scanning, and temporal narrowing.

It's not just speaking to audiences that can bring on stress as interrogations in general can also affect stress levels. In one experiment researchers studied whether guilt or innocence lead to increased stress (Guyll, Madon et al. 2013). They manipulated guilt by adding a second person that was tasked with soliciting help for an individual task, thus making the test subject guilty of contributing to cheating. The innocent subjects had lower 
physiological response to accusation and interrogation than guilty participants. However, the less stress experienced by innocent parties lead to lowered perceptions of risk which discouraged any self-protective actions. The innocent have a sense of protection from negative outcomes (Kassin 2005), which may lead to increased risk of self-incrimination. If an interrogator isn't sensitive to this fact they can elicit erroneous information by guiding the conversation from an unwitting participant.

If the goal of the respondent is to lie for self-preservation there are manifestations within their speech patterns that can provide means for detection. The cognitive load experienced by liars is much higher and can give rise to slowed responses, or stuttering during interviewing making it easier to distinguish them from truth tellers (DePaulo, Lindsay et al. 2003). For simple tasks the increase in cognitive load may not be detectable, but by assigning liars a difficult task, or a distraction task, the cognitive load will increase and should be detectable (Vrij, Fisher et al. 2006). Arguably the latter is the case of an information systems development project. In police interrogations and in intelligence elicitation activities, interview protocols often switch cognitive load by asking unexpected questions or by introducing forced turn-taking (Vrij and Granhag 2014). However, these techniques should be used with caution as pushing an unwilling participant to continuously provide information can result in collection of erroneous information as was shown to be the case when several people convicted of serious charges that were released due to a lack of reliability on confessions obtained during confrontational police interrogations (Williamson 1993). It turns out if you push people hard enough they may tell you what you want to hear, accurate or otherwise. Although someone may seem like they are not telling 
the truth, calling people out on their resistance may not be as fruitful as it may seem on the surface. If information quality is the focus, then a more fruitful approach is to re-establish rapport between the interviewer and interviewee, or to allow the subjects to be free from declining to participate without penalty (Menges 1973).

It is important to also understand that the respondents may not be lying for selfpreservation, and they may be doing so unwittingly. In another study subjects were shown video clips of traffic accidents in order to have them respond to questions that are difficult to discern, such as speed (Loftus and Palmer 1974). Questions were framed with different verbs describing the accident ranging from mild "how fast were the vehicles going when they contacted each other?" to more violent "how fast were the vehicles going when they smashed into each other?". The perceived speed of the vehicle showed to steadily increase along this same range. Furthermore, when asked if they saw broken glass (there was none) the groups with the more violent verbs had a false recollection of seeing it. What these studies show us is that it is important to craftily phrase the less exploratory questions such as not to indirectly lead the respondent and cause detriment to response quality.

\section{Summary}

IS professionals are knowledge brokers, whose work spans beyond their departmental boundaries (Pawlowski and Robey 2004). The systems analyst must be able to communicate with multiple stakeholders, understand their needs and concerns, and must be able to generate a functional requirements document through the effective communication with subject matter experts that the system is being designed for. Any ISD 
implementation proposes a change for the individual that is expected to use it, and in general change is not something humans are entirely comfortable with. The literature on user resistance and degradations in ISD performance tells us that users are not always willing participants and can actually serve to undermine an ISD effort in an overt or subvert manner.

The interview process itself can be intimidating for users. In domains that have to communicate with an apprehensive respondent, such as in healthcare, the need for effective communication is clear and approaches have to be multi-faceted. The interviewer must tailor information and dialogue with the respondent in mind, convey understanding of the emotional aspects and social impact of decisions to be made, elicit concerns of the respondent for discussion, determine the level of willing participation of the respondent, and provide constant feedback on performance (Maguire and Pitceathly 2002). Yet, there is no equivalent prescriptive methodology for the requirements determination process in IS, which can serve to mitigate some of the legitimate concerns of a user/respondent during an ISD. The social support from people in positions of authority, or from peers, is critical to mitigating any concerns (Greenhalgh and Rosenblatt 1984), and a good systems analyst must not only be able to detect perceived threats from the user but also mitigate them as a representative of the organization. The sources of concern for a user/respondent can be debilitating as the proposed ISD has the ability to affect not only their job roles, but also on how individuals identify (Kraig 2015). After all, if you ask someone what they are and they will likely identify with their occupation (Frone, Russell et al. 1995). 


\section{CHAPTER III. RESEARCH MODEL}

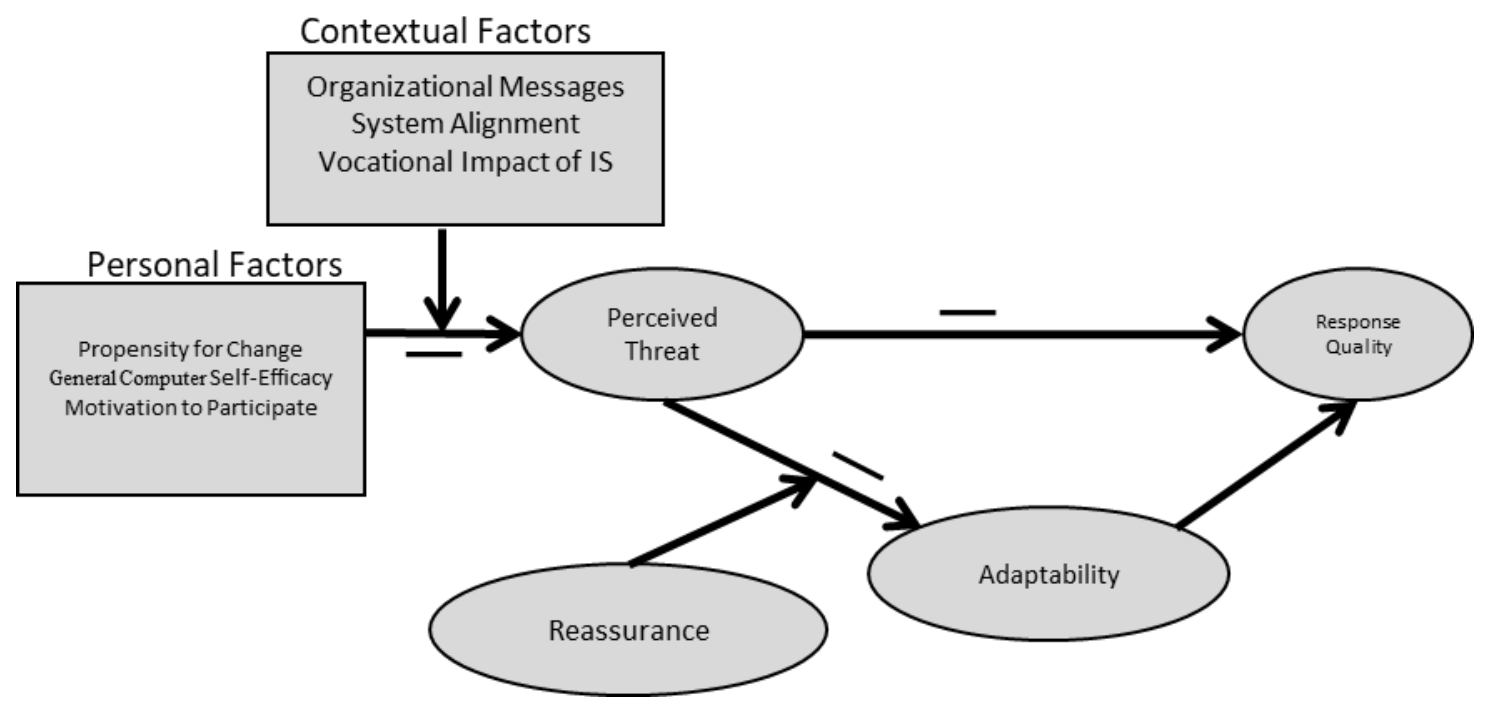

Figure 5. Proposed Research Model

The proposed research model is shown in Figure 5. What follows is a discussion of the hypothesis and constructs.

\section{Relationship between Perception of Threat and Response Quality}

Recall from the previous chapter that stressors can negatively affect the performance of an individual (Yerkes and Dodson 1908). Individuals under questioning exhibit anxiety, regardless if they are innocent or guilty of any wrong doing in the given context (Guyll, Madon et al. 2013). During interviewing, the perception of threat is manifested as an emotional arousal that can decline verbalization quality (Bergman and Craske 2000, Starcke, Wolf et al. 2008), and even make respondents more likely to deceive (Vrij, Fisher et al. 2006, Vrij and Granhag 2014). Assessment of risks and benefits has been shown to affect dispositional factors on information disclosure (Kehr, Kowatsch et al. 2015). 
Although respondents for requirements determination are assumed to be cooperative individuals, we also know that a user's resistance to a proposed information system can manifest itself as overt or covert resistance (Marakas and Hornik 1996). It is therefore reasonable to assume that the perception of a threat can lead to degradation in the response quality of a respondent; or more formally:

\section{H1: The presence of a significant perception of threat in a respondent during the requirements determination process will result in a degradation in the quality of the responses provided by that respondent.}

\section{Relationship between Personal and Contextual Factors on Perception of Threat}

Resistance to change is a well-known phenomenon in the psychology literature. Within business, change has been categorized as administrative change, technological change, and structural change (Dent and Goldberg 1999). Resistance to these changes can be attributed to resistance via people's fear of poor outcomes (e.g. earning less money, inconvenience, increase in work load), fear of the unknown, and realization of faults with change that was overlooked and the resulting concerns associated with resulting problems (Ireland 1993). Any perception of threat is therefore derived from the evaluation of the potential negative impact that an impending change will cause.

Information system implementations are no longer simplistic and have pervasive reach throughout all aspects of a business, resulting in administrative and structural changes a virtual necessity during an ISD. The disruption of a new information system triggers an iterative and adaptive process between people, the technology, and the organization (Orlikowski 1992). During an ISD effort the technology does not yet exist, although it's 
evolution is influenced via discovery about important characteristics within the workers, processes, and institution that it needs to co-exist with. The organization and its people are most important during this discovery process, as they will need to welcome and prepare for the eventual introduction of the ISD. It is therefore essential that the individuals, and the context (processes, organization, technological needs) be in favor of the impending change of the information system so that they are not threatened by it. This leads us to the following higher-order hypotheses, which are further developed in the following subsections:

H2: The higher the overall level of personal factors favoring change for a respondent during the requirements determination process, the lower the perceived threat in that respondent.

H3: The higher the overall level of contextual factors favoring change for a respondent during the requirements determination process, the lower the perceived threat in that respondent.

\section{Personal factors}

Personal factors will vary between individuals as something may be more important to some individuals than others. For example, some people may welcome change, while others reject it (Watson 1971). Those that reject it may simply have an innate conservatism that is threatened by change (Watson 1971, Hirschheim and Newman 1988), or they may simply be more dogmatic (Rokeach 1960). A primary driver that may provide explanation for fear of change, is the need for control by the user (Conner 2006). For example, a person that enjoys the autonomy of their job may not like the introduction of a new information system that compromises the autonomy (Kohli and Kettinger 2004). With humans being 
creatures of habit (Harrison 1968, Harrison and Zajonc 1970) many will feel threatened by the proposed change as a deviation from their normalcy (Goldsmith 1984), but others may actually welcome it. For example, some users may be confident in their skills and motivated by novelty of a new IS implementation (Goldsmith 1984, Kanter and Wales 1987), which provides the ability to learn something new. This leads us to the following sub-hypothesis:

H2a: The higher the propensity for change of a respondent during the requirements determination process, the lower the perceived threat in that respondent.

When change is imminent the resulting perception of threat depends on how well equipped the person feels they are at handling the threat (Bandura and McClelland 1977, Rogers and Prentice-Dunn 1997). During an ISD the user may feel computer anxiety due to a low perception of their ability to effectively use a computer at their job, termed general computer self-efficacy (CSE) (Compeau and Higgins 1995, Marakas, Yi et al. 1998). Computer anxiety is a fear about the implications of computer use, and can be somewhat related to the individual's propensity for change with psychological variables such as neuroticism and locus of control (Marakas, Johnson et al. 2000). Studies have shown that individuals with more confidence in their capabilities tend to have reductions in their anxiety, and a stronger proclivity to use computers (Jason Bennett, Perrew et al. 2002), which leads us to the following sub-hypothesis:

H2b: The higher the general computer self-efficacy for a respondent during the requirements determination process, the lower the perceived threat in that respondent. 
Individuals also have varying reasons, or motivations, for engaging in work, which can be extrinsic or intrinsic in nature. In the literature, research with aims in measuring this have typically used the Work Preference Inventory (WPI) to measure intrinsic and extrinsic motivators (Amabile, Hill et al. 1994), highly related to the propensity for change and CSE of the individual. The intrinsic motivations include self-determination, curiosity, task involvement, enjoyment and interest, and competence, while extrinsic motivations include concerns with competition, evaluation, recognition (money or other tangibles), and constraints by others. A recent book titled "The motivation to work", discusses that although both intrinsic and extrinsic motivators are important, they impact good feelings about a job with varying degrees. Out of the positive factors, the longest lasting all relate to the intrinsic content of the job, rather than the context in which the job is done. It is important that people like what they do, or the intrinsic motivation, not necessarily how or where they do it for long-term enjoyment. This was followed in impact with the extrinsic factors, which were more temporary in nature but also led to good feelings about work (Herzberg, Mausner et al. 2011). This leads to the following sub-hypothesis:

\section{H2c: The higher the motivation to participate for a respondent during the requirements determination process, the lower the perceived threat in that respondent.}

\section{Contextual Factors}

The reality is that the impact of contextual factors on perception of threat must be evaluated by considering the individual and/or group that is perceiving the threat. Contextual factors can pertain to the system, job role, or the organization. People in general resist change (Joshi 1991) and the ability of a proposed system to span organizational boundaries and 
cause a change to the status quo of the employees is not generally a pleasant experience as a result. As discussed previously, the pervasive effect of an information system has far reaching impact throughout the organization, with some information systems having more reach, and more impact of the worker's environment than others. Even when an individual may welcome change, during an ISD there is some level of anxiety with change because of the various areas of change that can be affected which may be important to the worker, even if it may not be as pronounced as for those individuals that do not welcome change (Ireland 1993).

Just as some individuals have varying resistance to change so do organizations, who have to restructure in support of change, termed structural inertia (Colombo and Delmastro 2002). Higher levels of structural inertia are the consequence of a selection process, rather than a precondition for selection (Hannan and Freeman 1984). Overtime an organization creates internal inertia via path dependency from sunk costs in equipment and personnel, political coalitions, and via precedents that become norms. Organizations also have external inertia due to legal constraints and barriers to entry and exit in the markets of which they engage in business activity. Even if an individual is welcoming change they may sense that the ISD may impose radical structural changes to the organization that could threaten legitimacy, creating a perception of threat (Hannan and Freeman 1984). It is therefore important that the organization communicate the change effectively to their employees while minimizing the uncertainty of the impending change. This has been formally accepted as a necessary part of risk mitigation and change management strategies in Project Management methodologies via championing, training, project kickoff meetings 
and communications, etc (Tesch, Kloppenborg et al. 2007). This leads us to the following sub-hypothesis:

\section{H3a: The higher the level of organizational messages for a respondent during the requirements determination process, the lower the perceived threat in that respondent.}

Recall from previous chapters that the ambivalence of an individual towards a proposed information system is multi-faceted (Kaplan 1972). The benefits of a proposed change must be weighed against the negative consequences of it for themselves and their group (Van Harreveld, Van der Pligt et al. 2009). There may be a "misfit" between an individual, or group's, beliefs and values and those embedded into the system, causing a source of tension for the user (Leidner and Kayworth 2006).

For example, the equity changes caused by a proposed system where some benefit more than others can also be misaligned from an individual's beliefs on maintaining the distribution (Joshi 1991). Markus found that some individuals may enjoy power and consider a system that makes organizational changes which do not support their desire for more power as threatening, as well as the opposite (Markus 1983). Another example of misalignment between the attributes of a system and personal belief is the mismatch of an individual's sense of privacy and capabilities embedded within the information system. Modern systems are not only used for storing information, but they are also used to discern actionable information about the people that the data is about via data mining technologies. Concerns of privacy with the data mining capabilities has become so important that it has given rise to an entire stream of research in privacy-preserving data mining (PPDM) (Xu, Jiang et al. 2014). 
Although the examples above are not exhaustive they illustrate that humans can find misalignment between an information system and their beliefs and values that results in feelings of being personally attacked. Formally stated, in a positive sense to maintain consistency with the contextual dimension, we have the following sub-hypothesis:

\section{H3b: The higher the level of system alignment for a respondent during the requirements determination process, the lower the perceived threat in that respondent.}

From a vocational perspective, a new system may entirely change the power/control distributions, structure, required skills, and interdependence previously experienced in the same job role that will be affected by the proposed system (Hirschheim and Newman 1988). These vocational sources of change can range from micro and negative, such as job insecurity, to macro and positive, such as shifts in the entire industry by redefining a job role (Greenhalgh and Rosenblatt 1984). Although some technology may be viewed as deskilling, fragmented work and loss of specialization and integrated skills, there are many opportunities for reskilling and upskilling (Commerce 2013). The labor force is in constant shift as technological developments occur, but it is important to note that the first mover advantage does not only belong to the organization. The individuals working in cuttingedge jobs also become more skilled and in demand. Although the introduction of a new technology can certainly cause negative changes within a job, it can also create areas of opportunity, such as improved productivity and opportunities for training and developing new skill sets; or formally stated:

H3c: The higher the level of vocational opportunity for a respondent during the requirements determination process, the lower the perceived threat in that respondent. 


\section{Relationship of Adaptability and Reassurance between Perception of Threat and Response Quality}

Although threat has been hypothesized to lead to a degradation in response quality, it may be too simplistic to tell the whole story. Protection Motivation Theory (PMT) indicates that after carefully appraising any perceived threats, the respondent can become so overwhelmed in their inability to adapt or respond to the threat that they simply become self-destructive and have a maladjusted response to the threat (Rogers and Prentice-Dunn 1997). In this case the perception of adaptability is virtually non-existent, making a direct path between threat and response quality a strong possibility. However, the respondents can also find that they are able to cope with the perceived threats to some degree, increasing their perceived adaptability and response efficacy to the threat (Rogers and Prentice-Dunn 1997). The perception of the user in being able to effectively respond is what will make the difference in the resulting impact to performance in an activity (Yerkes and Dodson 1908). This suggests that a perception of threat may affect response quality through perceived adaptability, or more formally stated:

H4: An increase in the perception of threat for a respondent during the requirements determination process will decrease response quality through its effect on adaptability; the higher the perception of threat, the lower the perceived adaptability, and the lower resulting response quality of a respondent.

Conversational techniques have shown to be more effective at eliciting tacit information (Zappavigna and Patrick 2010). When comparing conversational group techniques for requirements determination, those that were most successful were the ones that minimized 
the issues with groupthink, overbearing/powerful participant domination, and ineffective conflict resolution (Duggan 2003). The implementation of controls that provide isolation for participants can minimize destructive conversations that are counterproductive (Klonek, Lehmann-Willenbrock et al. 2014). Although we can minimize the group effects during requirements determination we know that social influences are very important to how users perceive a proposed change (Bandura and McClelland 1977, Eckhardt, Laumer et al. 2009, Bandura 2011). When a user perceives a threat, this means that group efforts can either serve to increase or decrease the way the user views their susceptibility and vulnerability to the threat. This effect is stronger if the social support comes from people in perceived positions of authority, or from peers (Greenhalgh and Rosenblatt 1984). The systems analyst is a representative of the organization tasked with elicitation of the requirements from the user and also plays a vital role in the detection and mitigation of any concerns during the requirements gathering process (Menges 1973, Maguire and Pitceathly 2002). If only for the duration of the requirements determination process, the systems analyst is in a position of authority (Markus 1983), and is therefore in a position to reinforce or subvert any doubts or concerns of the user. The fear appeals literature spans over 60 years now. It has been mainly used in the healthcare context, to understand how people can be influenced to address health concerns, using Protection Motivation Theory as the most common theoretical lens (Ruiter, Kessels et al. 2014). The work in this area has focused on two aspects of messaging: (1) the fear arousal component, and (2) threat aversion. According to the fear appeals literature, if there is to be any mitigation of an individual's perceived adaptability in responding to a threat during an ISD, then the messages conveyed by the system analyst must be provided in such a way as to minimize or reduce the 
evaluative process of the threat itself (threat appraisal) or how the individual can respond to the threat (coping appraisal). This is stated in the following hypothesis:

H5: The higher the level of reassurance provided to a respondent during the requirements determination process, the lower the effect of a perception of threat in the respondent on the respondent's level of adaptability. 


\section{CHAPTER IV. METHODOLOGY}

In this chapter the research strategy, pilots, subjects, variables, and protocols are discussed.

\section{Strategic choice}

In this research study, it is proposed that a perception of threat by a respondent can lead to a degradation in their response quality. A threat must be present that: (1) the recipient believes they have a susceptibility to, and which (2) is severe; both aspects must be present (Rogers and Prentice-Dunn 1997). Consider an example where a new information system may be created to fully automate the task of line-worker employees. Purely from viewing the information system as an agent of change, one employee may be technologically skilled and not see themselves particularly susceptible to the negative consequences of the system. They may view this as a reskilling paradigm, providing opportunity for professional growth in the industry. Alternatively, from this same lens, another employee that doesn't feel comfortable with technology may instead view themselves highly susceptible to this threat, and view the possible outcomes of introducing this system as severe. The later employee may view this information system as one of a deskilling paradigm, which would result in them becoming obsolete and eventually possibly losing their job. Subjects exposed to a threat must therefore interpret the threat as equivalently as possible in terms of susceptibility and severity.

Although we briefly discussed the information system as an agent of change, there are various personal factors that can lead to a perception of threat from the introduction of this information system. For example, there could be misalignment with their beliefs, culture, 
vocational preferences, norms, and customs. These personal factors can be numerous, and would be very difficult to measure parsimoniously. Even if adequate proxies were found that could provide accurate measurement for many of these personal factors, there still exists the potential for unintentionally omitting important personal factors from measurement, resulting in significant variance being attributed to the error term. The best recourse is therefore to randomize subjects to groups so that these personal factors would be manifested similarly between groups (Kerlinger and Lee 2000).

If a threat is high enough it may result in maladaptation, which could manifest itself in covert ways, including lying during the requirements elicitation process. Unfortunately, lying has been shown to be elusive to detect without physiological response measurement (perspiration, pupil dilation, heart rate, etc.), and even then, the fact they are being wired to measurement instruments increases anxiety and can affect the sensitivity of those measurements to become unreliable. Beyond physiological measurements there are some speech patterns that can also be detected (long response times, stuttering, misdirection, etc.), however with similar unreliability to the physiological measurements (e.g. a liar may still choose a quick satisficing answer based on salient clues in the environment). If you were to directly ask a respondent about their participation in an activity that is viewed societally in a negative fashion, or about opinions that may betray their personal actions as misaligned with perceptions of societal norm, the results you would get would vary depending on how protective the individuals chose to be and could prove to be untrustworthy. Various strategies for "threatening" interviewing protocols were studied for many decades, and an alternative strategy of ask probing questions that evaluates the 
person's beliefs about a negative activity that they may be engaged in without directly asking the respondent if they engage in that activity proved to be best (Bradburn and Sudman 1991). For example, if one were to ask an individual if they are an alcoholic they will likely answer that they are not. If you instead ask how many alcoholic drinks they believe people consume on average, they may provide an answer more aligned to their own engagement in the activity. The higher someone answers the more likely they engage frequently in the activity. The lower someone answers the more likely that they less frequently engage in the activity. The best mechanism for finding out the truth about an individual engaging in questionable behavior, or of opinions that may be the result of personal bias they think society would condemn, is to use probing questions that allow for eliciting their beliefs as a proxy, resulting in variance between group answers.

This research study also proposes that there may be a way to mitigate degradation in response quality via reassurance. Although there are many models that have been tested in the fear appeals literature over the last six decades, the largest theoretical contributor is Protection Motivation Theory (PMT) followed by the Extended Parallel Process Model (EPPM) (Ruiter, Kessels et al. 2014). Meta-analysis of work using PMT found that the most significant contributors to behavioral intention are self-efficacy, response efficacy, and various combinations of severity, susceptibility and response costs, in that order (Floyd, Prentice-Dunn et al. 2000, Milne, Sheeran et al. 2000). Solely looking at threat and efficacy interaction, it shows that when there is a high threat the greatest persuasive effect is high efficacy (Witte and Allen 2000). As a matter of fact, they can only affect behavioral intention when they exist together (high threat and high efficacy) (Peters, Ruiter et al. 
2013). In short, the threat appraisal variables are poor predictors of intention and behavior when compared to coping appraisal variables from PMT. The EPPM literature extends these ideas by viewing fear control and danger control (Witte, Meyer et al. 2001). Danger control is tied to coping appraisal in the sense that danger control motivates the reader to take risk-reducing action. Fear control is a last recourse when there is no way to mitigate a danger. In order to provide reassurance, we need to consider methods that increase efficacy and empower the respondent. If they feel helpless they may resort to maladaptation instead (or fear control).

A $2 \times 2$ experimental design was chosen for two factors: threat and reassurance. The subjects need to feel that they are susceptible to the threat, and rationalize the possible outcomes of the threat as severe. To this aim two framings were created: high threat and low threat. The low threat group was informed to role play based on their created profile. They are a senior loan officer with a bank. The organization is implementing a new information system to increase efficiency, and needs them to participate in an interview as part of the requirements determination process. They are informed that their peers and organization view this as a positive undertaking. The handout given to low threat subjects is included in the Appendix for reference.

The framing for high threat had to provide feelings of susceptibility and severity regardless of the personal factors. The high threat group had the same role and information provided to them as the low threat group, with the exception that they had been working in an unethical fashion and have severely deviated from established standard procedures during their processing of loans. They have done favors for friends and family over the years, 
provided bad loans, misreported or manipulated facts, used third party providers (such as appraisers) with the intention of making loans look more favorable, doctored documents, etc. They are also informed that up to this point no one in the organization knows that they have engaged in this activity, including the interviewer they will be interviewing with. The handout that was given to high threat subjects is also included in the Appendix for reference.

\section{Informed Pilot}

An inform pilot was carried out with four information systems doctoral candidates over the course of 3 hours. The materials were shared and each item was discussed for inclusion/exclusion or modification. What follows is the process used and the results of the informed pilot.

The pre-test was first discussed. The pre-test measures were intended to capture general demographic information, as well as generalized anxiety disorder scores; the later to help explain larger variance within the threat groups. There were also measures included that captured the subjects' motivation (intrinsic/extrinsic). These were discussed to not be necessary. The subjects can all be framed to believe the organization and peers like the system (extrinsic motivation), and that there is some benefit from the system to their own performance to be gained (intrinsic motivation) equally so that this aspect is controlled.

The subject framing was then discussed for both high threat and low threat. The context for the framing (loan process) was agreed to be universally understood by most business school students. Both framings were the same with the exception that the high-threat group 
was told they had significantly deviated from established norms of the organization and have given out loans out to family and friends that would be questionable at best. The overall concern of the inform pilot members is that the framing doesn't take or is poorly understood. To this end the test for the subject framing was slightly modified to ensure that their understanding of the following is tested on: their role in the organization, the perception of the system by peers, the perception of the system by the organization, the intent of the system, the reason they were selected within the organization, the success of the system is dependent on their interview, and that they are free to answer, or not answer, as they see best fit to their interests. The answer sheet provided to subjects with a basic outline of the loan process currently used was also cleaned-up to make for quicker reference.

The questioning protocol to be used by the interviewers was then reviewed. To further reinforce the subject framing a decision was made to create a gender-neutral name, Chris, that they are constantly referred to. This name was also included in the subject framing documents. The interview items were evaluated based on the perceived ability to achieve a different response from high-threat and low-threat individuals. Two inform pilot members assumed the low-threat framing and the other two assumed the high-threat framing. Although they are aware of the hypothesis being tested, it allowed for discussion on which items may not elicit a difference between groups. Several items were revised:

The first interview question was to rank the importance of various features of the intended information system. The items related to the loan process itself had to be omitted because 
they could elicit a high-ranking from both group as this is the stated purpose of the system. The items were modified to be value-added features that could be viewed differently by the two groups (i.e. artificial intelligence that learns how you make loan decisions).

- Some autonomy related questions may be perceived the same from low-threat and high-threat individuals depending on their personal views on autonomy. Some were modified and others removed. This is also applicable to all other antecedents of a perception of threat. Questions needed to stay focused on the manipulation of threat.

- Some questions were vague and/or biasing the interviewee. The vague questions were clarified and the biased questions were modified to ascertain their opinion or preference.

- Some interview questions were too wordy and could quickly lose the interviewee. These questions were shortened.

- Measures on the scales used for the interview questions were clarified.

The post interview questions were designed to capture a change in the perception of threat by the individuals, or if they felt reassured. They were phrased to capture changes (where 4 is still the same, 1 is decreased significantly, and 7 is increased significantly) carefully so that they are distinct from initial measurements, and there isn't the issue of having a repeated measure within a short period of time. Some of these items were unintentionally guiding the subjects and needed to be rephrased. 


\section{Experimental Pilot I}

Following completion of the informed pilot and an appropriate revision of the materials and protocols, an experimental pilot was conducted. The pilot was advertised within the classroom of business students (a statistics class) for subjects and within the information systems development courses for interviewers. The subjects that opted into the study notified the researchers via email and were added to the roster. The week before the study they were randomly assigned to one of four groups or reserved as a backup. Two large rooms were reserved (one for interviewer training, and another for checking-in and checking out), as well as 8 interview rooms. Two helpers were trained on how to perform the check-in and check-out process and were also given a handout for reference. The overall methodology is graphically shown in Figure 6.

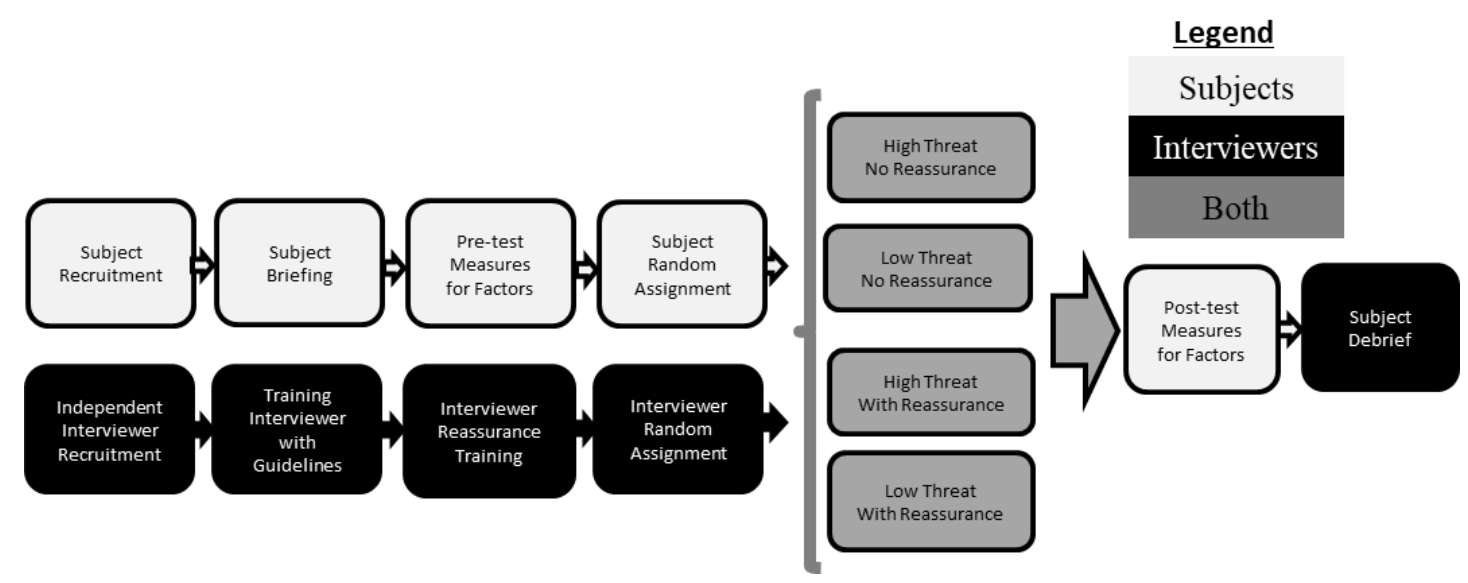

Figure 6. Experimental Flow 


\section{Recruiting and Group Assignment}

Independent interviewers were recruited. The systems analyst actors for the experiment were undergrad MIS students that were completing their Business Applications Development Course in Florida International University. They were then randomly assigned to perform interviews under the "reassurance" treatment group, or the "no reassurance" treatment group. The actors randomly assigned to the "reassurance" groups were trained with using a schema that provides reassurance to the respondents during the elicitation process. Those randomly assigned to the "no reassurance" groups were trained to NOT engage in reassurance during the elicitation process. All actors were given a basic semantic structuring inquiry training, which lasted for approximately 45-minutes. They practiced with a mock-interview using a provided rubric for evaluating their deviation for the protocol. The established attire was business formal.

Subjects were recruited from undergraduate courses in the business school at Florida International University. They were randomly assigned to either the "high-threat" treatment group, or the "low-threat" treatment group. Within each group, the subjects were then randomly assigned to either a "reassurance" interviewer, or a "no reassurance" interviewer.

There were 8 interviewers scheduled for three consecutive interview blocks of 30 minutes each. To prevent issues with no-shows two additional interviewers were also scheduled. They were trained for an hour prior to their first interview on the protocol that they will 
follow throughout the interview, which included a mock interview, and the grading rubric that will be used to evaluate their performance and adherence to the protocols established.

There also were 24 subjects randomly assigned to the interviewers. To avoid issues with no-shows they were told to arrive 15 minutes prior to their scheduled time and two backups were scheduled for each of the three interview time slots (see Table 1). Also, if a subject did not show up in time then a backup was used in their place to ensure a strict adherence to the schedule.

\begin{tabular}{|l|l|l|l|l|l|l|l|}
\cline { 2 - 7 } \multicolumn{1}{c|}{} & Brief & $\begin{array}{l}\text { Pre- } \\
\text { test }\end{array}$ & Framing & $\begin{array}{l}\text { Framing } \\
\text { Test }\end{array}$ & Interview & $\begin{array}{l}\text { Post- } \\
\text { test }\end{array}$ & Debrief \\
\hline $\begin{array}{l}\text { 1st } \\
\text { Group }\end{array}$ & $11: 45$ & $11: 50$ & $11: 55$ & $12: 05$ & $12: 10$ & $12: 40$ & $12: 45$ \\
\hline $\begin{array}{l}\text { 2nd } \\
\text { Group }\end{array}$ & $12: 20$ & $12: 25$ & $12: 30$ & $12: 40$ & $12: 45$ & $13: 15$ & $13: 20$ \\
\hline $\begin{array}{l}\text { 3rd } \\
\text { Group }\end{array}$ & $12: 55$ & $13: 00$ & $13: 05$ & $13: 15$ & $13: 20$ & $13: 50$ & $13: 55$ \\
\hline
\end{tabular}

Table 1. Experimental timeline

\section{Experimental Pilot I Execution}

The subjects were checked-in by group and handed a manila envelope containing the consent form, demographics, subject framing, and pre-test based on their group membership (high threat, low threat). If subjects were missing then alternates were used in their stead. At the scheduled time for their group they were briefed, and consent forms were collected. This was followed with a pretest questionnaire that collected subject demographic data including age, sex, general education level, ethnicity, race, years of 
experience in their field (combined educational and practical), motivation (intrinsic/extrinsic), and the generalized anxiety disorder (GAD) battery.

The subjects were then briefed on their task and asked to review the subject framing that was included in their manila envelope. After they reviewed the subject framing they were asked to take a test on how well they understood the framing. All materials were collected except for a reference sheet with the organization's basic protocol for approving loans and they were asked to go to their assigned room for the interview.

The interviewers recorded by hand to the best of their ability, without being disruptive to the process, the answers provided to the questions; any omitted information was discovered during transcription of the recorded interviews. The questions asked by the interviewer were compared to their provided guidelines during training and prior to interviewing to ensure adherence. The interview rooms were equipped with audio/visual recording equipment that was setup at the corner of the table, across from both the interviewer and the interviewee. Although the time was not strictly enforced, the interviewers were encouraged to manage their time effectively and spend about a half hour interviewing the subjects. If the next interviewee arrived before completion of the previous interview there was a chair for them to sit and wait for their turn.

After the interviews, the subjects were asked to go to the check-out room and given a posttest. The post-test contained manipulation checks and asked respondents about changes to their perceived threat level, if they felt reassured, and additional feedback question. 


\section{Experimental Pilot I Results}

After subjects reviewed their role they then took a test that captures how well they understood the framing, a 10-item test based on the content of the framing. The raw score on how well they understood the framing is the ratio of correct question to incorrect questions (mean of 9.21 with $\mathrm{SD}=1.062)$. One subject $(\mathrm{ID}=104)$ achieved a score under the $70 \%$ threshold (actual was 6/10) and was removed from further analysis, resulting in a new sample size of 23 .

Threat indicator variables were used for perceived job threat, personal threat, perceived adaptability to the system, how dependent they feel they may be on the interviewer during the interview, how capable they feel about conducting the interview, and anxiety about the interview. The post-framing measurement instrument was checked for normality using normality plots, as well as skewness (symmetry) and kurtosis (total probability contained in tails, resulting in a measure of how peaked the data is) measures. No item passed the Shapiro-Wilk test (using a .05 alpha), and all items were within $+/-2$ on both skewness and kurtosis with the exception of Kurtosis on the item for how dependent they felt on their interviewer. Observing the histograms showed two peaks on many of the items, which may be due to the two groups (low threat/high threat) responding differently. A separate analysis was conducted separating items by threat category, which only passed the ShapiroWilk test on how capable they feel about performing the interview (for the high threat group only), how dependent they feel on the interviewer (for the low threat group only), and their perceived adaptability to the system (for the high threat group only). 
Although perceived interviewer dependence (before the interview) could indicate a low perceived self-efficacy (apart from any anxiety triggered by the manipulation), it did not significantly correlate with any of the other threat indicator items. Looking at the stem and leaf plot it seems like there is a misinterpretation possible between low and high threat subjects. The low threat group had a much broader range $(2-7)$ than did the high threat group (5 -7), both being left skewed. The high threat group may clearly see that they will be at the mercy of the interviewer, while the low threat group is free to interpret their dependency on the interviewer in a much broader sense (e.g. minimize uncertainty of the interview process, make them more comfortable, help guide them to answer the questions properly, etc.) causing it to not correlate well with other threat indicator items. Further analysis showed a Cronbach's Alpha of .861 . The only item that resulted a substantial increase to this alpha was the omission of the interviewer dependence item, which confirms the suspicion from the previous analysis discussed. This item was discussed with members of the inform pilot and decidedly removed. The result was a Cronbach's Alpha of 0.89.

The post-test items were also analyzed. After removing cross-loaded items the reassurance indicator loaded alone, personal threat and job threat were too correlated with each other and job threat was omitted, and perceived adaptability was refined to three items (can adjust to work with system, can minimize negative outcomes, change in initial adaptability). The final set of items were 6 items with three factors (reassurance, perception of threat, adaptability) with all Cronbach's Alphas strong, greater than .80 .

Coding the response quality variables (time before response, number of words, speed of response) made apparent that many of the interviewers varied in the way they carried out 
the interviews, although the interviewers were trained to explicitly follow the protocol and not deviate from it. Here are some examples:

- One interviewer deviated from the protocol and did not hand out the index cards containing the items to rank (which would guarantee that items are not ordered together) and instead asked what they would rank each item independently. It was no surprise when subjects ranked most items as "important" and deemphasized a few others equally.

- Although the interviewers were trained to let the subjects offer any answer they want, including no answer, some interviewers may have felt they would go above and beyond what is required of them by forcing answers out of their subjects. This made coding the interview questions for time unreliable as there is no way to ascertain how much of that time was the information they wanted to volunteer and how much was forced.

- Another interviewer chose to ignore the scale labels entirely and simply asked subjects "please tell me how important this is from $1-7$ ", which made it impossible to rely on any answers provided by many of the subjects (some asked for clarification on the scale).

- Another interviewer ended each question with "Basically, ..." followed by their misinterpretation of the question. It was not possible to determine if the answer the subjects gave were for the original question or the misinterpretation by the interviewer. 
The groups were compared on every interview question to see if there is a response difference between high-threat/low-threat and reassurance/no reassurance groups. Many of the interactions were present in the graphs (showing intersections when graphing reassurance category on the $\mathrm{X}$ axis and threat category as separate line), however none of these results are reliable due to the issues discussed above.

The pilots made clear that the interviewers need to be as standardized as possible to reliably measure the effects of the manipulations. Although the interviewer training emphasized adherence to the protocol there was still too much variability in how the interviewers were carried out. Unfortunately, training mock interviewers is simply too unpredictable. For this reason, an experienced interviewer was selected and trained to act out the scenes. These were recorded and edited for consistency. Although reassurance may be more difficult to establish using less of a face-to-face approach, there must be a reliable way of measuring threat's effect on response quality without additional variance from a poorly conducted interview.

\section{Pilot II and Migration to Qualtrics}

Based on the results obtained from experimental pilot I, it was determined that standardization of the framing and manipulation portions of the study needed to occur. As such, the experiment was migrated to Qualtrics. The flow of the original experiment was equivalently reproduced. Observation was maintained by using a controlled lab setting with a camera set to record in the front of the room. This also allowed control of the subjects for focusing on the task without distractions from their cellular phones, internet browsing, etc. 
Randomization was utilized to ensure an even distribution of subjects between high threat/low threat treatment groups and reassurance/no reassurance sub groups (see Figure 7).

As stated in the previous section, all questions related to the interview were video-taped using an experienced and trained interviewer. This change in the manipulation allowed for the establishment of consistency in the interview process as all subjects were now being questioned by the same person and, as such, no bias could be introduced due to the use of multiple interviewers. It must be acknowledged that this condition sacrificed a portion of the real-world aspects of the process as no follow-up or probing could occur. This sacrifice was deemed to be an acceptable limitation despite the loss of rich data that could be obtained through follow-up. It was determined that the collection of such qualitative data be deferred to a future study.

JavaScript was used to control the presentation of the actual question and response for each of the videos shown. This allowed standardization of page submit timers between all subjects as some videos may last longer than others or load differently. The summary questions that were textually presented after the video were also equivalent to minimize variances due to reading length. 


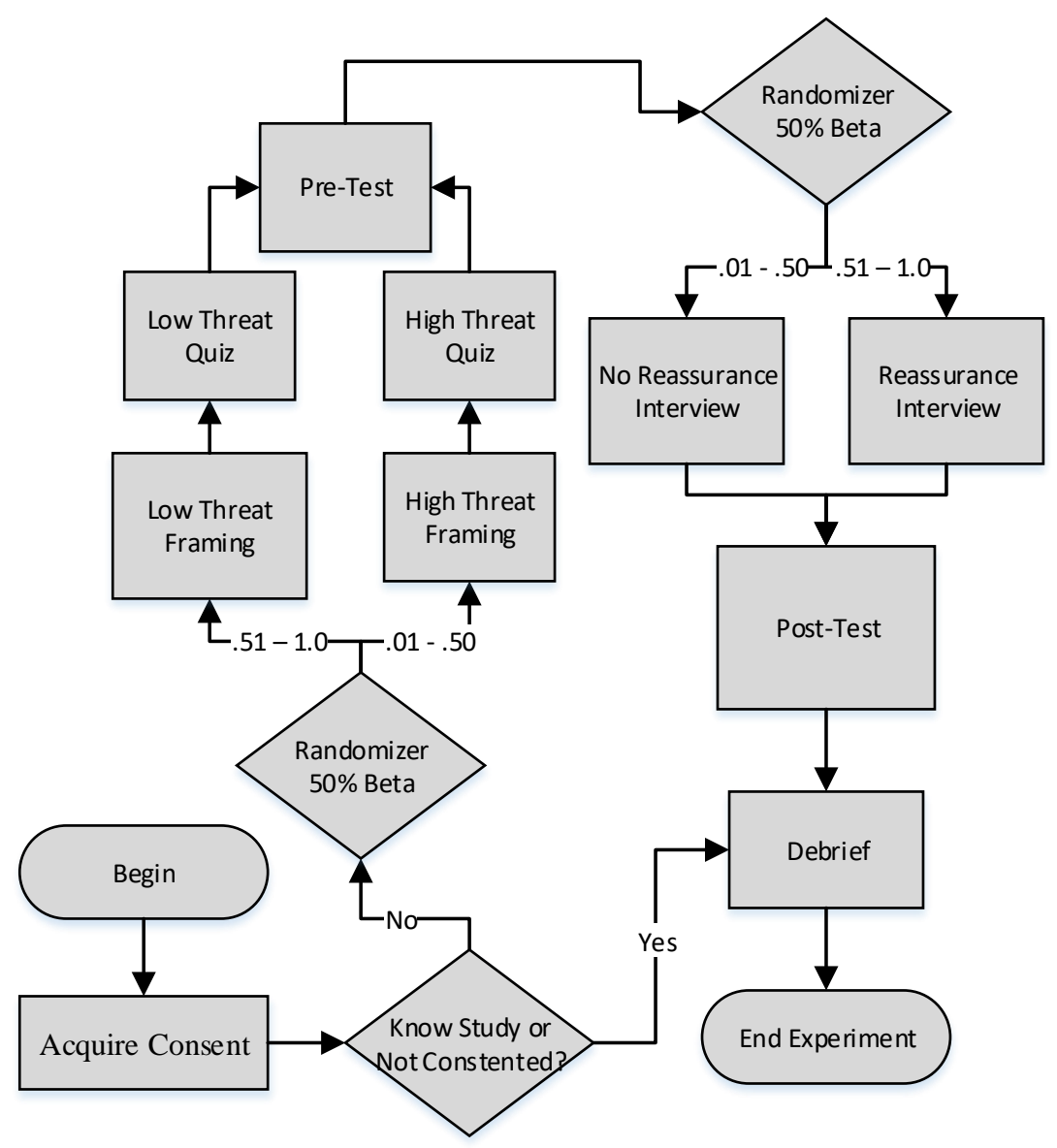

Figure 7. Qualtrics Experimental Study II Flow 


\section{CHAPTER V. RESULTS}

Subjects were recruited from Masters programs throughout the College of Business. A call was sent via email and six professors responded, allowing classroom time for recruiting purposes. The total number of solicited students were 162, and 58 scheduled a time on Doodle. Although a response rate of $36 \%$ is high it should be noted that one of the professors agreed to help by using class time for his students to participate. This produced 39 subjects. Removing this from consideration produces a response rate of 15\% (19/123). Out of the 58 subjects that volunteered there were three no-shows, four were removed for beginning and not completing or being excused for being disruptive, and three did not achieve a score of at least $70 \%$ on the framing test. The final sample was 51 subjects which is described below in Table 2. 


\begin{tabular}{|c|c|c|c|}
\hline & & Frequency & Percent \\
\hline & $19-24$ & 10 & $\overline{19.6}$ \\
\hline & $25-30$ & 18 & 35.3 \\
\hline & $31-36$ & 13 & 25.5 \\
\hline & $37-42$ & 6 & 11.8 \\
\hline & $\overline{43+}$ & 4 & 7.8 \\
\hline \multirow[t]{3}{*}{ Age } & Total & 51 & 100 \\
\hline & Male & 34 & 66.7 \\
\hline & Female & 17 & 33.3 \\
\hline \multirow[t]{6}{*}{ Gender } & $\overline{\text { Total }}$ & 51 & 100 \\
\hline & White & 10 & 19.6 \\
\hline & Hispanic & 25 & 49 \\
\hline & Black & 3 & 5.9 \\
\hline & Asian & 12 & 23.5 \\
\hline & Other & 1 & 2 \\
\hline \multirow[t]{3}{*}{ Race / Ethnicity } & $\overline{T o t a l}$ & 51 & 100 \\
\hline & Singie & 32 & 62.7 \\
\hline & Married & 19 & 37.3 \\
\hline \multirow[t]{5}{*}{ Marital Status } & Total & 51 & 100 \\
\hline & High School & 0 & 0 \\
\hline & Some college & 1 & 2 \\
\hline & Bachelors & 22 & 43.1 \\
\hline & Masters & 28 & 54.9 \\
\hline \multirow[t]{11}{*}{ Highest Education } & Total & 51 & $\overline{100}$ \\
\hline & Retail & 8 & 34.8 \\
\hline & Civil/Government & 7 & 30.4 \\
\hline & Education & 2 & 8.7 \\
\hline & Finance/Banking & 4 & 17.4 \\
\hline & Healthcare & 2 & 8.7 \\
\hline & Other Service & 9 & 17.6 \\
\hline & Private Practice & 1 & 2 \\
\hline & Sales/Retail & 3 & 5.9 \\
\hline & Technology & 19 & 37.3 \\
\hline & Transportation & 1 & 2 \\
\hline \multirow[t]{4}{*}{ Primary Business Category } & Total & 51 & $\overline{100}$ \\
\hline & Line personnel & 20 & 39.2 \\
\hline & Middle Management & 24 & 47.1 \\
\hline & Senior Management & 7 & 13.7 \\
\hline Highest Responsibility Held & $\overline{\text { Total }}$ & 51 & 100 \\
\hline
\end{tabular}

Table 2. Subject Descriptives

Analysis of the various demographics associated with each treatment group revealed no unexpected significant differences among them that could materially or adversely confound the results obtained. Further, tests of normality revealed no significant deviations in the data collected. 
The pre-test items were analyzed and the correlations for the threat indicator items are shown in Table 3. A principal axis factoring with oblique rotation was conducted on the pre-test items. It is common in the social sciences that questionnaires have items that are not entirely different from other items, making an oblique rotation preferred over the orthogonal rotations (Field 2009). They all loaded highly on a single factor (see Table 4). The Kaiser-Meyer-Olkin Measure of Sampling Adequacy was .792, above the commonly recommended value of .6 , and Bartlett's test of sphericity was significant $\left(\chi^{2}(10)=\right.$ 114.293, $\mathrm{p}<.001)$. The communalities were all above 0.3. The reported Cronbach's Alpha was 0.848 for the five items.

\begin{tabular}{|c|c|c|c|c|c|}
\hline \multicolumn{6}{|c|}{ Correlations } \\
\hline & $\begin{array}{l}\text { Interview } \\
\text { Anxiety } \\
\end{array}$ & $\begin{array}{l}\text { Personal } \\
\text { Threat }\end{array}$ & $\begin{array}{l}\text { Job } \\
\text { Threat } \\
\end{array}$ & $\begin{array}{l}\text { Interview } \\
\text { Capability } \\
\end{array}$ & $\begin{array}{l}\text { Perceived } \\
\text { Adaptability }\end{array}$ \\
\hline $\begin{array}{l}\text { Interview } \\
\text { Anxiety }\end{array}$ & 1 & & & & \\
\hline $\begin{array}{l}\text { Personal } \\
\text { Threat } \\
\end{array}$ & $.634 * *$ & 1 & & & \\
\hline Job Threat & .652** & $.790 * *$ & 1 & & \\
\hline $\begin{array}{l}\text { Interview } \\
\text { Capability }\end{array}$ & $0.437 * *$ & $0.419 * *$ & $0.431 * *$ & 1 & \\
\hline $\begin{array}{l}\text { Perceived } \\
\text { Adaptability }\end{array}$ & 0.396 ** & 0.470 ** & $0.478 * *$ & $0.589 * *$ & 1 \\
\hline
\end{tabular}

Table 3. Threat indicator Correlations 


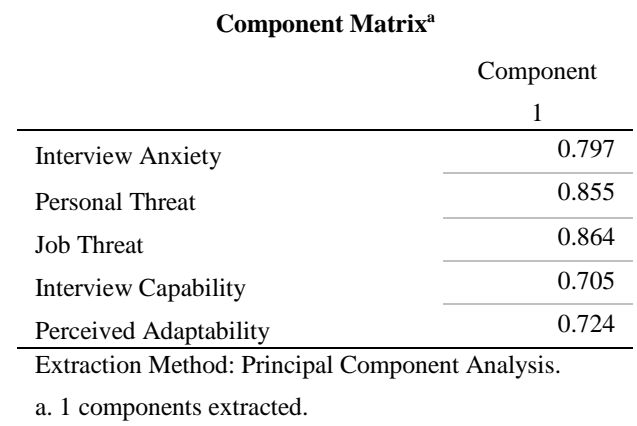

Table 4. Threat indicator factor loading

These were combined into an averaged composite score called "Threat". A comparison of means was done for the high threat and low threat groups on the composite "Threat" variable. The results showed the mean for the high threat group was 4.59 with a standard deviation of 1.24 , and the mean for the low threat group was 2.48 with a standard deviation of 1.06. There was homogeneity of variance (Levene's test results: $F=0.473, p=0.495$ ) and the t-test comparing the means showed significance $(\mathrm{p}<.001)$.

The post-test measures were also analyzed. The correlations for the indicator items (change in threat, and reassurance) along with adaptability indicator items are shown in Table $\mathbf{5}$. They all loaded highly on a single factor (see Table 4). The Kaiser-Meyer-Olkin Measure of Sampling Adequacy was .726, above the commonly recommended value of .6, and Bartlett's test of sphericity was significant $\left(\chi^{2}(15)=130.254, \mathrm{p}<.001\right)$. The communalities were all above 0.3. Although "changes of initial concerns" and "system poses a threat" loaded together the inter-item correlation was only .497 , resulting in a Cronbach Alpha of 0.664. Due to the weak factor loading (0.518), and the low Cronbach Alpha (0.664) the change of initial concern item was removed. The remaining 3-items for 
adaptability produced a Cronbach's Alpha of 0.902, and the removal of any item would result in a reduction.

\begin{tabular}{|c|c|c|c|c|c|c|}
\hline & \multicolumn{4}{|c|}{ Correlations } & \multirow[b]{2}{*}{$\begin{array}{l}\text { Can } \\
\text { Minimize } \\
\text { Negative } \\
\text { Outcomes } \\
\end{array}$} & \multirow[b]{2}{*}{$\begin{array}{l}\text { Perceived } \\
\text { Adaptability }\end{array}$} \\
\hline & $\begin{array}{l}\text { System } \\
\text { Poses } \\
\text { Threat }\end{array}$ & $\begin{array}{l}\text { Change } \\
\text { of initial } \\
\text { Concerns }\end{array}$ & $\begin{array}{l}\text { Interviewer } \\
\text { Reassurance }\end{array}$ & $\begin{array}{l}\text { Can } \\
\text { Adjust }\end{array}$ & & \\
\hline System Poses Threat & 1 & & & & & \\
\hline $\begin{array}{l}\text { Change of initial } \\
\text { Concerns }\end{array}$ & $.497 * *$ & 1 & & & & \\
\hline $\begin{array}{l}\text { Interviewer } \\
\text { Reassurance }\end{array}$ & -0.243 & -0.105 & 1 & & & \\
\hline Can Adjust & -0.251 & $-0.284 *$ & $0.306 *$ & 1 & & \\
\hline $\begin{array}{l}\text { Can Minimize } \\
\text { Negative Outcomes }\end{array}$ & $-0.314 *$ & $-0.433 * *$ & $0.367 * *$ & $0.733 * *$ & 1 & \\
\hline $\begin{array}{l}\text { Perceived } \\
\text { Adaptability }\end{array}$ & 0.440 ** & $-0.341 *$ & $0.297 *$ & $0.785 * *$ & $.744 * *$ & 1 \\
\hline
\end{tabular}

***Correlation is significant at the 0.01 level (2-tailed).

*Correlation is significant at the 0.05 level (2-tailed).

Table 5. Post-test Correlations

\begin{tabular}{|c|c|c|}
\hline \multicolumn{3}{|c|}{ Pattern Matrix ${ }^{\mathrm{a}}$} \\
\hline & \multicolumn{2}{|l|}{ Factor } \\
\hline & 1 & 2 \\
\hline System Poses Threat & & 0.883 \\
\hline Change of Initial Concerns & & 0.518 \\
\hline Interviewer Reassurance & & \\
\hline Can Adjust & 0.966 & \\
\hline $\begin{array}{l}\text { Can Minimize Negative } \\
\text { Outcomes }\end{array}$ & 0.839 & \\
\hline Perceived Adaptability & 0.822 & \\
\hline
\end{tabular}

Table 6. Post-test factor loading

The three items were combined into an averaged composite score called "Adaptability". A comparison of means was done for the high threat and low threat groups on the composite "Adaptability" variable. The results showed the mean for the high threat group was 4.373 
with a standard deviation of 1.75 , and the mean for the low threat group was 5.73 with a standard deviation of 1.16. Levene's test results indicated that equal variances should not be assumed $(\mathrm{F}=4.967, \mathrm{p}=0.030)$ and the t-test comparing the means showed significance $(\mathrm{p}<.01)$

A principal axis factoring with oblique rotation was conducted on the 18 interview questions. The correlation matrix for the entire set of interview questions is provided in Table 7 and the resulting loadings are provided in Table 8. The Kaiser-Meyer-Olkin Measure of Sampling Adequacy was .738, above the commonly recommended value of .6, and Bartlett's test of sphericity was significant $\left(\chi^{2}(153)=528.65, \mathrm{p}<.001\right)$. The communalities were all above .3 except for Q2, which did not load on any factor. 
Correlation Matrix

\begin{tabular}{|c|c|c|c|c|c|c|c|c|c|}
\hline $\begin{array}{l}\text { Interview } \\
\text { Questions }\end{array}$ & $\begin{array}{l}\text { Q1 Rank } \\
\text { Fraud }\end{array}$ & $\begin{array}{l}\text { Q5 System } \\
\text { learning }\end{array}$ & $\begin{array}{l}\text { Q7b Retain } \\
\text { appraiser } \\
\text { selection }\end{array}$ & $\begin{array}{c}\text { Q7c Retain } \\
\text { mortgage } \\
\text { broker } \\
\text { selection }\end{array}$ & $\begin{array}{l}\text { Q7d Retain } \\
\text { closing } \\
\text { agency } \\
\text { selection }\end{array}$ & $\begin{array}{l}\text { Q9 Amount } \\
\text { of historical } \\
\text { data to load }\end{array}$ & $\begin{array}{c}\text { Q10 } \\
\text { Necessity of } \\
\text { fraud } \\
\text { detection }\end{array}$ & $\begin{array}{c}\text { Q11b } \\
\text { LEDS } \\
\text { based fraud } \\
\text { flagging }\end{array}$ & $\begin{array}{l}\text { Q12 Desire } \\
\text { for system }\end{array}$ \\
\hline Q1 Rank Fraud & 1 & & & & & & & & \\
\hline $\begin{array}{l}\text { Q5 System } \\
\text { learning }\end{array}$ & $0.587 * *$ & 1 & & & & & & & \\
\hline $\begin{array}{l}\text { Q7b Retain } \\
\text { appraiser } \\
\text { selection }\end{array}$ & -0.11 & -0.134 & 1 & & & & & & \\
\hline $\begin{array}{l}\text { Q7c Retain } \\
\text { mortgage broker } \\
\text { selection }\end{array}$ & -0.187 & $-0.237^{*}$ & $0.612 * *$ & 1 & & & & & \\
\hline $\begin{array}{l}\text { Q7d Retain } \\
\text { closing agency } \\
\text { selection }\end{array}$ & -0.199 & -0.223 & $0.703 * *$ & $0.871 * *$ & 1 & & & & \\
\hline $\begin{array}{l}\text { Q9 Amount of } \\
\text { historical data to } \\
\text { load }\end{array}$ & $0.705 * *$ & $0.486^{* *}$ & -0.103 & $-0.256^{*}$ & $-0.271^{*}$ & 1 & & & \\
\hline $\begin{array}{l}\text { Q10 Necessity of } \\
\text { fraud detection }\end{array}$ & $0.644 * *$ & $0.654 * *$ & $-0.279 *$ & $-0.375^{* *}$ & $-0.395 * *$ & $0.753 * *$ & 1 & & \\
\hline $\begin{array}{l}\text { Q11b LEDS } \\
\text { based fraud } \\
\text { flagging }\end{array}$ & $0.517 * *$ & $0.536 * *$ & -0.229 & $-0.382 * *$ & $-0.341 * *$ & $0.566 * *$ & $0.835^{* *} *$ & 1 & \\
\hline $\begin{array}{l}\text { Q12 Desire for } \\
\text { system }\end{array}$ & $0.631 * *$ & $0.677 * *$ & $-0.241^{*}$ & $-0.378 * *$ & $-0.38 * *$ & $0.581 * *$ & $0.767 * *$ & $0.702 * *$ & 1 \\
\hline $\begin{array}{l}\text { Q2 Modify closed } \\
\text { loans }\end{array}$ & 0.182 & 0.17 & -0.193 & -0.219 & $-0.284^{*}$ & $0.351 * *$ & $0.429 * *$ & $0.42 * *$ & $0.395^{* *}$ \\
\hline $\begin{array}{l}\text { Q3 Subjective vs. } \\
\text { Objective }\end{array}$ & $0.431 * *$ & $0.441 * *$ & 0.018 & -0.019 & -0.054 & $0.339 * *$ & $0.413 * *$ & $0.302 *$ & $0.393 * *$ \\
\hline $\begin{array}{l}\text { Q4 Subjective } \\
\text { allows fraud }\end{array}$ & 0 & -0.135 & $0.259^{*}$ & $0.441 * *$ & $0.349 * *$ & -0.042 & -0.054 & -0.104 & -0.172 \\
\hline $\begin{array}{c}\text { Q6 Decision } \\
\text { making }\end{array}$ & $-0.484 * *$ & $-0.442 * *$ & $0.254 *$ & $0.358 * *$ & $0.37 * *$ & $-0.445 * *$ & $-0.546^{* *}$ & $-0.528 * *$ & $-0.605^{* *}$ \\
\hline $\begin{array}{l}\text { Q7 Allowing } \\
\text { overrides }\end{array}$ & $-0.393 * *$ & $-0.328 * *$ & $0.237^{*}$ & $0.322 *$ & 0.192 & $-0.36^{* *}$ & $-0.397 * *$ & $-0.387 * *$ & $-0.397 * *$ \\
\hline $\begin{array}{c}\text { Q7a Retain } \\
\text { financing options }\end{array}$ & -0.107 & $-0.386^{* * *}$ & $0.412 * *$ & $0.364 * *$ & $0.41 * *$ & -0.09 & $-0.291^{*}$ & $-0.248 *$ & $-0.312 *$ \\
\hline $\begin{array}{l}\text { Q8 Adequacy of } \\
\text { exisitng fraud } \\
\text { detection }\end{array}$ & $-0.298^{*}$ & $-0.246^{*}$ & 0.127 & $0.334 * *$ & $0.373 * *$ & $-0.341 * *$ & $-0.346^{* *}$ & $-0.387 * *$ & $-0.442 * *$ \\
\hline $\begin{array}{l}\text { Q11a Retaining } \\
\text { loan officer fraud } \\
\text { flagging }\end{array}$ & $-0.293^{*}$ & $-0.32 *$ & 0.193 & 0.121 & $0.25^{*}$ & $-0.237 *$ & $-0.292 *$ & $-0.254 *$ & $-0.401 * *$ \\
\hline $\begin{array}{l}\text { Q11c Peer audit } \\
\text { fraud flagging }\end{array}$ & -0.129 & -0.023 & 0.118 & 0.069 & 0.154 & -0.143 & -0.077 & -0.062 & -0.121 \\
\hline
\end{tabular}

Table 7a. Interview Question Correlation Matrix 


\begin{tabular}{|c|c|c|c|c|c|c|c|c|c|}
\hline \multirow[b]{2}{*}{$\begin{array}{l}\text { Interview } \\
\text { Questions }\end{array}$} & \multicolumn{9}{|c|}{ Correlation Matrix (Continued) } \\
\hline & $\begin{array}{l}\text { Q2 Modify } \\
\text { closed loans }\end{array}$ & $\begin{array}{c}\text { Q3 } \\
\text { Subjective } \\
\text { vs. Objective }\end{array}$ & $\begin{array}{c}\text { Q4 } \\
\text { Subjective } \\
\text { allows } \\
\text { fraud }\end{array}$ & $\begin{array}{c}\text { Q6 } \\
\text { Decision } \\
\text { making }\end{array}$ & $\begin{array}{c}\text { Q7 } \\
\text { Allowing } \\
\text { overrides }\end{array}$ & $\begin{array}{c}\text { Q7a } \\
\text { Retain } \\
\text { financing } \\
\text { options }\end{array}$ & $\begin{array}{c}\text { Q8 } \\
\text { Adequacy } \\
\text { of exisitng } \\
\text { fraud } \\
\text { detection }\end{array}$ & $\begin{array}{c}\text { Q11a } \\
\text { Retaining } \\
\text { loan } \\
\text { officer } \\
\text { fraud } \\
\text { flagging }\end{array}$ & $\begin{array}{c}\text { Q11c } \\
\text { Peer } \\
\text { audit } \\
\text { fraud } \\
\text { flagging }\end{array}$ \\
\hline $\begin{array}{l}\text { Q2 Modify } \\
\text { closed loans }\end{array}$ & 1 & & & & & & & & \\
\hline $\begin{array}{l}\text { Q3 Subjective vs. } \\
\text { Objective }\end{array}$ & $0.422 * *$ & 1 & & & & & & & \\
\hline $\begin{array}{l}\text { Q4 Subjective } \\
\text { allows fraud }\end{array}$ & -0.175 & -0.059 & 1 & & & & & & \\
\hline $\begin{array}{l}\text { Q6 Decision } \\
\text { making }\end{array}$ & $-0.267 *$ & $-0.349 * *$ & $0.241 *$ & 1 & & & & & \\
\hline $\begin{array}{c}\text { Q7 Allowing } \\
\text { overrides }\end{array}$ & -0.142 & $-0.421 * *$ & 0.103 & $0.545^{* *}$ & 1 & & & & \\
\hline $\begin{array}{c}\text { Q7a Retain } \\
\text { financing options }\end{array}$ & -0.221 & $-0.362 * *$ & $0.28 *$ & $0.333 * *$ & $0.453 * *$ & 1 & & & \\
\hline $\begin{array}{l}\text { Q8 Adequacy of } \\
\text { exisitng fraud } \\
\text { detection }\end{array}$ & $-0.328^{* *}$ & -0.175 & $0.49 * *$ & 0.209 & 0.189 & $0.244^{*}$ & 1 & & \\
\hline $\begin{array}{l}\text { Q11a Retaining } \\
\text { loan officer fraud } \\
\text { flagging }\end{array}$ & -0.201 & $-0.298^{*}$ & $0.24 *$ & $0.32 *$ & 0.088 & $0.281 *$ & $0.557 * *$ & 1 & \\
\hline $\begin{array}{l}\text { Q11c Peer audit } \\
\text { fraud flagging }\end{array}$ & -0.188 & 0.107 & 0.129 & $0.275^{*}$ & -0.094 & 0.122 & 0.23 & $0.412 * *$ & 1 \\
\hline
\end{tabular}

Table 7b. Interview Question Correlation Matrix (Continued) 


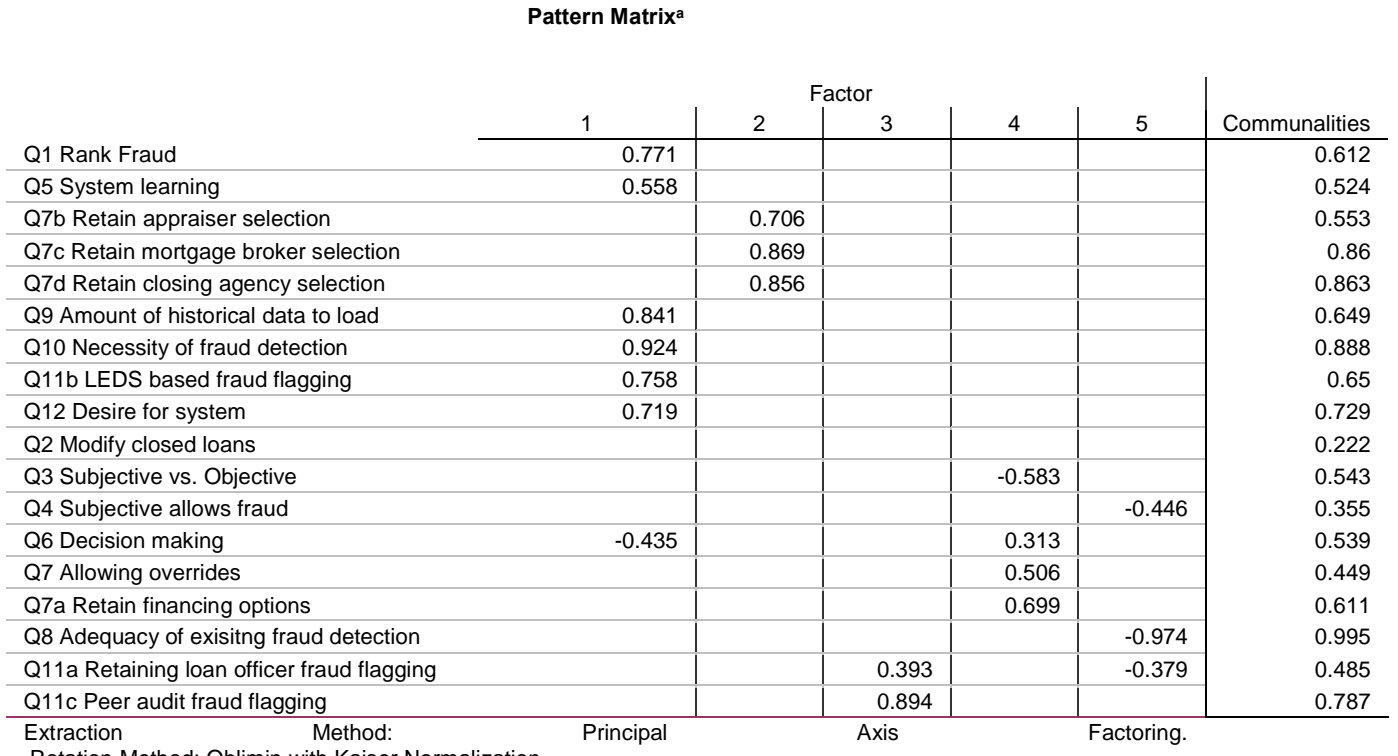

Table 7. Interview Questions Factor Loadings

The removal of Q2 resulted in a Pattern Matrix with four factors, one cross-loaded item (Q4). Removing this item resulted in Q11c having lower than .3 communality. Several iterations of removing cross-loaded items (above .3 for multiple factors) resulted in the final pattern matrix using 9 of the interview questions shown in Table 9, with 2 factors that corresponds to $68.7 \%$ of the variance. The determinant was .001 , higher than the .00001 cutoff, the Kaiser-Meyer-Olkin Measure of Sampling Adequacy was .801, above the commonly recommended value of .6 , and Bartlett's test of sphericity was significant $\left(\chi^{2}\right.$ $(55)=361.549, \mathrm{p}<.001)$ 


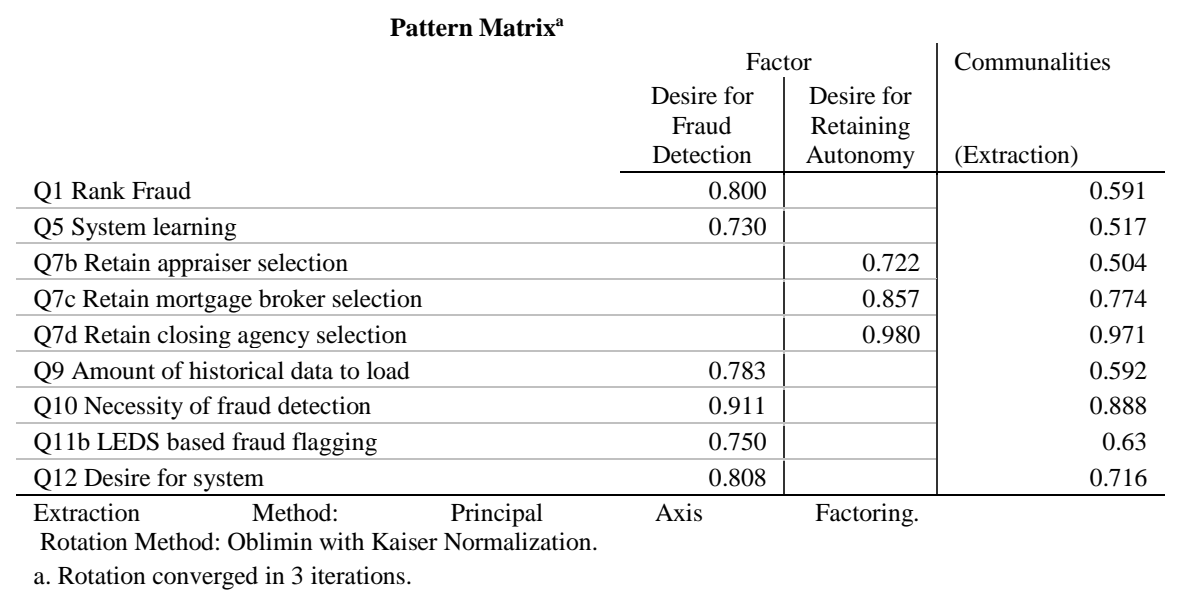

Table 9. Final Interview Question Factor Loadings

The labels were created based on the thematic composition of the questions that loaded highly on it: (1) Desire for Fraud Detection, (2) Desire for Retaining Autonomy. Internal consistency for each of the factors was examined using Cronbach's alpha. The Cronbach's alpha was high for both factors: .910 for "Desire for Fraud Detection" (6 items), and .890 for "Desire for Retaining Autonomy" (3 items). No substantial increases in alpha for any of the scales could have been achieved by eliminating further items. Composite scores were created for each of the factors, based on the mean of the items. Lower scores on items indicate a low desire for fraud detection or a low desire for autonomy, and higher scores the opposite.

For the dependent variables, tests of normality showed significant results for fraud and autonomy factors (Shapiro-Wilk $=.851$ and $.923, \mathrm{df}=51$, respectively), which violates assumptions of normality. Also, Box's $\mathrm{M}$ was borderline on significance (Box's $\mathrm{M}=$ 18.212, F $(3,455999.945)=5.802, \mathrm{p}$-value $=.001)$. The descriptive statistics provided in Table 10 shows that although the results for all are comparable, the low threat treatment 
group had very little variance (consistently rated Fraud-related questions highly as a desirable feature). With a sample size greater than 20 per group, and Pillai's Trace used for its robustness against violations of assumptions, a MANOVA is appropriate.

\begin{tabular}{|c|c|c|c|c|}
\hline \multicolumn{5}{|c|}{ Descriptive Statistics } \\
\hline Group_Threat & & Mean & $\begin{array}{c}\text { Std. } \\
\text { Deviation }\end{array}$ & $\mathrm{N}$ \\
\hline \multirow[t]{3}{*}{ Fraud } & High Threat & 4.0667 & 1.67567 & 25 \\
\hline & Low Threat & 5.6410 & 0.69553 & 26 \\
\hline & Total & 4.8693 & 1.49046 & 51 \\
\hline \multirow[t]{3}{*}{ Autonomy } & High Threat & 5.0933 & 1.47045 & 25 \\
\hline & Low Threat & 4.4872 & 1.69766 & 26 \\
\hline & Total & 4.7843 & 1.60392 & 51 \\
\hline
\end{tabular}

Table 10. Dependent Variable Descriptive Statistics

\section{Test of Hypotheses}

H1: The presence of a significant perception of threat in a respondent during the requirements determination process results in a degradation in the quality of the responses.

The MANOVA produced a significant Pillai's Trace $(\mathrm{F}(2,48)=9.541$, p-value $<.001)$, with group membership (high threat/low threat) explaining almost $30 \%$ of the variance in responses related to threat and autonomy. Table 11 contains the ANOVA results. Respondents subjected to the high threat manipulation exhibited a significantly lower desire for implementing fraud-related features (High Threat: mean=4.067, SE=0.255; Low Threat: mean=5.641, SE=0.250). These results were verified with a nonparametric test (Mann-Whitney U Test) and confirmed to be significant for fraud ( $\mathrm{p}$-value $=.001$ ) and not significant for autonomy $(\mathrm{p}$-value $=.118)$ at significance level of 0.05 . The comparison of scores from the high threat and low threat subjects provide support for $\mathrm{H} 1$ for Fraud interview questions, but not for Autonomy. 


\begin{tabular}{|c|c|c|c|c|c|c|c|c|}
\hline \multicolumn{9}{|c|}{ Tests of Between-Subjects Effects } \\
\hline Source & & $\begin{array}{l}\text { Type III } \\
\text { Sum of } \\
\text { Squares }\end{array}$ & df & $\begin{array}{c}\text { Mean } \\
\text { Square }\end{array}$ & $\mathrm{F}$ & Sig. & $\begin{array}{l}\text { Partial } \\
\text { Eta } \\
\text { Squared }\end{array}$ & $\begin{array}{c}\text { Observed } \\
\text { Power }^{c}\end{array}$ \\
\hline \multirow{2}{*}{$\begin{array}{l}\text { Corrected } \\
\text { Model }\end{array}$} & Fraud & $31.590^{\mathrm{a}}$ & 1 & 31.590 & 19.475 & 0.000 & 0.284 & 0.991 \\
\hline & Autonomy & $4.683^{b}$ & 1 & 4.683 & 1.851 & 0.180 & 0.036 & 0.266 \\
\hline \multirow[t]{2}{*}{ Intercept } & Fraud & 1201.089 & 1 & 1201.089 & 740.453 & 0.000 & 0.938 & 1.000 \\
\hline & Autonomy & 1169.824 & 1 & 1169.824 & 462.476 & 0.000 & 0.904 & 1.000 \\
\hline \multirow[t]{2}{*}{ Threat Group } & Fraud & 31.590 & 1 & 31.590 & 19.475 & 0.000 & 0.284 & 0.991 \\
\hline & Autonomy & 4.683 & 1 & 4.683 & 1.851 & 0.180 & 0.036 & 0.266 \\
\hline \multirow[t]{2}{*}{ Error } & Fraud & 79.483 & 49 & 1.622 & & & & \\
\hline & Autonomy & 123.945 & 49 & 2.529 & & & & \\
\hline \multirow[t]{2}{*}{ Total } & Fraud & 1320.278 & 51 & & & & & \\
\hline & Autonomy & 1296.000 & 51 & & & & & \\
\hline \multirow[t]{2}{*}{ Corrected Total } & Fraud & 111.073 & 50 & & & & & \\
\hline & Autonomy & 128.627 & 50 & & & & & \\
\hline \multicolumn{9}{|c|}{$\begin{array}{l}\text { a. } \mathrm{R} \text { Squared }=.284(\text { Adjusted R Squared }=.270) \\
\text { b. } \mathrm{R} \text { Squared }=.036(\text { Adjusted R Squared }=.017) \\
\text { c. } \text { Computed using alpha }=.05\end{array}$} \\
\hline
\end{tabular}

Table 11. ANOVA Results

H2: The higher the overall level of personal factors favoring change for a respondent during the requirements determination process, the lower the perceived threat in that respondent.

H3: The higher the overall level of contextual factors favoring change for a respondent during the requirements determination process, the lower the perceived threat in that respondent.

For hypothesis 2, the study did not directly collect data about individual or contextual antecedents to threat. The primary reason for this is because the subjects were being framed, and analyzing the various permutations of the possible personal factors would have required significantly more subjects than were available. The secondary reason for this was to reduce cognitive load on subjects with making the subject framing less complex by not manipulating more factors they will need to remember.

The antecedents to threat are well established in the literature, and both contextual and personal factors were used to generate manipulations of threat between the two groups in the subject framing. The results show the mean perceived threat for the high threat group 
was 4.592 with a standard deviation of 1.24 , and the mean for the low threat group was 2.485 with a standard deviation of 1.06 . Levene's test was non-significant $(\mathrm{F}=.473, \mathrm{p}$ $=0.495)$ and the $\mathrm{t}$-test comparing the means showed significance $(\mathrm{p}<.001)$. The results indicate that the framing, which included both personal and contextual factors to induce varying degrees of threat, produced results that support $\mathrm{H} 2$ and $\mathrm{H} 3$.

H4: An increase in the perception of threat for a respondent during the requirements determination process will decrease response quality through its effect on adaptability; the higher the perception of threat, the lower the perceived adaptability, and the lower resulting response quality of a respondent.

To test $\mathrm{H} 4$ a regression was done using threat as the independent variable and adaptability as the dependent variable (see Table 12). Threat significantly $(F(1,49)=26.004, p<.001)$ accounts for $33.3 \%$ of the variance in the respondent's perceived adaptability. The significant $(\mathrm{p}<.001)$ beta of -0.612 indicates that as threat increases, there is a decrease in adaptability. 


\begin{tabular}{|c|c|c|c|c|c|c|}
\hline \multicolumn{7}{|c|}{ ANOVA $^{a}$} \\
\hline Model & & $\begin{array}{c}\text { Sum of } \\
\text { Squares }\end{array}$ & df & $\begin{array}{l}\text { Mean } \\
\text { Square }\end{array}$ & $\mathrm{F}$ & Sig. \\
\hline \multirow[t]{3}{*}{1} & Regression & 45.381 & 1 & 45.381 & 26.004 & $.000^{\mathrm{b}}$ \\
\hline & Residual & 85.512 & 49 & 1.745 & & \\
\hline & Total & 130.893 & 50 & & & \\
\hline
\end{tabular}

\section{Table 12. Regression Threat $\rightarrow$ Adaptability}

Moderation was tested using a custom package on SPSS that uses ordinary least squares or logistic regression-based path analysis, and bootstrapping for accurate estimates. The first two models generated test assumptions. The first assumption tested whether Threat predicts Response Quality, which was significant $\left(\mathrm{F}(1,49)=19.6647, \mathrm{p}<.001, R^{2}=.5353\right)$. For every unit increase in threat there is a 0.5121 reduction in response quality $(b=-0.5121$, $\mathrm{t}(49)=-4.4345, \mathrm{p}<.001)$. The second assumption tested makes sure that threat predicts adaptability, which was significant $\left(\mathrm{F}(1,49)=26.0043, \mathrm{p}<.001, R^{2}=.3467\right)$. For every unit increase in threat there is a corresponding 0.6117 reduction in adaptability $(b=$ $0.6117, \mathrm{t}(49)=-5.0994, \mathrm{p}<.001)$.

The moderation is then tested by seeing whether Threat and Adaptability together predicts Response Quality, which was significant $\left(\mathrm{F}(2,48)=25.9459, \mathrm{p}<.001, R^{2}=.5195\right)$. Every unit increase in Adaptability results in an increase of .5502 to Response Quality ( $b=.5502$, $\mathrm{t}(48)=4.8254, \mathrm{p}<.001)$. The direct effect of Threat to Response Quality was reduced to an insignificant level $(b=-0.1755, t(48)=-1.4819, \mathrm{p}=0.0626)$, indicating moderation. Thus, H4 is supported. 
H5: The higher the level of reassurance provided to a respondent during the requirements determination process, the lower the effect of a perception of threat in the respondent on the respondent's level of adaptability.

Mediation was tested using a custom package on SPSS that uses ordinary least squares or logistic regression-based path analysis, and centralization of the variables. The overall regression model (IV: reassurance, threat, and interaction, DV: adaptability) showed significance and explained $40.99 \%$ of the variance in Adaptability $(\mathrm{F}(3,47)=9.4368, \mathrm{p}<$ $.001, R^{2}=.4099$ ), however not all the coefficients achieved significance (see Table 13). The only significant beta was for Threat $(b=-0.524, t(47)=-3.019, p<.01)$.

\begin{tabular}{|c|c|c|c|c|c|c|c|}
\hline \multicolumn{8}{|c|}{ Coefficients } \\
\hline \multirow[b]{2}{*}{ Moc } & & \multicolumn{2}{|c|}{ Coefficient } & \multirow[b]{2}{*}{$t$} & \multirow[b]{2}{*}{ Sig. } & \multicolumn{2}{|c|}{$\begin{array}{c}\text { Confidence } \\
\text { Interval }\end{array}$} \\
\hline & & & $\begin{array}{l}\text { Std. } \\
\text { Error }\end{array}$ & & & $\begin{array}{l}\text { Lower } \\
\text { Limit }\end{array}$ & $\begin{array}{l}\text { Upper } \\
\text { Limit }\end{array}$ \\
\hline 1 & (Constant) & 5.009 & 0.204 & 24.514 & 0.000 & 4.5975 & 5.4195 \\
\hline & Reassurance & 0.318 & 0.165 & 1.922 & 0.061 & -0.015 & 0.650 \\
\hline & Threat & -0.524 & 0.174 & -3.019 & 0.004 & -0.874 & -0.175 \\
\hline & Interaction & -0.109 & 0.152 & -0.718 & 0.476 & -0.415 & -0.197 \\
\hline
\end{tabular}

Table 13. Moderation coefficients

A post-hoc analysis shows the conditional effect of Reassurance on the relationship between Threat and Adaptability, based on values of the moderator (see Table 14). For low values of Reassurance $($ Reassurance $=4.032, \mathrm{~b}=-0.3759, \mathrm{t}(47)=1.1965, \mathrm{p}=0.238$ ), there is no relationship between Threat and Adaptability. For average values of Reassurance $($ Reassurance $=5.39, \mathrm{~b}=-0.5242, \mathrm{t}(47)=3.0188, \mathrm{p}<0.01)$, each unit of threat results in a -0.5242 change in Adaptability. For high-values of Reassurance (Reassurance $=6.748, \mathrm{~b}=-0.6725, \mathrm{t}(47)=3.1041, \mathrm{p}<0.01)$, each unit of threat results in a larger -0.6725 change in Adaptability. Johnson-Neyman's analysis was used to find the exact significance region of values for Reassurance. At reassurance levels of 4.76 and higher $(74.5 \%$ of the 
data), Threat and Adaptability are significantly related $(\mathrm{t}(47)=-2.0118, \mathrm{p}=.05, \mathrm{~b}=-$ 0.455). As Reassurance increases, the relationship between Threat and Adaptability becomes more negative. Hypothesis 5 is partially supported, however, in the opposite direction than hypothesized.

\begin{tabular}{|c|c|c|c|c|c|c|}
\hline \multirow[b]{2}{*}{ Reassurance } & \multicolumn{4}{|c|}{ Conditional Effects } & \multirow[b]{2}{*}{ LLCI } & \multirow[b]{2}{*}{ ULCI } \\
\hline & Effect & $\begin{array}{c}\text { Standard } \\
\text { Error }\end{array}$ & t-value & Significance & & \\
\hline 4.032 & -0.3759 & 0.3142 & -1.1965 & 0.2375 & -1.0079 & 0.2561 \\
\hline 5.39 & -0.5242 & 0.1736 & -3.0188 & 0.0041 & -0.8735 & -0.1749 \\
\hline 6.748 & -0.6725 & 0.2166 & -3.1041 & 0.0032 & -1.1083 & -0.2366 \\
\hline
\end{tabular}

Table 14. Conditional effects of Reassurance on Threat $\rightarrow$ Adaptability 


\section{CHAPTER VI. DISCUSSION}

\section{Limitations to the Study}

There are several limitations in this work that require acknowledgement and discussion.

First, due to several logistical issues, it was decided that the main study would not include the qualitative measures of response quality, or the use of a live interviewer. Methods for including these measures need to be improved and refined while ensuring the quality and integrity of the data collected. The primary opportunity for detection and mitigation of threat during the interview portion of the requirements determination process resides with the systems analyst, and, although the interviewer was decidedly removed as a variable to control for variance, they are an important part of the puzzle that future work should explore.

The timing of responses had to be eliminated as a variable but can be a further indicator of a threat condition, or, at the very least, of a high cognitive load. Several computers labs of FIU were scheduled for carrying out the experiment based on resource availability, and although they were entirely booked such as to avoid distractions from other students, the rooms were not identical. One of the labs had a scrolling LED banner with market data which may have proven distracting to subjects. An analysis of response times showed some differences in the experimental study, but not in the main study.

In addition, it should be noted that this study focused on only a few triggers of threat during the requirements determination process. Antecedents of threat were successfully manipulated to create a threat condition; however, specific personal and contextual factors 
may have varying magnitude of impact on the perception of threat. Experimental controls afford clear analysis of manipulations and their consequences. Limited personal factors were measured to minimize survey fatigue (Porter, Whitcomb et al. 2004) during the experiment, and testing for the numerous contextual factors would have created more groups and an issue of statistical power with the available sample pool. Randomization of subjects into the treatment groups aids with reducing the possibility that numerous unmeasured factors are not more prevalent in one group than another (Kerlinger and Lee 2000), resulting in skewed results due to sampling errors. Demographically, the groups were statistically similar, but it is possible that the framing took differently between groups based on chance differences of their unmeasured personal factors. The sample used was adequate to reflect subject matter expert demographics that would be expected in various business disciplines, with more than half of them achieving enough proficiency in their business discipline to have held middle and upper management positions, but the demographics in different domains may constitute a population with unexpected fluctuations in personal or contextual factors leading to a threat condition.

Within FIU, there exists cross-pollination within the business disciplines with information systems as a business necessity, leading to our low expectations of any impact by generalized computer self-efficacy, but this is not always the case. For example, in highly specialized positions, such as with physicians, the time invested by the individuals to achieve subject matter expert status would make them a much older subject pool. In medicine, the average age composition of actively licensed physicians is 47 years for females and 55 for males (Young, Chaudhry et al. 2011), which only represents $8 \%$ of the 
subjects in our study. Studies have shown a negative relationship between age and computer performance (Reed, Doty et al. 2005), which indicates that manifestation of threat may not solely be attributed to manipulations, but may also be a function of the demographical composition of subjects under scrutiny. This may diminish over time as technology is accepted as a normal part of newer generation's lives, but it has still shown a significant relationship in older generations that did not grow up with ubiquitous computing. The findings in this study should be considered preliminary proof of existence of the phenomena, but various domains may show differences in the magnitude of resulting perceived threat due to the numerous personal and contextual factors.

\section{Discussion and Conclusions}

With the limitations of this work discussed, the principal objective of this study, to provide insight into the two stated research questions, appears to have been realized. The findings should lead to a greater level of understanding of outcomes when respondents feel threatened during the requirements determination process. Several implications, both theoretical and applied, arise as a result.

The general hypothesis $\mathrm{H} 1$ was focused on answering the first research question regarding the relationship between the perception of threat by respondents and the resulting response quality during the requirements elicitation process. Support for the general hypothesis was strong for interview questions that related to the primary manipulated threat condition, fraud detection. Interview questions related to autonomy impacting system features provided interesting results. Prior research indicates that it is virtually impossible to 
eliminate perceptions of threat during the requirements elicitation process as there could be numerous intra-personal, inter-personal, vocational, contextual, and system-related reasons for a perception of threat by an individual, leading to the experimental design consideration of a low-threat versus a no-threat group. For this reason, it is not surprising that autonomy related questions did show a difference between low and high threat groups, just not with significance at the $\mathrm{a}=.05$ level. Respondents that were framed under highthreat provided a more elevated response for autonomy related questions than that of the low-threat group. The magnitude of subject responses to autonomy impacting questions, by both high and low threat groups, indicates that autonomy is perceived as threatened by the low-threat group, however, more so by the high-threat group.

During the exploratory pilot study subjects were subsequently asked "why" they felt their answer were justified and not a single answer exposed their true concerns as explicitly written in their framing. Instead, the answers provided to threatening questions were either brief satisficing answers (e.g. "I just don't think it is necessary given existing processes."), or elaborate and convoluted explanations on how the rigidity of a system cannot ever fully capture the complexity of their job roles in regards to specific features (e.g. "As for my freedom for my own determination, I've been doing this for a long time and according to laws somethings will change overtime [so] we can't buy a system only for it to be updated all the time"; "If we want the best out of this system, it means we need a subject matter expert, such as I and those I'm also training so that they can be ready for this position. It means that overrides do have to happen from time to time, and AI isn't perfect. Neither is a human, but we get access to new knowledge faster and it would take time for the software 
to get update patches, which would mean more interviews like these with me trying to explain to you how things now work and have changed, and me trying to understand your new system. I have to understand what this system does."; "I believe you said you were a computer science major, and one of the biggest things I'm sure they taught you that a computer isn't smart, what makes it smart is the humans knowing and using the computers and the programs. We can't rely on a system, we need to rely on our own minds to accelerate the technology....").

The exploratory qualitative results of the pilot provide some explanation for findings in the literature that even iterative methodologies, where features are iteratively defined instead of defined a priori, still result in systems that are not successful and accepted. The academic and corporate-sponsor training programs in system analysis acknowledge users as important stakeholders with expectations that their involvement in the system requirements process will maximize user acceptance. The literature shows mixed results in this regard, and the results obtained in this study provide further evidence that user involvement does not guarantee that the elicited system requirements will necessarily be in the best interest of the organization, and that users may instead covertly provide answers in their own best interest serving to subvert the initiative. There can be a significant difference between the needs of an organization and that of the individuals, and if a system analyst is not able to detect the perception of threat by respondents of a feature that is determined by the organization as important, they may consume valuable resources and time in addressing the symptoms of an unwavering belief, without ultimate acceptance from the individuals. 
For hypotheses $\mathrm{H} 3$ and $\mathrm{H} 4$, it was not possible to manipulate all personal and contextual factors leading to a threat condition in the framing of the subjects, while preserving empirically sound results within the limitations in quantity of the available subject pool. Many of the contextual factors were made constant between groups, which included positive organizational messages, excitement among their peers for the introduction to this system, and vocational opportunity in learning cutting-edge technology for loan processing. To adequately interpret variance due to manipulations inducing threat, the high threat group differed in that they were framed to have exploited the subjective aspects of the loan process, leading to deviations from established organizational protocols and procedures, such that a system capturing and analyzing the loan processes would bring their deviations to light with possibly detrimental consequences. This created an individual that is intrinsically motivated to participate as they would want to ensure that they are aware of, and can influence, the resulting information system. It also created an individual resistant to change as they have been exploiting aspects of their job that could become unavailable within the clearly defined heuristics embedded in an information system. This manipulation was enough to generate a significant difference in perception of threat between the two groups, supporting the hypotheses, however, future work should manipulate additional factors to establish the magnitude of response quality degradations based on types of threats.

The perception of threat was shown to be fully mediated by the perceived adaptability to the threat by respondents in this study, confirming H4. This was expected because there is an appraisal process where the subject is determining the magnitude of a threat in terms of 
imagined negative impacts and their ability to cope with them. This confirms prior research in Protection Motivation Theory, and the relationship between anxiety and performance, which suggests that if a threat is high enough the performance can suffer to the point of maladaptation to the threat; where perceived adaptability is either non-existent or negligible. During the requirements gathering process a subject may feel threatened in some manner, but the magnitude of threat's impact on their response is mostly controlled by their perceived adaptability to the threat. This provides an additional lens for prior research findings where by adaptability reinforcing activities, such as providing training, significantly aids in user acceptance. Admittedly, threats due to de-skilling paradigms or low generalized computer self-efficacy are intuitively addressed via providing user training, but other threats are less superficial to detect and mitigate. The findings here suggest that it is a worthwhile endeavor for organizations to detect possible areas of perceived threat and increase their employee's perceived adaptability to those threats to increase the yield and efficiency of the requirements elicitation process. Future work should consider various strategies for addressing different types of threats. For example, in this study the manipulation was a grotesque deviation from established practices by the organization which would clearly result in penalties should they be discovered, however no individual admitted their deviations as a rationale for their responses. An organization that would like to standardize their processes with the introduction of an information system would have a difficult time of doing so if many of the features of said information system would bringing those deviations to light, via the de-emphasis of those features by respondents of those features. A feasible approach would be to provide communications illustrating why standardization is important for the organization, and providing a grace 
period for penalty-free discovery of the various ways employees perform their work, which may not be part of standard operating procedure, under the guise of taking it into consideration for improving existing policies and procedures. This would serve to make individuals feel that how they've become accustomed to working matters to the organization and increase their perceived adaptability to the threat of standardization. The possibilities are endless and it may be of value to do an open forum where individuals can express their opinions without penalty. For example, Infosys encouraged dissenting opinions of subordinates via their "voice of youth" with much success (Garud, Kumaraswamy et al. 2006).

The last hypothesis H5 was partially supported in the opposite direction of what was hypothesized, and would have been fully supported at the $\mathrm{a}=.05$ level with a slight increase in sample size. This was a concerning find, as it seemed a theoretical initially, but there is possible explanation. Reassurance was encoded in the pleasant and approachable demeanor of the systems analyst, and in prefacing the interview questions with threat appraisal influencers, possible explanations serving to diminish the respondent's imagined severity and vulnerability to the feature, which may be perceived as threatening. The threat appraisal strategy was chosen over the coping appraisal strategy due to issues with increasing response efficacy, self-efficacy, or decreasing the response cost for the manipulated items intended to trigger a high-threat response in an experimental design. For example, when asked about how much system learning they believe should be incorporated in the system it was prefaced with, "Let's talk about artificial intelligence and expert systems. As I'm sure you can understand, these types of systems are some of the 
most difficult to design correctly." The intention was to reassure the respondents by admitting that it will be very difficult and likely take time for this feature to perform well, or may never perform well and be eventually eliminated entirely. Reasonably this would lead to a reduction in the envisioned immediate potential impact of the feature (threat appraisal), and hence increase their perceived adaptability to it. Interestingly, it may have instead actually served as a version of "sustain talk", communications where the individual's resistance to change is actually reinforced (Klonek, Lehmann-Willenbrock et al. 2014). Focus group moderators are trained to detect and stop sustain talk in group settings so that a snow-ball effect doesn't occur, where the concern is magnified for participants via discovery that other participants also have concerns about a specific feature, or that a concern is created by having others point out something concerning they did not originally see. This provides an explanation for why the more reassured the individuals felt they were by the systems analyst, the less the resulting perception of adaptability to the perceived threats. It also explains why during the exploratory pilot the respondents were more verbose about reasons they didn't want a feature in the reassurance group, for both high and low threat groups. The analyst unintentionally provided a cue that it was "ok" to discuss concerns. Although verbosity was a qualitative measure of response quality during the initial face-to-face pilot, the group memberships and low sample size masked detection of this very important phenomena. Furthermore, the unintended consequence of reassurance in reducing the perceived adaptability of the low-threat group, essentially making a neutral party feel less adaptable to the change, illustrates that preempting a threat where there isn't one could also produce negative consequences. A possible conclusion is that the analyst should avoid reassurance, especially when it can be 
interpreted as support for resistance to change, because it reduces the perceived adaptability of all respondents to features of an IS. Although situations of sustain talk have been mostly studied in group settings, this confirms, and adds to, previous work that the way questions are asked by an interviewer during the requirements determination process is going to determine the answers you get (Marakas and Elam 1998).

\section{Implications for Future Research}

Future research into the sources of threat and its impact to response quality should focus on several key areas of investigation. First, additional examination is needed with regard to refinement of the model proposed in this study. The antecedents of threat were used for manipulating a high-threat condition, and were successful, however the mechanisms of how those antecedents interact should be explored further.

Second, it is generally accepted that "experienced" systems analysts provide better results, but this has yet to be operationalized. For example, this study provides evidence that a wellintended reassurance manipulation can have ill results. It begs the question, "what are the positive attributes of a good systems analyst, and procedurally what makes them better than another?"

Third, this study showed how respondents under a perception of threat result in a degradation in their response quality, but mechanisms for detecting and pre-empting threat conditions during the requirements determination process remain yet unexplored. For preemption, there may be certain aspects of a job, context, or individual that lends itself to a 
perception of threat. An example of this is a job with employees that rarely use an information system, and therefore should manifest low computer self-efficacy.

For detection, future research should focus on providing physiological and verbalization indicators that are useful to a systems analyst for detecting the presence of a threat condition during the interview. At the least, better understanding of sources of threat would serve to inform the education process for professional analysts, and place greater emphasis on the possibility that respondents may not be willing participants during an ISD effort, and serving to subvert the effort.

Fourth, the unexpected negative moderation of reassurance by the interviewer on the relationship between threat and adaptability must be better understood by looking at additional dimensions of reassurance (e.g. coping appraisal factors) during the interview process. Coping appraisal factors are more difficult to manipulate in an experimental design, suggesting the use of case or field studies, or action research.

Lastly, cross-cultural validity of the threat factors has to be established. It seems likely that individuals with varying tolerance for power distance may be more willing to accept inequality triggered in an IS, less individualistic societies may be more extrinsically motivated or willing to compromise their own needs in an IS for the needs of the organization, and so on. 


\section{LIST OF REFERENCES}

Ackoff, R. L. (1967). "Management misinformation systems." Management science 14(4): B-147-B-156.

Alavi, M. (1984). "An assessment of the prototyping approach to information systems development." Communications of the ACM 27(6): 556-563.

Amabile, T. M., Hill, K. G., Hennessey, B. A. and Tighe, E. M. (1994). "The Work Preference Inventory: assessing intrinsic and extrinsic motivational orientations." Journal of personality and social psychology 66(5): 950.

Arkowitz, H. (2002). "Toward an integrative perspective on resistance to change." Journal of clinical psychology 58(2): 219-227.

Ashforth, B. E. (1989). "The experience of powerlessness in organizations." Organizational behavior and human decision processes 43(2): 207-242.

Au, N., Ngai, E. W. T. and Cheng, T. C. E. (2008). "Extending the understanding of end user information systems satisfaction formation: An equitable needs fulfillment model approach." Mis Quarterly 32(1): 43-66.

Bakeman, R. and Quera, V. (2011). Sequential analysis and observational methods for the behavioral sciences, Cambridge University Press.

Bandura, A. (2011). "Social cognitive theory." Handbook of social psychological theories: 349-373.

Bandura, A. and McClelland, D. C. (1977). "Social learning theory."

Bartunek, J. M. and Murninghan, J. K. (1984). "The nominal group technique: expanding the basic procedure and underlying assumptions." Group \& organization management 9(3): 417-432.

Bergman, R. L. and Craske, M. G. (2000). "Verbalization and imagery during worry activity." Depression and Anxiety 11(4): 169-174.

Bhattacherjee, A. and Hikmet, N. (2007). "Physicians' resistance toward healthcare information technology: a theoretical model and empirical test." European Journal of Information Systems 16(6): 725-737.

Boehm, B. W. (1981). Software engineering economics, Prentice-hall Englewood Cliffs $(\mathrm{NJ})$. 
Boisot, M. H. (1995). Information space, Int. Thomson Business Press.

Bond, C. F. and DePaulo, B. M. (2006). "Accuracy of deception judgments." Personality and social psychology Review 10(3): 214-234.

Bradburn, N. M. and Sudman, S. (1991). THE CURRENT STATUS OF QUESTIONNAIRE RESEARCH. New York, John Wiley \& Sons Inc.

Bradford, M. and Florin, J. (2003). "Examining the role of innovation diffusion factors on the implementation success of enterprise resource planning systems." International journal of accounting information systems 4(3): 205-225.

Brooks, F. P. (1975). The mythical man-month, Addison-Wesley Reading, MA.

Browne, G. J. and Ramesh, V. (2002). "Improving information requirements determination: a cognitive perspective." Information \& Management 39(8): 625-645.

Browne, G. J. and Rogich, M. B. (2001). "An empirical investigation of user requirements elicitation: Comparing the effectiveness of prompting techniques." Journal of Management Information Systems 17(4): 223-249.

Brynjolfsson, E. and Hitt, L. M. (2000). "Beyond computation: Information technology, organizational transformation and business performance." The Journal of Economic Perspectives 14(4): 23-48.

Byrd, T. A., Cossick, K. L. and Zmud, R. W. (1992). "A synthesis of research on requirements analysis and knowledge acquisition techniques." MIS quarterly: 117-138.

Cecez-Kecmanovic, D., Galliers, R. D., Henfridsson, O., Newell, S. and Vidgen, R. (2014). "The Sociomateriality of Information Systems: Current Status, Future Directions." Mis Quarterly 38(3): 809-830.

Coch, L. and French Jr, J. R. (1948). "Overcoming resistance to change." Human relations.

Colombo, M. G. and Delmastro, M. (2002). "The determinants of organizational change and structural inertia: technological and organizational factors." Journal of Economics \& Management Strategy 11(4): 595-635.

Commerce, C. C. o. (2013). Upskilling the Workforce: Employer-sponsored Training and Resolving the Skills Gap, Canadian Chamber of Commerce.

Compeau, D. R. and Higgins, C. A. (1995). "Computer self-efficacy: Development of a measure and initial test." MIS quarterly: 189-211. 
Conner, D. R. (2006). Managing at the speed of change: How resilient managers succeed and prosper where others fail, Random House.

Davis, G. B. (1982). "Strategies for information requirements determination." IBM systems journal 21(1): 4-30.

Deci, E. L., Connell, J. P. and Ryan, R. M. (1989). "Self-determination in a work organization." Journal of applied psychology 74(4): 580.

Dennis, A. R., Hayes, G. S. and Daniels Jr, R. M. (1999). "Business process modeling with group support systems." Journal of Management Information Systems 15(4): 115-142.

Dent, E. B. and Goldberg, S. G. (1999). "Challenging "resistance to change"." The Journal of Applied Behavioral Science 35(1): 25-41.

Denzin, N. K. (1978). The research act: A theoretical orientation to sociological methods, New York: McGraw-Hill.

DePaulo, B. M., Lindsay, J. J., Malone, B. E., Muhlenbruck, L., Charlton, K. and Cooper, H. (2003). "Cues to deception." Psychological bulletin 129(1): 74.

Duggan, E. W. (2003). "Generating systems requirements with facilitated group techniques." Human-Computer Interaction 18(4): 373-394.

Eckhardt, A., Laumer, S. and Weitzel, T. (2009). "Who influences whom? Analyzing workplace referents' social influence on IT adoption and non-adoption." Journal of Information Technology 24(1): 11-24.

Eden, C., Ackermann, F. and Williams, T. (2005). "The amoebic growth of project costs." Project Management Journal 36(1): 15-27.

Eisenberger, R., Huntington, R., Hutchison, S. and Sowa, D. (1986). "Perceived Organizational Support." Journal of Applied Psychology 71(3): 500-507.

Ferneley, E. H. and Sobreperez, P. (2006). "Resist, comply or workaround? An examination of different facets of user engagement with information systems." European Journal of Information Systems 15(4): 345-356.

Field, A. (2009). Discovering statistics using SPSS, Sage publications.

Floyd, D. L., Prentice-Dunn, S. and Rogers, R. W. (2000). "A Meta-Analysis of Research on Protection Motivation Theory." Journal of Applied Social Psychology 30(2): 407-429. 
Frone, M. R., Russell, M. and Cooper, M. L. (1995). "Job stressors, job involvement and employee health: A test of identity theory." Journal of Occupational and Organizational Psychology 68(1): 1-11.

Garud, R., Kumaraswamy, A. and Sambamurthy, V. (2006). "Emergent by design: Performance and transformation at Infosys Technologies." Organization Science 17(2): 277-286.

Gavrilova, T. and Andreeva, T. (2012). "Knowledge elicitation techniques in a knowledge management context." Journal of Knowledge Management 16(4): 523-537.

Gist, M. E. (1987). "Self-efficacy: Implications for organizational behavior and human resource management." Academy of management review 12(3): 472-485.

Goldsmith, R. E. (1984). "Personality characteristics associated with adaption-innovation." The Journal of psychology 117(2): 159-165.

Graesser, A. C. and Franklin, S. P. (1990). "Quest - a Cognitive Model of Question Answering." Discourse Processes 13(3): 279-303.

Greenhalgh, L. and Rosenblatt, Z. (1984). "Job Insecurity - toward Conceptual Clarity." Academy of Management Review 9(3): 438-448.

Guyll, M., Madon, S., Yang, Y., Lannin, D. G., Scherr, K. and Greathouse, S. (2013). "Innocence and resisting confession during interrogation: Effects on physiologic activity." Law and human behavior 37(5): 366.

Hannan, M. T. and Freeman, J. (1984). "Structural Inertia and Organizational Change." American Sociological Review 49(2): 149-164.

Hansson, C., Dittrich, Y., Gustafsson, B. and Zarnak, S. (2006). "How agile are industrial software development practices?" Journal of systems and software 79(9): 1295-1311.

Harrison, A. A. (1968). "Response competition, frequency, exploratory behavior, and liking." Journal of Personality and Social Psychology 9(4): 363.

Harrison, A. A. and Zajonc, R. B. (1970). "The effects of frequency and duration of exposure on response competition and affective ratings." The Journal of Psychology 75(2): 163-169.

Herzberg, F., Mausner, B. and Snyderman, B. B. (2011). The motivation to work, Transaction publishers. 
Hickey, A. M. and Davis, A. M. (2003). Requirements elicitation and elicitation technique selection: model for two knowledge-intensive software development processes. System Sciences, 2003. Proceedings of the 36th Annual Hawaii International Conference on, IEEE.

Hirschheim, R. and Newman, M. (1988). "Information-Systems and User Resistance Theory and Practice." Computer Journal 31(5): 398-408.

Hoeks, J. C. J., Stowe, L. A., Hendriks, P. and Brouwer, H. (2013). "Questions Left Unanswered: How the Brain Responds to Missing Information." Plos One 8(10): 9.

Ireland, R. D. (1993). Management \& organization, South-Western Pub.

Ives, B. and Olson, M. H. (1984). "User Involvement and Mis Success - a Review of Research." Management Science 30(5): 586-603.

Jason Bennett, T., Perrew, xe and L., P. (2002). "An Empirical Examination of Individual Traits as Antecedents to Computer Anxiety and Computer Self-Efficacy." MIS Quarterly 26(4): 381-396.

Johnson, T. (1984). "The commercial application of expert systems technology." The Knowledge Engineering Review 1(01): 15-25.

Joshi, K. (1991). "A model of users' perspective on change: the case of information systems technology implementation." Mis Quarterly: 229-242.

Kanter, R. M. and Wales, N. S. (1987). Managing the human side of change, Staff Development Unit, New South Wales Attorney-General's Department.

Kaplan, K. J. (1972). "On the ambivalence-indifference problem in attitude theory and measurement: A suggested modification of the semantic differential technique." Psychological Bulletin 77(5): 361.

Kassin, S. M. (2005). "On the psychology of confessions: Does innocence put innocents at risk?" American Psychologist 60(3): 215.

Kaulio, M. A. and Karlsson, I. C. M. (1998). "Triangulation strategies in user requirements investigations: a case study on the development of an IT-mediated service." Behaviour \& Information Technology 17(2): 103-112.

Kehr, F., Kowatsch, T., Wentzel, D. and Fleisch, E. (2015). "Blissfully ignorant: the effects of general privacy concerns, general institutional trust, and affect in the privacy calculus." Information Systems Journal 25(6): 607-635. 
Keinan, G. (1987). "Decision making under stress: scanning of alternatives under controllable and uncontrollable threats." Journal of personality and social psychology 52(3): 639.

Kerlinger, F. N. and Lee, H. B. (2000). Foundations of behavioral research. Fort Worth, TX, Harcourt College Publishers.

Kim, H. W. and Kankanhalli, A. (2009). "Investigating User Resistance to Information Systems Implementation: A Status Quo Bias Perspective." Mis Quarterly 33(3): 567-582.

Klonek, F. E., Lehmann-Willenbrock, N. and Kauffeld, S. (2014). "Dynamics of resistance to change: a sequential analysis of change agents in action." Journal of Change Management 14(3): 334-360.

Kohli, R. and Kettinger, W. J. (2004). "Informating the clan: Controlling physicians' costs and outcomes." Mis Quarterly: 363-394.

Lauer, T. W., Peacock, E. and Jacobs, S. M. (1992). "Question Generation and the SystemsAnalysis Process." Questions and Information Systems: 47-61.

Leavitt, H. J. and Whisler, T. L. (1958). Management in the 1980's, November.

Leidner, D. E. and Kayworth, T. (2006). "Review: A Review of Culture in Information Systems Research: Toward a Theory of Information Technology Culture Conflict." MIS Quarterly 30(2): 357-399.

Lerouge, C., Newton, S. and Blanton, J. E. (2005). "Exploring the systems analyst skill set: Perceptions, preferences, age, and gender." Journal of Computer Information Systems 45(3): 12-23.

Lewin, K. (1952). "Field theory in social science."

Lim, E. T. K., Pan, S. L. and Tan, C. W. (2005). "Managing user acceptance towards enterprise resource planning (ERP) systems - understanding the dissonance between user expectations and managerial policies." European Journal of Information Systems 14(2): 135-149.

Loftus, E. F. and Palmer, J. C. (1974). "Reconstruction of automobile destruction: An example of the interaction between language and memory." Journal of verbal learning and verbal behavior 13(5): 585-589.

Madeyski, L. (2009). Test-driven development: An empirical evaluation of agile practice, Springer Science \& Business Media. 
Maguire, P. and Pitceathly, C. (2002). "Key communication skills and how to acquire them." British Medical Journal 325(7366): 697-+.

Marakas, G. M. and Elam, J. J. (1998). "Semantic structuring in analyst acquisition and representation of facts in requirements analysis." Information Systems Research 9(1): 3763.

Marakas, G. M. and Hornik, S. (1996). "Passive resistance misuse: Overt support and covert recalcitrance in IS implementation." European Journal of Information Systems 5(3): 208-219.

Marakas, G. M., Johnson, R. D. and Palmer, J. W. (2000). "A theoretical model of differential social attributions toward computing technology: when the metaphor becomes the model." International Journal of Human-Computer Studies 52(4): 719-750.

Marakas, G. M., Yi, M. Y. and Johnson, R. D. (1998). "The multilevel and multifaceted character of computer self-efficacy: Toward clarification of the construct and an integrative framework for research." Information systems research 9(2): 126-163.

March, J. G. (1991). "Exploration and Exploitation in Organizational Learning." Organization Science 2(1): 71-87.

Markus, M. L. (1983). "Power, politics, and MIS implementation." Communications of the ACM 26(6): 430-444.

Martinko, M. J., Henry, J. W. and Zmud, R. W. (1996). "An attributional explanation of individual resistance to the introduction of information technologies in the workplace." Behaviour \& Information Technology 15(5): 313-330.

McAvoy, J. and Butler, T. (2009). "The role of project management in ineffective decision making within Agile software development projects." European Journal of Information Systems 18(4): 372-383.

Menges, R. J. (1973). "Openness and honesty versus coercion and deception in psychological research." Am Psychol 28(12): 1030-1034.

Miller, W. R., Moyers, T. B., Ernst, D. and Amrhein, P. (2003). "Manual for the motivational interviewing skill code (MISC)." Unpublished manuscript. Albuquerque: Center on Alcoholism, Substance Abuse and Addictions, University of New Mexico.

Milne, S., Sheeran, P. and Orbell, S. (2000). "Prediction and intervention in health-related behavior: A meta-analytic review of protection motivation theory." Journal of Applied Social Psychology 30(1): 106-143. 
Montazemi, A. R. (1988). "Factors Affecting Information Satisfaction in the Context of the Small Business Environment." Mis Quarterly 12(2): 239-256.

Montazemi, A. R. and Conrath, D. W. (1986). "The Use of Cognitive Mapping for Information Requirements Analysis." Mis Quarterly 10(1): 45-56.

Munro, M. C. and Davis, G. B. (1977). "Determining management information needs: a comparison of methods." MIS quarterly: 55-67.

Newman, M. and Noble, F. (1990). "User Involvement as an Interaction Process: A Case Study." Information Systems Research 1(1): 89-113.

Newman, M. and Robey, D. (1992). "A Social-Process Model of User-Analyst Relationships." Mis Quarterly 16(2): 249-266.

Newman, M. and Sabherwal, R. (1989). A process model for the control of information system development projects. International Conference on Information Systems: Proceedings of the tenth international conference on Information Systems: Boston, Massachusetts, United States.

Nonaka, I. and Takeuchi, H. (1995). The knowledge-creating company: How Japanese companies create the dynamics of innovation, Oxford university press.

Nord, W. R. and Jermier, J. M. (1994). "Overcoming resistance to resistance: Insights from a study of the shadows." Public Administration Quarterly: 396-409.

O'Brien, L. T. and Crandall, C. S. (2003). "Stereotype threat and arousal: Effects on women's math performance." Personality and Social Psychology Bulletin 29(6): 782-789.

Oreg, S. (2003). "Resistance to change: developing an individual differences measure." J Appl Psychol 88(4): 680-693.

Oreg, S. and Sverdlik, N. (2011). "Ambivalence Toward Imposed Change: The Conflict Between Dispositional Resistance to Change and the Orientation Toward the Change Agent." Journal of Applied Psychology 96(2): 337-349.

Orlikowski, W. J. (1992). "The duality of technology: Rethinking the concept of technology in organizations." Organization science 3(3): 398-427.

Orlikowski, W. J. and Scott, S. V. (2008). "10 sociomateriality: challenging the separation of technology, work and organization." The academy of management annals 2(1): 433-474.

Patton, M. Q. (1999). "Enhancing the quality and credibility of qualitative analysis." Health services research 34(5 Pt 2): 1189. 
Pawlowski, S. D. and Robey, D. (2004). "Bridging user organizations: Knowledge brokering and the work of information technology professionals." Mis Quarterly 28(4): 645-672.

Peters, G. J. Y., Ruiter, R. A. C. and Kok, G. (2013). "Threatening communication: a critical re-analysis and a revised meta-analytic test of fear appeal theory." Health Psychology Review 7: S8-S31.

Porter, M. E. (2008). "The five competitive forces that shape strategy." Harvard Business Review 86(1): 78-+.

Porter, S. R., Whitcomb, M. E. and Weitzer, W. H. (2004). "Multiple surveys of students and survey fatigue." New Directions for Institutional Research 2004(121): 63-73.

Ramsin, R. and Paige, R. F. (2008). "Process-centered review of object oriented software development methodologies." Acm Computing Surveys 40(1): 3.

Reed, K., Doty, D. H. and May, D. R. (2005). "The impact of aging on self-efficacy and computer skill acquisition." Journal of Managerial Issues: 212-228.

Rogers, R. W. and Prentice-Dunn, S. (1997). "Protection motivation theory."

Rokeach, M. (1960). "The open and closed mind."

Ruiter, R. A. C., Kessels, L. T. E., Peters, G.-J. Y. and Kok, G. (2014). "Sixty years of fear appeal research: Current state of the evidence." International Journal of Psychology 49(2): 63-70.

Runeson, P. and Höst, M. (2009). "Guidelines for conducting and reporting case study research in software engineering." Empirical software engineering 14(2): 131-164.

Sagie, A. and Koslowsky, M. (2000). "Participation and empowerment in organizations." Team Performance Management: An International Journal 6(1/2): 37-38.

Sarker, S. and Sarker, S. (2009). "Exploring agility in distributed information systems development teams: an interpretive study in an offshoring context." Information Systems Research 20(3): 440-461.

Sawyer, S., Guinan, P. J. and Cooprider, J. (2010). "Social interactions of information systems development teams: a performance perspective." Information Systems Journal 20(1): 81-107.

Schmader, T., Johns, M. and Forbes, C. (2008). "An integrated process model of stereotype threat effects on performance." Psychological review 115(2): 336. 
Siau, K. and Rossi, M. (2011). "Evaluation techniques for systems analysis and design modelling methods-a review and comparative analysis." Information Systems Journal 21(3): 249-268.

Siau, K. and Tan, X. (2006). "Using cognitive mapping techniques to supplement UML and UP in information requirements determination." Journal of Computer Information Systems 46: 59-66.

Smith, J. (2016). "The 19 hottest jobs for 2016." Retrieved 3/26/2016, 2016, from http://www.businessinsider.com/hottest-jobs-for-2016-2015-12\#comments.

Spreitzer, G. M. (1995). "Psychological Empowerment in the Workplace - Dimensions, Measurement, and Validation." Academy of Management Journal 38(5): 1442-1465.

Starcke, K., Wolf, O. T., Markowitsch, H. J. and Brand, M. (2008). "Anticipatory stress influences decision making under explicit risk conditions." Behavioral neuroscience 122(6): 1352.

Stecklein, J. M., Dabney, J., Dick, B., Haskins, B., Lovell, R. and Moroney, G. (2004). "Error cost escalation through the project life cycle."

Tanriverdi, H., Rai, A. and Venkatraman, N. (2010). "Reframing the Dominant Quests of Information Systems Strategy Research for Complex Adaptive Business Systems." Information Systems Research 21(4): 822-834.

Teichroew, D. (1972). A survey of languages for stating requirements for computer-based information systems. Proceedings of the December 5-7, 1972, fall joint computer conference, part II, ACM.

Tesch, D., Kloppenborg, T. J. and Frolick, M. N. (2007). "IT project risk factors: the project management professionals perspective." Journal of Computer Information Systems 47(4): 61-69.

Thomas, K. W. and Velthouse, B. A. (1990). "Cognitive elements of empowerment: An "interpretive" model of intrinsic task motivation." Academy of management review 15(4): 666-681.

Van Harreveld, F., Van der Pligt, J. and Yael, N. (2009). "The agony of ambivalence and ways to resolve it: Introducing the MAID model." Personality and Social Psychology Review 13(1): 45-61.

Vrij, A., Fisher, R., Mann, S. and Leal, S. (2006). "Detecting deception by manipulating cognitive load." Trends in cognitive sciences 10(4): 141-142. 
Vrij, A. and Granhag, P. A. (2014). "Eliciting Information and Detecting Lies in Intelligence Interviewing: An Overview Of Recent Research." Applied Cognitive Psychology 28(6): 936-944.

Warmelink, L., Vrij, A., Mann, S., Leal, S. and Poletiek, F. H. (2013). "The Effects of Unexpected Questions on Detecting Familiar and Unfamiliar Lies." Psychiatry Psychology and Law 20(1): 29-35.

Watson, G. (1971). "Resistance to change." The American Behavioral Scientist 14(5): 745.

Wenger, E. (1998). "Communities of practice: Learning as a social system." Systems thinker 9(5): 2-3.

Williamson, T. M. (1993). "From Interrogation to Investigative Interviewing - Strategic Trends in Police Questioning." Journal of Community \& Applied Social Psychology 3(2): 89-99.

Wilson, C. E. (2006). "Triangulation: the explicit use of multiple methods, measures, and approaches for determining core issues in product development." interactions 13(6): 46-ff.

Witte, K. and Allen, M. (2000). "A meta-analysis of fear appeals: Implications for effective public health campaigns." Health education \& behavior 27(5): 591-615.

Witte, K., Meyer, G. and Martell, D. (2001). Effective health risk messages: A step-bystep guide, Sage.

Xu, L., Jiang, C., Wang, J., Yuan, J. and Ren, Y. (2014). "Information security in big data: privacy and data mining." IEEE Access 2: 1149-1176.

Yadav, S. B. (1983). "Determining an organization's information requirements: a state of the art survey." ACM SIGMIS Database 14(3): 3-20.

Yerkes, R. M. and Dodson, J. D. (1908). "The relation of strength of stimulus to rapidity of habit-formation." Journal of comparative neurology and psychology 18(5): 459-482.

Young, A., Chaudhry, H. J., Rhyne, J. and Dugan, M. (2011). "A census of actively licensed physicians in the United States, 2010." Journal of Medical Regulation 96(4): 1020 .

Zappavigna, M. and Patrick, J. (2010). "Eliciting tacit knowledge about requirement analysis with a Grammar-targeted Interview Method (GIM)." European Journal of Information Systems 19(1): 49-59. 
Zmud, R. W., Anthony, W. P. and Stair Jr, R. M. (1993). "The use of mental imagery to facilitate information identification in requirements analysis." Journal of Management Information Systems 9(4): 175-191.

Zuboff, S. (1988). In the age of the smart machine: The future of work and power, Basic Books. 


\section{APPENDIX}

Pre-test

Demographics

Age:
O 18 and under
O $19-24$
O $25-30$
O $31-36$
O $37-42$
O 43 and over

Gender:
O Male
O Female

Race/Ethnicity:
O White/Caucasian
O Hispanic/Latino
O Black/African American
O Asian/Pacific Islander
O American Indian/Alaskan Native
O Other

Marital Status:
O Single
O Married

Highest level of education completed:

O High School graduate

O Some college credit, no degree 
O Trade/technical/vocational training

O Associate degree

O Bachelor's degree

O Master's degree

O Professional degree

O Doctoral degree

Highest degree of responsibility held:
O Senior Management
O Middle management
O Line personnel

Primary business activity classification:
O Primary (farming, fishing, mining, etc.)
O Manufacturing
O Selling, distribution and retailing
O Finance and banking
O Transportation
O Other service industries
O Civil Service and local government
O Armed Forces
O Professions in private practice
O Education

Total years of work experience in a business-related capacity:

Generalized Anxiety Disorder:

\begin{tabular}{|l|c|c|c|c|}
\hline $\begin{array}{l}\text { Over the last 2 weeks, how often have you } \\
\text { been bothered by any of the following } \\
\text { problems? }\end{array}$ & $\begin{array}{c}\text { Not at } \\
\text { all }\end{array}$ & $\begin{array}{c}\text { Several } \\
\text { days }\end{array}$ & $\begin{array}{c}\text { More } \\
\text { than } \\
\text { half the } \\
\text { days }\end{array}$ & $\begin{array}{c}\text { Nearly } \\
\text { every } \\
\text { day }\end{array}$ \\
\hline Feeling nervous, anxious or on edge & 0 & 1 & 2 & 3 \\
\hline Not being able to stop or control worrying & 0 & 1 & 2 & 3 \\
\hline Worrying too much about different things & 0 & 1 & 2 & 3 \\
\hline Trouble relaxing & 0 & 1 & 2 & 3 \\
\hline Being so restless that it is hard to sit still & 0 & 1 & 2 & 3 \\
\hline Becoming easily annoyed or irritable & 0 & 1 & 2 & 3 \\
\hline $\begin{array}{l}\text { Feeling afraid as if something awful might } \\
\text { happen }\end{array}$ & 0 & 1 & 2 & 3 \\
\hline
\end{tabular}


Motivation: $\quad($ Instrinsic(I) + Enjoyment(E)/Challenge(Ch), Extrinsic(E) $\quad+$ Outward(O)/Compensation(C))

1. I enjoy tackling problems that are completely new to me. (I-Ch)

\begin{tabular}{|c|c|c|c|c|c|c|}
\hline 1 & 2 & 3 & 4 & 5 & 6 & 7 \\
\hline Not at all
\end{tabular}

2. The more difficult the problem, the more I enjoy trying to solve it. (I-Ch)

\begin{tabular}{|c|c|c|c|c|c|c|}
\hline 1 & 2 & 3 & 4 & 5 & 6 & 7 \\
\hline Not at all & \multicolumn{4}{|c|}{ Very much so } \\
\hline
\end{tabular}

3. I want to find out how good I really can be at my work. (I-E)

\begin{tabular}{|c|c|c|c|c|c|c|}
\hline 1 & 2 & 3 & 4 & 5 & 6 & 7 \\
\hline Not at all
\end{tabular}

4. I prefer to figure things out for myself (I-E)

\begin{tabular}{|c|c|c|c|c|c|c|}
\hline 1 & 2 & 3 & 4 & 5 & 6 & 7 \\
\hline Not at all
\end{tabular}

5. I am strongly motivated by the [grades][money] I can earn. (E-C)

\begin{tabular}{|c|c|c|c|c|c|c|}
\hline 1 & 2 & 3 & 4 & 5 & 6 & 7 \\
\hline Not at all & \multicolumn{5}{|c|}{ Very much so } \\
\hline
\end{tabular}

6. I am keenly aware of the [GPA (grade point average)][promotion] goals I have for myself. (E-C)

\begin{tabular}{|c|c|c|c|c|c|c|}
\hline 1 & 2 & 3 & 4 & 5 & 6 & 7 \\
\hline Not at all & \multicolumn{5}{|c|}{ Very much so } \\
\hline
\end{tabular}

7. I am strongly motivated by the recognition I can earn from other people. (E-O)

\begin{tabular}{|c|c|c|c|c|c|c|}
\hline 1 & 2 & 3 & 4 & 5 & 6 & 7 \\
\hline Not at all
\end{tabular}


8. I want other people to find out how good I really can be at my work. (E-O)

\begin{tabular}{|c|c|c|c|c|c|c|}
\hline 1 & 2 & 3 & 4 & 5 & 6 & 7 \\
\hline Not at all & \multicolumn{5}{|c|}{ Very much so } \\
\hline
\end{tabular}

Subject Framing

\section{SLIDE 1}

You are being asked to participate in an exercise requiring you to play a specific role. You will be interviewed during this exercise and it is very important for you to attempt to remain in character at all times until the interview has concluded. Staying in character includes answering as you believe your character would answer under the circumstances and feeling what your character might feel under the circumstances. Upon completion of the exercise, we ask that you do not share any details of what you learn here with any other participants or potential participants to insure the accuracy and integrity of the exercise.

\section{SLIDE 2}

Your name is Chris and you are a senior loan officer for a large multi-national bank. While doing your job, you evaluate loan applications from your customers based on their criteria provided by your organization. You job is to apply the criteria and decide on whether to fund the loan or deny the loan to the customer. You have been given specific guidelines that you are obligated to follow when making your loan funding decisions.

\section{SLIDE 3}


A new project is underway within your organization that will create much greater transparency of the loan decision process. In addition, much stronger controls associated with your strict adherence to the loan criteria and guidelines will be put in place. As part of this project, your organization is designing and implementing a new computer-based information system called the Loan Evaluation and Determination System (LEDS). Due to your vast knowledge and experience with the loan decision process, you have been selected to work with the development team that will be designing and implementing LEDS.

\section{SLIDE 4}

Your participation and input is essential to the successful implementation of LEDS. The new system will virtually completely automate the loan decision process for you and will provide you with a recommended decision regarding whether customer loan applications should be approved or not. For the immediate future, you will still retain the final loan decision.

\section{SLIDE 5}

LEDS will be automatically and constantly updated with changes in regulations relating to loans and will provide the rationale for the recommendations it makes to you. Finally, the new system will create a permanent record of all transactions and communications related to the loan granting process, including all loans that were processed by you before LEDS. This will include a complete record of the criteria you used in making the final loan decision and any overrides to the criteria provided to you by the new system. These 
permanent records of your actions in each loan decision will be automatically created and stored by LEDS and cannot be deleted by anyone.

\section{SLIDE 6}

Your organization, along with your peers, sees LEDS as a positive step toward streamlining the loan process and the voluminous documentation associated with it. There is excitement that your group will be leading the industry in loan processing due to the support of this new and innovative information system!

\section{SLIDE 7}

You will be interviewed by a member of the system design team to obtain information you possess to help make LEDS a success. The information to assist you in answer many of the questions you may be asked by the interviewer were provided to you for your reference although you are free to provide any answer you believe Chris would provide - specific or general - particularly if you believe you answer will be in your best interest. Remember, think and feel what Chris might think under these circumstances.

The interviewer and the rest of the system design team have never met you before and have no knowledge about you other than your name and your role as a senior loan officer.

\section{SLIDE 8 - High-threat only}

Several of your family members work in the same industry as you as mortgage brokers, closing agents, appraisers, and realtors. Despite the illegal and unethical practice of 
securing loans for family and friends, you have quietly and regularly assisted them in obtaining loans for their clients that were questionable and might otherwise have been turned down. You have also solicited their professional services to help you hide your illegal and unethical actions.

\section{SLIDE 9 - High-threat only}

You have been successful to date in preventing these unethical and illegal activities from being discovered by your organization because you and your family control the entire loan process and you have the authority to make final loan decisions with no oversight. No one suspects you up to this point, including the system design team that you will be meeting with soon.

\section{SLIDE 10 - High-threat only}

By performing these favors, you have been regularly and illegally taking advantage of your position within the bank to secure questionable loans. Throughout your career you have:

- Overlooked derogatory information on credit reports that would otherwise disqualify the borrower.

- Used the highest of the three scores from reporting agencies although the criteria set by your organization requires that you accept the lowest credit score.

- Repeatedly placed borderline credit scores in the higher category.

- Doctored documents to show evidence of funds availability for securing the loans when none existed. 
- Removed additional financial burdens that are admitted by applicants that would otherwise not qualify them for a loan based on debt-to-income ratio.

- Used appraisers that are known to you and your family/friends for overestimation of the value of the collateral.

- Provided loan options that the borrower would otherwise be disqualified for.

- Misreported facts to underwriters for the purposes of securing a loan.

\section{SLIDE 11 - High-threat only}

The newly proposed system will include safeguards intended to prevent the unethical and illegal actions you have freely taken in the past. In addition, LEDS will scan all loans for ten prior years and will likely discover and highlight any loans which are questionable or suspicious. This will most assuredly reveal and uncover your unethical and illegal activities of the past. LEDS will be designed such that any loans processed will be available for review by management, government agencies, or law enforcement for audit purposes. There is a high likelihood that any deviations from established practices, which you have been selected to provide, will be detected and may result in various consequences depending on the severity of the infraction.

\section{SLIDE 12 - High-threat only}

LEDS is a clear and direct threat to you and, if successful, will likely result in discovery of your crimes, loss of your job and pension, significant damage to your reputation, and 
eventual criminal prosecution. It is in your best interests to ensure that this system does not become successfully operational.

\section{SLIDE 13}

You will be interviewed by a member of the system design team to obtain information you possess to help make LEDS a success. The information to assist you in answer many of the questions you may be asked by the interviewer were provided to you for your reference although you are free to provide any answer you believe Chris would provide - specific or general - particularly if you believe you answer will be in your best interest. Remember, think and feel what Chris might think under these circumstances.

The interviewer and the rest of the system design team have never met you before and have no knowledge about you other than your name and your role as a senior loan officer.

When you are ready to begin the interview, click on the button marked Go to the interview. 
Interview Answer sheet

Possible Answers during interview: (You do not need to memorize this information. It is provided for your quick reference during the interview. Feel free to take the time to refer to it before answering any question if you find that you need it):

The general guidelines your organizations expects you to adhere to are below:

1. Process initial documentation:

a. Tax returns for last 2 years

i. Reject if not employed for at least 2 years

b. Pay stubs for last 3 months

i. Carefully examine fluctuations/trends

c. Bank statements for last 3 months

i. Estimate stability of income

2. Determine Credit Qualification:

a. Credit worthiness

i. Evaluate credit report score

1. $400-649$ scores will be denied

2. 650-689 scores will be considered high risk

3. 690-719 scores will be considered moderate risk

4. 720-759 scores will be considered low risk

5. 760+ scores will be considered no risk

ii. Establish patterns of behavior 
iii. Evaluate negative items on credit report

3. Determine Financial Qualification

a. Adequate income for repayment.

i. Add estimated loan payment to revolving credit and determine the debt to gross income ratio

1. $50 \%$ or higher will be denied

2. $40 \%-49 \%$ will be considered high risk

3. $30 \%-39 \%$ will be considered moderate risk

4. $20 \%-29 \%$ will be considered low risk

5. $19 \%$ or lower will be considered no risk

b. Fund availability

i. Ensure presence of enough funds to provide down payment and first repayment

4. Make offer and close

a. Order appraisal from third party, secure payment from borrower

b. Provide financing options

i. Agree on type of loan, ensure qualifications for type

ii. Lock interest rate based on credit worthiness and financial qualification

c. Provide estimate and disclosures to borrower 
Framing test

1. (TF) You are playing the role of a senior loan officer for a large multi-national bank.
a. True
b. False

2. (MA) The organization wants to create a computer information system that:
a. Creates permanent records of all transactions and communications related to the loan granting process.
b. Logs into record all the criteria you used in making the final loan decision.
c. Allows you to override the recommendation provided by it.
d. All of the above.

3. (TF) The success of this proposed information system will be largely due to your participation.
a. True
b. False

4. (TF) Your peers do not see the proposed information system as a positive step.
a. True
b. False

5. (TF) The final decision on a loan approval is yours, but if it is in conflict with what the system proposed then you must provide overrides.
a. True
b. False 
6. (MC) You will be interviewed by:
a. A fellow loan processer
b. The vice president of sales
c. A member of the system design team
d. None of the above.

7. (TF) You can provide any answer to, or omit from answering, any question you wish during the interview.
a. True
b. False

8. (TF) You are to answer during the interview based on what is in your best interest.
a. True
b. False

9. (TF) The computer information system will not create records of previously processed loans. The system will only have new records.
a. True
b. False

10. (TF) You have been selected as a subject matter expert.
c. True
d. False 
Interview Questions

Reassurance group text is coded with bold highlighting.

Intro

Hi Chris! My name is John Taylor and I am with the development team for the LEDS project. Thank you for agreeing to this interview. Your input to this project is very important to its success as your role in the loan processing area brings much knowledge to the project. I'm going to ask you a series of question that my system development team has assembled. Your answers will have a direct effect on the design and implementation of LEDS. So, let's get started.

Let's begin with some background information on you. [Basic Demographic Questions]

1. OK, I've got all that down. Let's turn our attention now to LEDS. The system, as you can imagine, is quite complex and will have many functions. That said, there are five specific functions which we believe to have the greatest importance to the success of the system. I would like you to rank these five functions in the order you believe has the greatest importance to the least importance ( 1 being greatest importance, 5 being least importance). Here are the five functions I would like you to rank:

a. The LEDS system is web-based and accessible from the company intranet

b. The LEDS system uses artificial intelligence to learn how you make decisions 
c. The LEDS system allows you the freedom to make your own determination on loans

d. The LEDS system provides storage of documentation for historical purposes

e. The LEDS system provides extensive fraud detection.

Ranking: $\mathrm{a} \_\mathrm{b} \ldots \mathrm{c} \ldots \mathrm{d} \ldots \mathrm{e}$

2. A system is only as good as its embedded rules when it needs to make decision in unique situations that may require deviations from the norm. In your professional opinion, how flexible should the system be made in allowing the loan officers to modify documents and information for loans that have already been closed?

\begin{tabular}{|l|c|c|c|c|c|c|}
\hline 1 & 2 & 3 & 4 & 5 & 6 & 7 \\
\hline Completely \\
Flexible
\end{tabular}

3. Sometimes experienced loan officers may make decisions based on "gut" feeling. Unfortunately, these are very difficult to program into a system. In your capacity as a loan officer, how much of your role do you believe is subjective ("it depends on the situation") vs objective ("clearly defined")?

\begin{tabular}{|c|c|c|c|c|c|c|}
\hline 1 & 2 & 3 & 4 & 5 & 6 & 7 \\
\hline Entirely Subjective & \multicolumn{5}{|c|}{ Entire Objective } \\
\hline
\end{tabular}

4. We must consider the reality that there is no such thing as a perfect system. We want your evaluation of the potential for misuse; although we understand it may be impossible to design the system to avoid it entirely. Chris, how much do the 
subjective parts of the loan process - where "it depends" - allow for fraudulent actions by unethical loan officers?

\begin{tabular}{|c|c|c|c|c|c|c|}
\hline 1 & 2 & 3 & 4 & 5 & 6 & 7 \\
\hline \multicolumn{7}{|l|}{ Not at all } \\
\hline
\end{tabular}

5. Great! Let's talk about artificial intelligence and expert systems. As I'm sure you can understand, these types of systems are some of the most difficult to design correctly. They are intended to capture how people make decisions so that they can later repeat these processes and mimic the actual decision maker. How much system learning do you believe should be incorporated into LEDS? In other words, should the system be designed to learn from the actions of a loan officer, create a profile on how each loan officer makes their decisions, and then use this prof?

\begin{tabular}{|c|c|c|c|c|c|c|}
\hline 1 & 2 & 3 & 4 & 5 & 6 & 7 \\
\hline \multicolumn{5}{|l|}{ No System learning } \\
\hline
\end{tabular}

6. It is our understanding that whether a loan should be given or not is a case-bycase decision, which is as much about the person as it is about their record. Beyond simply providing recommendations, the LEDS system can also make decisions based on a loan applicant's information. How much of this decisionmaking capability do you believe should be incorporated into LEDS versus being reserved to the loan officer?

\begin{tabular}{|c|c|c|c|c|c|c|}
\hline 1 & 2 & 3 & 4 & 5 & 6 & 7 \\
\hline $\begin{array}{l}\text { Complete } \\
\text { based decision-making }\end{array}$ & $\begin{array}{r}\text { System- } \\
\text { basion- }\end{array}$ \\
\hline
\end{tabular}


7. As we just discussed, while context may be of importance when making loan decisions, it is virtually impossible to design a system that can handle every possible situation. IF the system were designed to make decisions on some loans that clearly meet qualification or disqualification criteria, what are your thoughts regarding the importance of allowing loan officers the ability to override any loan recommendations or decision made by LEDS?

\begin{tabular}{|c|c|c|c|c|c|c|}
\hline 1 & 2 & 3 & 4 & 5 & 6 & 7 \\
\hline \multicolumn{5}{|l|}{ Not very important } \\
\hline
\end{tabular}

a. Ok, Chris. Continuing our focus on retaining loan officer overrides to decisions made by LEDS. We understand there are many financing options as well as professional relationships with third parties that are built over time and may be important to loan officers. LEDS will make many of these types of assignments automatically if desired. So, what is your feeling regarding the importance of retaining this decision-making with the loan officer regarding providing applicants a variety of financing options such as balloon payment, interest only, fixed rate, adjustable, etc., versus letting LEDS make such decisions and offers?

\begin{tabular}{|c|c|c|c|c|c|c|}
\hline 1 & 2 & 3 & 4 & 5 & 6 & 7 \\
\hline \multicolumn{7}{|l|}{ Not very important } \\
\hline
\end{tabular}

b. Staying with this function of LEDS, how about the importance of retaining loan officer overrides to decisions made by LEDS regarding allowing loan officers the ability to choose their own personal appraiser for evaluating 
collateral on secured loans such as mortgages, instead of having the system automatically assign an appraiser from a list of pre-approved appraisers?

\begin{tabular}{|c|c|c|c|c|c|c|}
\hline 1 & 2 & 3 & 4 & 5 & 6 & 7 \\
\hline \multicolumn{7}{l}{ Not very important } \\
\hline
\end{tabular}

c. Continuing our focus on retaining loan officer overrides to decisions made by LEDS, what is the importance of loan officers retaining the ability to choose their own personal mortgage brokers, instead of having the system automatically assign a broker from a pre-approved list?

\begin{tabular}{|c|c|c|c|c|c|c|}
\hline 1 & 2 & 3 & 4 & 5 & 6 & 7 \\
\hline Not ve & & & & & \multicolumn{2}{|c|}{ Very important } \\
\hline
\end{tabular}

d. That's great, Chris! These answers are really going to be helpful in designing LEDS. So, continuing with the same thoughts, what is the importance of allowing loan officers to choose the closing agency for loan disbursement and document signing, versus having the system automatically assign one from a list of pre-approved closing agencies?

\begin{tabular}{|c|c|c|c|c|c|c|}
\hline 1 & 2 & 3 & 4 & 5 & 6 & 7 \\
\hline Not ve & $\overline{a n t}$ & & & & \multicolumn{2}{|c|}{$\begin{array}{c}\text { Very important } \\
\text { Ver }\end{array}$} \\
\hline
\end{tabular}

8. You are really being helpful and your answers will certainly guide us in designing LEDS. Now let's turn our focus to fraud detection. Loans are, of course, based to a large extent on trust. There is trust that the applicants will pay back the borrowed funds as well as trust that the loan officers will make the proper 
decisions on providing those loans. Based on your experience as a loan officer, what is your assessment of the level of fraud detection in the current loan process?

\begin{tabular}{|c|c|c|c|c|c|c|}
\hline 1 & 2 & 3 & 4 & 5 & 6 & 7 \\
\hline Inadequate & \multicolumn{5}{|c|}{ Adequate } \\
\hline
\end{tabular}

9. One intention for LEDS is the loading of paper-based historical data for all the closed loans over the years into its database. As you can imagine, this is a very labor-intensive and expensive manual process. That said, converting the preexisting paper-based loan data to electronic will help the system learn how loans have been approved in the past as well as uncover evidence of potential fraudulent activities. In your opinion, how much of these historical paper-based loans should be loaded into the system?

\begin{tabular}{|l|l|l|l|l|r|r|}
\hline 1 & 2 & 3 & 4 & 5 & 6 & 7 \\
\hline $\begin{array}{l}\text { No historical data } \\
\text { loaded }\end{array}$ & \multicolumn{5}{r|}{$\begin{array}{r}\text { All historical data } \\
\text { possible }\end{array}$} \\
\hline
\end{tabular}

10. When fraud occurs, it is a very embarrassing situation for the organization, and generally can be very public if the organization chooses to take action. It is therefore much better to prevent, rather than detect and react to fraud. One of the major functions of LEDS is the ability to detect fraud, errors, and any level of criminal activity. In your opinion, how necessary do you believe the fraud detection feature is?

\begin{tabular}{|c|c|c|c|c|c|c|}
\hline 1 & 2 & 3 & 4 & 5 & 6 & 7 \\
\hline Not at all
\end{tabular}


11. As you know, there are many methods to address fraud detection. I'm going to ask you to rate several potential fraud detection methods based on how effective you feel it would be towards achieving the goal of total fraud detection by LEDS.

a. First, how important to successful fraud detection is allowing the loan officer to flag suspicious loans that they have a "gut" feeling on versus allowing LEDS to handle all fraud detection?

\begin{tabular}{|c|c|c|c|c|c|c|}
\hline 1 & 2 & 3 & 4 & 5 & 6 & 7 \\
\hline \multicolumn{7}{|l|}{ Not Important } \\
\hline
\end{tabular}

b. How important is it for LEDS to automatically flag suspicious loans via triangulation of information (verification of provided banking reports, credit reports, etc.) versus leaving this up to the loan officer?

\begin{tabular}{|c|c|c|c|c|c|c|}
\hline 1 & 2 & 3 & 4 & 5 & 6 & 7 \\
\hline \multicolumn{2}{|l|}{ Not Important } \\
\hline
\end{tabular}

c. How effective for fraud detection would an annual audit/review of $20 \%$ of randomly selected loans by a team of your peers and superiors be versus having LEDS perform all fraud detection?

\begin{tabular}{|c|c|c|c|c|c|c|}
\hline 1 & 2 & 3 & 4 & 5 & 6 & 7 \\
\hline Not Effective & \multicolumn{5}{|c|}{ Very Effective } \\
\hline
\end{tabular}

12. Now for my last question. As you know, there is significant cost associated with designing and implementing LEDS. Up to this point, the loan process has always been a people intensive process. In your opinion, how good of an idea is the implementation of LEDS versus leaving things the way they are?

\begin{tabular}{|l|l|l|l|l|l|l|}
\hline 1 & 2 & 3 & 4 & 5 & 6 & 7 \\
\hline
\end{tabular}




\section{OUTRO:}

Christ, you have been great and I really appreciate your time today to help guide the design and implementation of LEDS. This concludes my portion of the interview process. It has been a pleasure talking with you today!

Post-test

For the following survey items please answer to the best of your ability, keeping in mind your role in the organization. Carefully look at the answers that are associated with the range between 1 and 7 (some are different) and select the number that most accurately reflects your answer.

1. After the interview, I feel that the proposed loan processing information system poses a potential threat to me.

\begin{tabular}{|c|c|c|c|c|c|c|}
\hline 1 & 2 & 3 & 4 & 5 & 6 & 7 \\
\hline Not at all & \multicolumn{5}{|c|}{ Very much so } \\
\hline
\end{tabular}

2. After the interview, I feel that the loan processing information system that may result from my interview may put my job in jeapordy.

\begin{tabular}{|c|c|c|c|c|c|c|}
\hline 1 & 2 & 3 & 4 & 5 & 6 & 7 \\
\hline Not at all & \multicolumn{5}{|c|}{ Very much so } \\
\hline
\end{tabular}


3. I feel that any initial concerns I may have had about the proposed loan processing information system are now:

\begin{tabular}{|c|c|c|c|c|l|c|}
\hline 1 & 2 & 3 & 4 & 5 & 6 & 7 \\
\hline \multicolumn{7}{|l|}{ Strongly decreased } \\
\hline
\end{tabular}

4. The interviewer played a vital role in making me feel at ease during the interview.

\begin{tabular}{|c|c|c|c|c|c|c|}
\hline 1 & 2 & 3 & 4 & 5 & 6 & 7 \\
\hline Strongly disagree & \multicolumn{5}{|c|}{ Strongly agree } \\
\hline
\end{tabular}

5. After the interview, I feel I may be able to adjust to the new way of working with the proposed loan processing information system.

\begin{tabular}{|c|c|c|c|c|c|c|}
\hline 1 & 2 & 3 & 4 & 5 & 6 & 7 \\
\hline Strongly disagree & \multicolumn{5}{|c|}{ Strongly agree } \\
\hline
\end{tabular}

6. After the interview, I feel confident that I will be able to minimize any negative impacts of the proposed loan processing information system.

\begin{tabular}{|c|c|c|c|c|c|c|}
\hline 1 & 2 & 3 & 4 & 5 & 6 & 7 \\
\hline Strongly disagree & \multicolumn{5}{|c|}{ Strongly agree } \\
\hline
\end{tabular}

7. After the interview, I feel my initial beliefs on my ability to adapt to the proposed loan processing information system has:

\begin{tabular}{|c|c|c|c|c|l|c|}
\hline 1 & 2 & 3 & 4 & 5 & 6 & 7 \\
\hline \multicolumn{7}{|l|}{ Strongly decreased } \\
\hline
\end{tabular}


VITA

ALFRED CASTILLO

Born, Miami, Florida

2002-2006

United States Marine Corps

Tactical Data Network Specialist, Sergeant

Quantico, Virginia

$2006-2012$

Operating Systems Programmer

Miami-Dade County ETSD

Miami, Florida

2010

B.A., Computer Science

Park University

Parkville, Missouri

2011

M.S., Management Information Systems

Florida International University

Miami, Florida

$2012-2017$

Doctoral Candidate

Florida International University

Miami, Florida 